\title{
NONSPECIFIC THERAPY IN ARTHRITIS AND INFECTIONS
}

\author{
A STUDY OF THE CHANGES IN THE BLOOD CONSEQUENT ON THE INTRA- \\ VENOUS INJECTION OF TYPHOID PROTEIN
}

A CONSIDERATION OF THE ANALOGY BETWEEN THE TYPHOID PAROXYSM AND THE MALARIAL PAROXYSM *

DAVID MURRAY COWIE, M.D. AND

HENRIETTA CALHOUN, M.D. ANN ARBOR, MICH.

Many of the clinical effects of the intravenous injection of foreign protein have been known for some time, particularly since the introduction of intravenous dosage of diphtheria antitoxin in diphtheria. ${ }^{1}$ It has been observed that, following a previous almost afebrile or slightly febrile period in the course of disease, a more or less pyrogenic reaction followed the intravenous injection of antitoxin. For example, of twenty-six recent cases from my records in the contagious hospital, treated by intravenous injection of antitoxin, twenty-one reacted with chill and rise of temperature. In some cases the rise in temperature was as high as $108 \mathrm{~F}$.

The explanation of this reaction was not generally known until the researches of Vaughan and his co-workers were made (1909). Prior to this time, Buchner (1890), Krehl and Matthes (1895) had induced fever in animals by the subcutaneous injection of bacterial and other proteins.

No importance was attached to the protein reaction as a therapeutic measure until quite recently. Indeed, as yet no cognizance has been given to the possible effect of the foreign protein on the disease process

* Submitted for publication Aug. 8, 1918.

* From the Department of Pediatrics and Contagious Diseases, University of Michigan Hospital, and the Cowie Hospital. Address before the Chicago Pediatric Society, May 21, 1918.

1. An Italian physician, Zamboni (Gazz. d. osp., 1900, 8, 4), was the first to use antitoxin by the intravenous route. He reported increase of temperature following the injection. Von Behring (1901) (quoted from Beyer, München. med. Wchnschr., Aug. 26, 1913) recommended the intravenous injection in severe cases of diphtheria. Fette (Med. Klin., 1909, No. 50) reported 145 cases treated by intravenous injections of antitoxin, and he also records temperature reactions. Park (Boston M. and S. J., 168:73, 1913) reported 200 cases, the first in America, treated by this method. He records chill, nausea, vomiting, fever, sweating and pain as common symptoms following the injection. 
itself in diphtheria. Efforts have always been directed at minimizing the effect of the protein contained in the antitoxin.

The recent work on the remarkable effects of intravenous injections of foreign protein in arthritis by Miller and Lusk ${ }^{2}$ and others has stimulated not only the usual therapeutic enthusiasm consequent on such reports, but also an interest in studies which may, in the first place, reveal what happens in the body after the foreign protein enters the blood stream; secondly, why these changes bring about an amelioration of symptoms and arrest disease processes; and thirdly, what its effect on the body tissues either for weal or woe may be.

Thus far it has been determined repeatedly that a typical protein reaction is characterized by chilliness or a definite chill, fever, pain, sweating, and characteristic changes in the formed elements of the blood, a leukopenia, followed by a leukocytosis sometimes of very marked degree. ${ }^{3}$

In 1912 Brown and $\operatorname{Ross}^{4}$ reported that there was always a leukocytosis four to ten hours after an intramuscular injection of sodium nucleinate. The count went as high as 23,000 and returned to normal in from three to five days. This calls to memory the early work done in the University of Michigan on leukocytosis induced by the subcutaneous injection of nuclein (Vaughan, 1892). The explanation for this reaction is now elucidated.

We became interested in the changes in the formed elements of the blood. Unable to find any work on the successive cell changes, we directed our attention to this somewhat arduous task, with prospective reward, however, because either positive or negative results seemed to us to be of value. Through the courtesy of Dr. Newburg of the Department of Internal Medicine all adult cases of "arthritis" which did not clear up after the removal of all known foci of infection were referred to us for treatment. These together with three private cases make up our small list of ten carefully studied cases.

The first intravenous injections of typhoid protein (vaccine) we find are those reported by Ichikawa ${ }^{5}$ in Japan. He records eightyseven cases of typhoid fever treated in this way. An immediate rise in temperature and the end of the disease by crisis occurred in many of the cases.

2. Miller and Lusk: J. A. M. A., 68:764 and 1940, 1917. Boston M. \& S. J., January, 1913.

3. Ewing's observations, 1895, are of interest in this connection (New York M. J., 62:196, 1895).

4. Brown \& Ross: J. Ment. Sc., 58: 1912.

5. Ichikawa: Ztschr. f. Immunitätsf., 23:32, 1914; abstr. in J. A. M. A.. 64: 546, 1915. 
ORDER OF OUR INVESTIGATION

Controls.-In each case a control count preceded the injection or was made at the time of the injection. In a few a prolonged hourly or two hourly control count was made the day preceding the injection. For lack of time and assistance this could not be done in all cases. In Case 10 all the counts were made on 500 cells. In Case 8 most of the counts were on 500 cells. In all others 200 cells were counted. A 1/12 Leitz oil immersion lens was used in all counts. The leukocyte counts were always made in each case by the same person and were carefully checked. All differential counts were made by us and all abnormal and atypical cells were checked by both of us.

Total leukocyte counts and complete differentiais were made starting from the beginning of injection, $1 / 2,1,1 \frac{1}{2}, 2,3,4$ and every hour thereafter until the height of the reaction or its end was reached in most cases. Great care was taken to observe closely in controls as well as subsequent counts the presence and the number of abnormal or atypical cells both in the white and the red groups.

A few observations were made on the platelets and also a few spectroscopic observations.

Parke, Davis and Company's typhoid vaccine was used. Two minutes were consumed each time in making the injection, which was always given at least six hours after a meal.

The roentgenographic records are from Professor Van Zwaluwenburg's reports excepting Case 1.

The ten cases were made up as follows:

2 chronic multiple periarthritis deformans

1 hypertrophic arthritis deformans

1 chronic multiple periarthritis deformans in a child with developmental epiphyseal changes

2 "acute rheumatism," polymuscular and periarticular

1 atrophic arthritis

1 hypertrophic spinal arthritis

1 gonorrheal vulvovaginitis

1 suppurative mastoiditis with chronic pulmonary tuberculosis

Four of these were children and six were adults.

\section{REPORT OF CASES}

CASE 1.--Polyperiarthritis deformans, chronic.

History.-Florence S., aged 11/2, entered the Cowie Hospital Sept. 16, 1917, complaining of stiffness and contractures of the legs and upper extremities, cramps in the hips, fever and inability to walk.

Feb. 16, 1911, the patient had measles. The eruption did not "come out good." She had night sweats, was nauseated and had projectile vomiting until May. She was able to be up in July, when it was noticed that she dragged her right foot and leg. She had a severe cough following the measles. In August her head was drawn to one side for a period of three weeks and the arms were drawn up. In September it became impossible for her to walk and contractures began to develop. In October she had an attack of fever (recurrent attacks); her temperature went as high as $103 \mathrm{~F}$., but she had no chills. In January, 1912, she came to the Pediatric Clinic. She was treated by Biers' hyperemic stasis. She began to walk in May, 1912, but it was fall before she walked well. In April, 1915, she had another attack of fever with "inflammatory rheumatism, neuritis and malnutrition" which lasted until September. At this time she walked stiffly, but was able to go seven blocks. The improvement continued until July, 1916, when she had another attack of measles. In November, 1916, she had a chill, temperature 105 F.; was nauseated and had projectile vomiting. Dec. 18, 1916, she had chills and fever, and since then 
she had been unable to walk. During this month she had her tonsils and adenoids removed and was treated with an autogenous vaccine made from cultures from the tonsils, without improvement. During December and January she was given passive movements and hot baths. In December, 1917, she walked a few steps across the room. In May she was given stock vaccine without results.

She has always been constipated. In 1914 she had a skin eruption starting as tiny vesicles between the fingers. She now had scaling on the hands, and vesicles about the anus and on the inside of the thigh. The heart was negative.

Blood: Red cells, 4,600,000; whites, 7,200; polynuclears, 54 per cent.; small lymphocytes, 31 per cent.; large lymphocytes, 13 per cent.; transitionals, 2 per cent.

Urine, negative.

Roentgenographic (from Dr. A. W. Crane) report: "Sinuses all negative. Teeth negative. Abnormally dense areas about the hilum of each lung of tuberculous type, but may result from other kinds of infection. Spleen and liver slightly enlarged. Barium gastro-intestinal study negative. Hand, wrist and knee show a decalcifying process in the joint region; joint surfaces, however, are left emphasized, giving the appearance of egg shell fragility, especially the knee joint. The articulating surfaces are smooth. No erosions."

Nonspecific Protein Therapy Record.-This patient was given three injections (Fig. 1) of typhoid vaccine, to each of which she responded with chill, nausea, vomiting, temperature and leukocytic changes associated with pain localized in the back, arms, and legs. Following the second injection the fingers of the left hand became more flexible and it was now possible to insert two fingers between her fingers and palm; this had been impossible before. Following the third injection the patient felt like walking, and with assistance walked down the hall. This was the first time she had walked at all since the previous March (eight months). This day her knees were definitely more flexible than on her entrance and she could flex the toes.

CASE 2.-Chronic periarthritis; no structural joint change.

History.-Mrs. W., aged 59, entered the medical clinic, University Hospital, complaining of pain in the knees, inability to stand or walk, inability to freely move right elbow. Referred to us for treatment March 19, 1918.

Present illness began one year before admission with migrating swelling of the fingers, elbows and shoulders. Three months later the knees became involved, swollen and tender. The fingers and shoulders were better, the right elbow and knees were still involved, the third left finger had one thickened joint. She was unable to stand or walk. The patient had a course of serum treatment, but no chills, fever or pain resulted.

Aside from marked wasting of the musculature of the extremities, contracture of right elbow and knees, marked swelling of the knees (periarticular -no floating of patella), examination was negative. The heart had soft blowing systolic murmur at apex, without enlargement or displacement.

Infected teeth and tonsils had been removed.

Roentgen Report.-The skull showed extensive atrophic changes and therefore was more than ordinarily difficult to read. The frontals were voluminous and air-containing; the ethmoids were very narrow and difficult to see, probably denser than normal, but judgment was difficult because of the bilateral involvement. The antra were small, thin walled and apparently normal. The nasal passages were unusually wide; probably an atrophic rhinitis. The sphenoid was very small, and was scarcely to be distinguished in the density of this region. Diagnosis: Bilateral posterior ethmoiditis. No roentgenogram of joints made.

The patient made no improvement and was referred to us for nonspecific protein treatment.

Nonspecific Protein Therapy Record.-This patient received ten intravenous injections of typhoid vaccine, dosage 1 billion (Fig. 2). Following the first, 


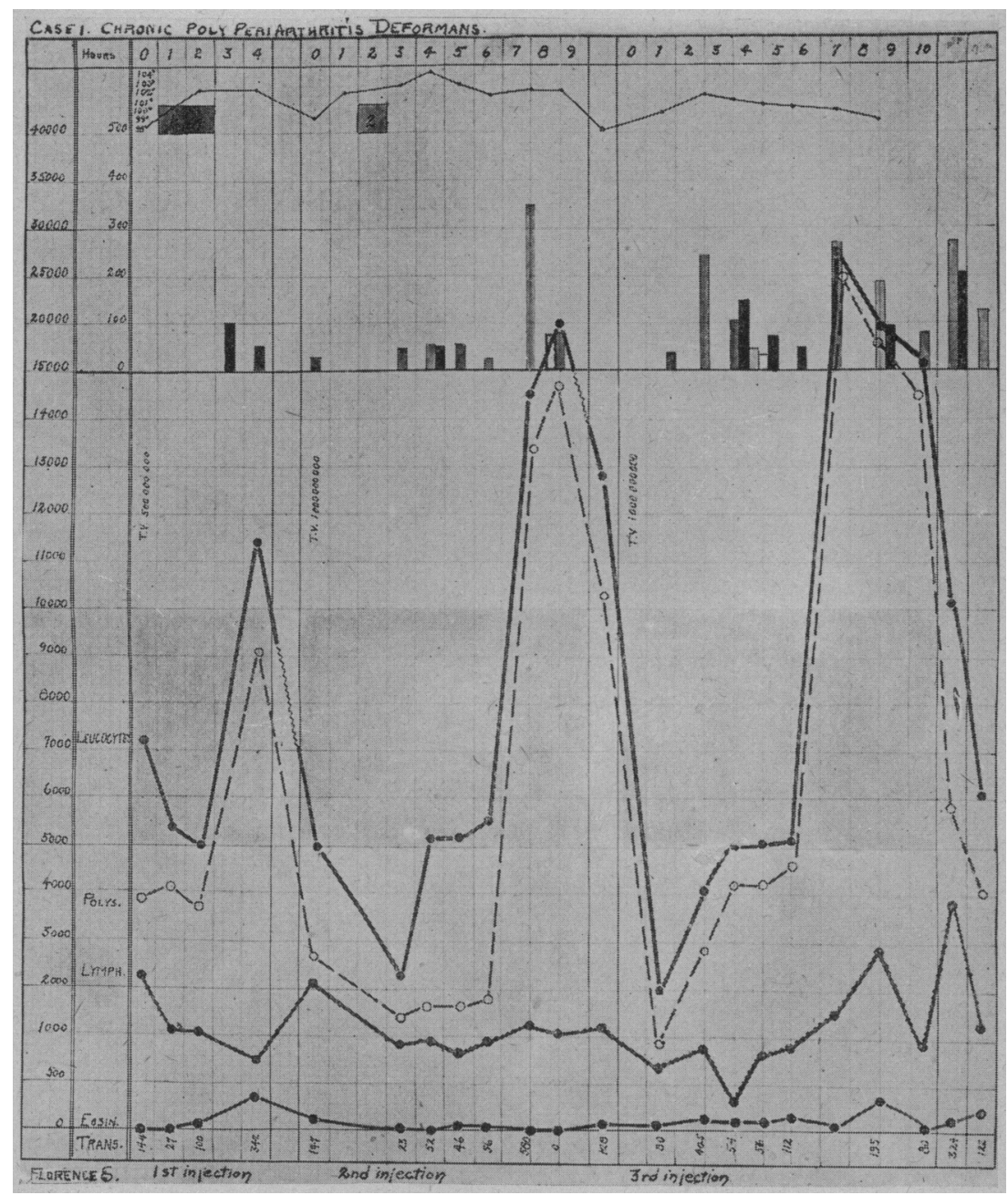

Fig. 1.-Case 1. Chronic polyarthritis deformans. In this and the following charts black columns $=$ myelocytes; white colums $=$ basophil polynuclears; gray columns $=$ atypical cells; squares at top $=$ nucleated reds. The absolute count for blood cells is given in the column at the left. The abnormal cells are drawn on a base line in the upper half of the chart, the absolute count being given in the second column of figures to the left. The black columns represent myelocytes, the white basophilia polynuclears, and the gray the number of atypical cells. The shaded blocks between five thousand and ten thousand represent the normal limits for the total leukocyte count during each reaction. Nucleated red blood corpuscles are indicated by squares at the top of the chart, the figure indicating the number seen during the differential count. The transitionals per cubic millimeter are given in figures at the bottom of the chart. The temperature curve is indicated at the top of the chart. 
which caused a slight clinical reaction, her right arm was more stiff than before. After the sixth injection the patient said that for the first time she was able to straighten out her legs and she thought the treatments were benefiting her, but she complained of swelling of the ankles. The chill in the first six reactions was present, but was slight. Following the seventh reaction her knees were swollen, but she could bend and move them without pain and she was very

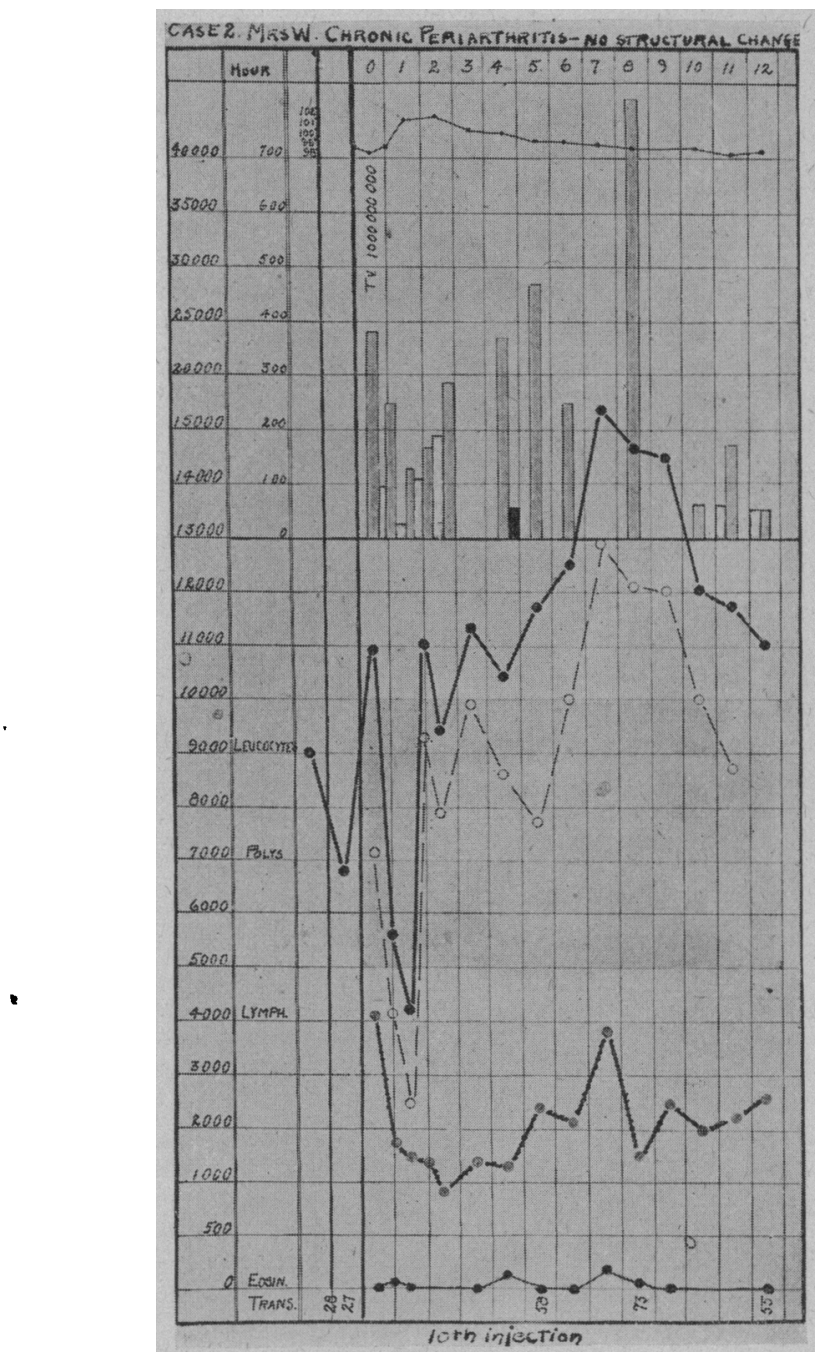

Fig. 2.-Case 2, Mrs. W. Chronic periarthritis. No structural change.

anxious to attempt to walk. Following the eighth injection she was allowed to walk and took about ten steps. The tenth reaction is recorded on the chart (Fig. 2). She was at the time of the report able to get about by hanging on to the bed and chairs. She stood straighter than previously and showed considerable improvement. The injections were made on the following dates: March 20,24, 27, and 31; April 3,6,11;13,16 and 20. Each injection showed the characteristic reaction. 
CASE 3.-Polyperiarthritis deformans, chronic, infectious.

History.-Blais, farmer, aged 59, entered the medical clinic Jan. 10, 1918, complaining of pain and swelling and stiffness of many joints, and muscle pain.

The family history was negative.

The present illness began about sixteen years prior to admission with pains in the back, chiefly during the winter months. Three or four days' rest in bed served to clear up the attacks. These attacks occurred frequently until six years prior to admission when they became more severe, and his "hands swelled." He was given intramuscular injections every day for four or five weeks with no benefit. He then took a series of hot baths in conjunction with subcutaneous injections for three weeks; no improvement. After this he took a course of subcutaneous injections of "rheumatic serum" which gave him much relief. At the end of the first week he was markedly improved and was able to return to work. He continued to work until last November, but at no time did the symptoms completely disappear. He was well enough so that he could work; much of the time there was considerable pain in his joints and muscles. This had recently become worse.

Physical Examination.-Large frame; well nourished; large musculature; no teeth; tonsils infected; patient almost entirely helpless; has to be helped from chair to bed; could not remove his shirt or raise his arms above his shoulders; limitation of neck movement. Joints showed marked deformity of metacarpalphalangeal joint; fingers held in part flexion and stiff; complete extension could be obtained with only a little pain; marked deformity of fingers of both hands and of the left thumb; elbows cannot be completely extended; rotation of shoulder joints markedly limited; knees held in partial flexion; cannot be extended. Some ankylosis of the hips; the pelvis tilts when the leg is raised; the involvement of the joints, for the most part, is periarticular. The roentgenogram showed that the bones themselves are but slightly involved.

The lungs, heart and abdomen are negative.

The tonsils were removed, as they contained large and small pus pockets. The patient was given a course of large doses of acetyl salicylic acid without noteworthy result.

Wassermann negative. Urine negative.

Blood count: Reds, 5,100,000; whites, 8,200; hemoglobin, 70 per cent.

Roentgen Report.-(Dr. Van Zwaluwenburg.) Dorsopalmar stereogram of hands shows extensive deformity, with comparatively little destruction of the bones. Certain of the articulations show an inconsiderable reduction in the joint spaces, and there is some irregularity of the heads and bases of the phalanges. The most typical feature is the subluxation. The lesions are faintly more active in the soft tissues than in the joint itself; jaws negative. Diagnosis, infectious arthritis.

Nonspecific Protein Record.-This patient always reacted violently, with chill, fever, sweating and pain. He received ten injections (Fig. 3). There was no permanent improvement in the case. There was marked immediate improvement following the first injections. The bedside notes on this case may be of interest because of the marked reaction, with slight blood changes which, however, were otherwise characteristic.

Bedside Notes.-Jan. 30, 1918. The patient was injected yesterday with 1 billion typhoid bacillus intravenously at $10: 30$. He showed no reaction until $11: 30$, when quite a violent chill began. This lasted for about twenty-five minutes. At the end of this time the chill stopped; patient still complaining of being cold. This lasted for about an hour. At the end of this time he began sweating profusely. Patient's temperature began to rise a half hour after the injection, but did not rise markedly until five hours after the injection. At ten hours after the injection he reached his maximum temperature $103.8 \mathrm{~F}$. A peculiarity of the leukocyte count was seen. The patient had been running a count between 8 and 9,000 in his control. Immediately after the injection 
he showed a leukopenia, and four hours afterward he was back to normal again. Since then his counts have been about 1,000 below normal.

Jan. 31, 1918. The patient's fingers and toes are distinctly more flexible. He makes a fairly good fist and stiffness of the fingers before the injection has given place to distinct relaxation. He was unable to move the toes before the injection, and this morning all of the toes on the left foot move very perceptibly, while those on the right foot move more. There is little if any pain in the fingers, but there is still pain in the toes.

Feb. 1, 1918. The second injection was given at 10:30 a. m. The patient had no breakfast; 1 billion typhoid vaccine. At 11 o'clock pulse was fuller, more rapid, regular; at $11: 35$ patient began to feel chilly. At 11:40 patient

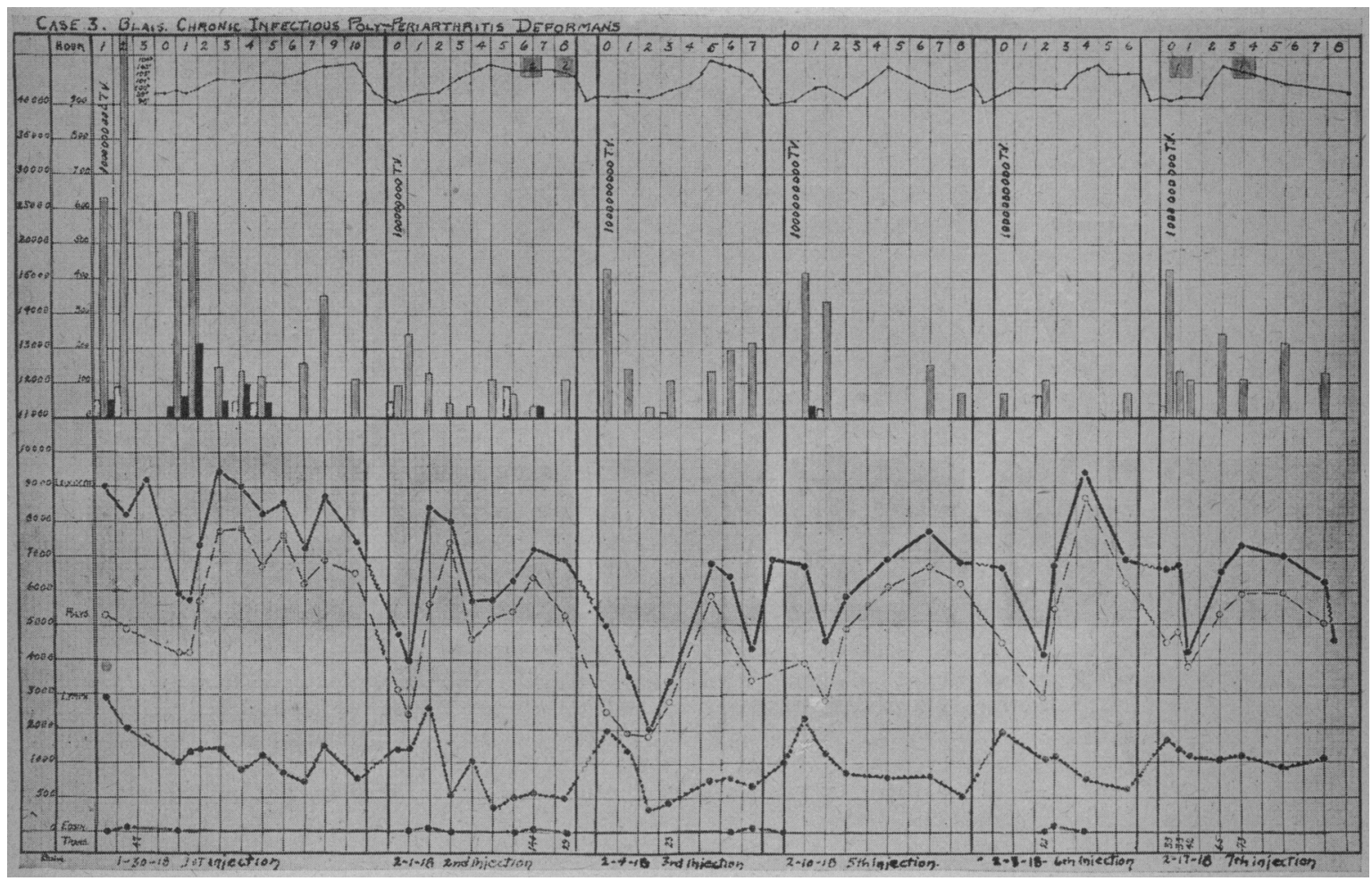

Fig. 3.-Case 3, Blais. Chronic infectious polyarthritis deformans.

was shaking severely and the skin was dry. At 12 patient shaking slightly, at 12:05 chill stopped. The chill lasted for half an hour. Patient now fell asleep. Twenty minutes after the chill stopped patient went into a profuse sweat which lasted for an hour and a half and he complained of feeling hot, much more than at the first injection. This was after the sweat was over, and the skin did not feel particularly moist. This morning there is no question but that the fingers and toes are much more flexible. The patient speaks of this himself. The pain is less marked. The highest temperature was $103.8 \mathrm{~F}$.

Feb. 4, 1918. The patient was seen this morning and complained more of pain than he had at any time since the injection. He has a little more difficulty than was experienced two days ago in flexing the forearm.

Feb. 5, 1918. Patient himself says he is very much better this morning. He makes almost a complete fist with both hands and moves the toes of both 
feet, and the feet are very much better. He straightens his knees some better and flexes them fairly well, but the improvement is not so marked in these joints.

Feb. 6, 1918. He does not make quite so good a fist this morning; says his toes and his knees are better. Says his toes are as good as they ever were. He has stiffness in his hands and elbows.

Feb. 7, 1918. Preceding the injection the patient was unable to move his right arm any more than at the beginning; he could not move his left arm. The injection was given at $11: 30$; dosage 1 billion. The patient reacted by a chill; his temperature went to $104.8 \mathrm{~F}$.

Feb. 8, 1918. Patient is able to move his right arm very freely in all directions. He makes a good fist in both hands. He says the pain in his arms is not in the joint but in the "muscles." The toes are moved freely; hands same. Patient is able to straighten his knees completely.

Feb. 11, 1918. Patient received his fifth injection yesterday. He feels worse this morning; has great difficulty in making a fist. The fingers are stiff; pain in both arms; is unable to straighten his knees.

Feb. 13, 1918. Examination before the sixth injection: The fingers of the right hand are greatiy distorted. Patient is unable to flex or extend his fingers completely. Right elbow very sore and movement limited. Fingers of the left hand are extended straight and when flexed lack $2 \mathrm{~cm}$. of reaching abductor pollicis muscle. The left elbow extends the same as the other, but flexion is more equal on either side; is able to extend right knee better than the left. He has movement of the toes.

Following the injection: Patient has noticed a slight improvement, as in previous injections. The chill was less severe than the previous one but he continued perspiring through the night. $\mathrm{He}$ is able to close the fingers of the right hand with effort (which he could not do before the injection). The right elbow seems less sore today. The left hand shows slight improvement in flexion of the fingers-within $1 \mathrm{~cm}$. of adductor pollicis.

Feb. 17, 1918. Patient was given seventh intravenous injection today. $\mathrm{He}$ had a chilly sensation during the day but no severe chills. Perspiration was very profuse and continued well into the night. The pyrogenic reaction was marked.

Feb. 21, 1918. Patient is in a miserable condition this morning, as bad as at any time since entering the hospital. His wrists are swollen and he cannot close his fingers, and he moves the right arm only slightly and with considerable pain. His knees and toes are practicably immobile. There are no heart murmurs. The rhythm is regular. Because of the discomfort to the patient, further examination could not be satisfactorily carried out.

Feb. 28, 1918. Practically no beneficial results were obtained from the use of typhoid vaccine.

\section{CASE 4.-Multiple periarthritis deformans and chronic arthritis.}

History.-Shag. Indian girl, aged 12, entered the orthopedic department of the University Hospital because of multiple joint deformities. Transferred to the pediatric department Feb. 24, 1918, for examination and nonspecific protein therapy. Family history, very indefinite.

Past History.-Patient had never been able to walk; said she used to crawl on hands and knees, later used a wheel chair. She said her condition was the same at the time of examination as it had always been; had become neither better nor worse. She never went to school; was able to write some, but could not read. She had not had measles, chickenpox or smallpox, but had had mumps.

The patient had been living with her aunt. She insisted that the vaginal discharge had always been present. There was no burning urination or other symptom. Patient had a tendency to constipation; no nocturia; appetite was good. 
Orthopedic Record.-Patient entered the orthopedic ward Oct. 27, 1917, as an emergency state case. No definite history obtained. The lower and upper extremities were deformed, due to arthritic process in the elbows, wrist, fingers, hip, knees, ankles and toes. The right hip was completely ankylosed, the left partially. The knee joints were both hypertrophied, while the surrounding muscular tissue was atrophied. The toes on either foot were deformed, producing hallus valgus deformity of both large toes. Several other toes were of the hammer type. There was ulnar flexion deformity of the fingers. The fingers showed hypertrophic joints and Heberden's nodes. The elbow joints were partially ankylosed so that the forearm could not be fully extended. On the posterior surface of either elbow were bursae, possibly due to the fact that the child had been compelled to creep on the forearms and knees. The

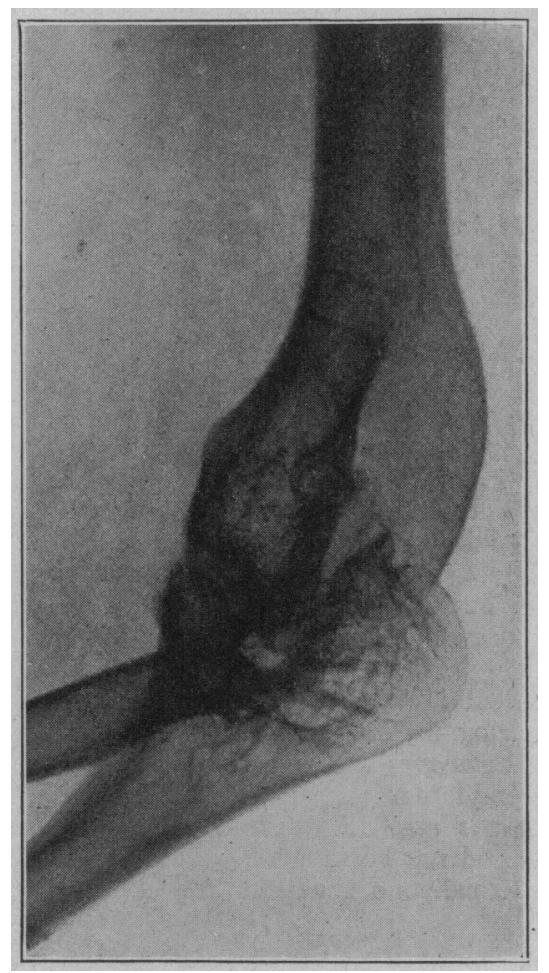

Fig. 4.-Case 4. Elbow showing the absence of epiphyses.

reflexes were normal; tonsils were enlarged; teeth in fair condition; lungs negative; heart negative.

Roentgen Report.-Stereogram of the pelvis and hips. The pelvis is irregularly deformed. There appears to be complete ankylosis of the left hip, while the right is not entirely ankylosed. There remains a plane of separation between the flat head of the femur and the acetabulum. The lesser trochanters are enormously enlarged. The femurs are hyperplastic. There seems to be ankylosis of the lower lumbars and no epiphyses are seen. Stereogram of elbow (Fig. 4) shows similar changes. This is not a true ankylosis but a marked deformity of the articular surfaces. The joint surface is V-shaped and the bony trabeculae are unusually distinct. No epiphyses. There is evidently some gross anomaly in development. We are unable to conceive of these changes as the result of an inflammation. Diagnosis impossible. 
Nonspecific Protein Therapy.-This patient received ten intravenous injections of typhoid vaccine. Each one was followed by a typical clinical reaction (Fig. 5). The patient felt so much better after each reaction that she begged for the next. She was always more supple and generally more comfortable. The patient made undoubted improvement. The joints were more relaxed; she moved about remarkably well in her bed, a thing she could not do before

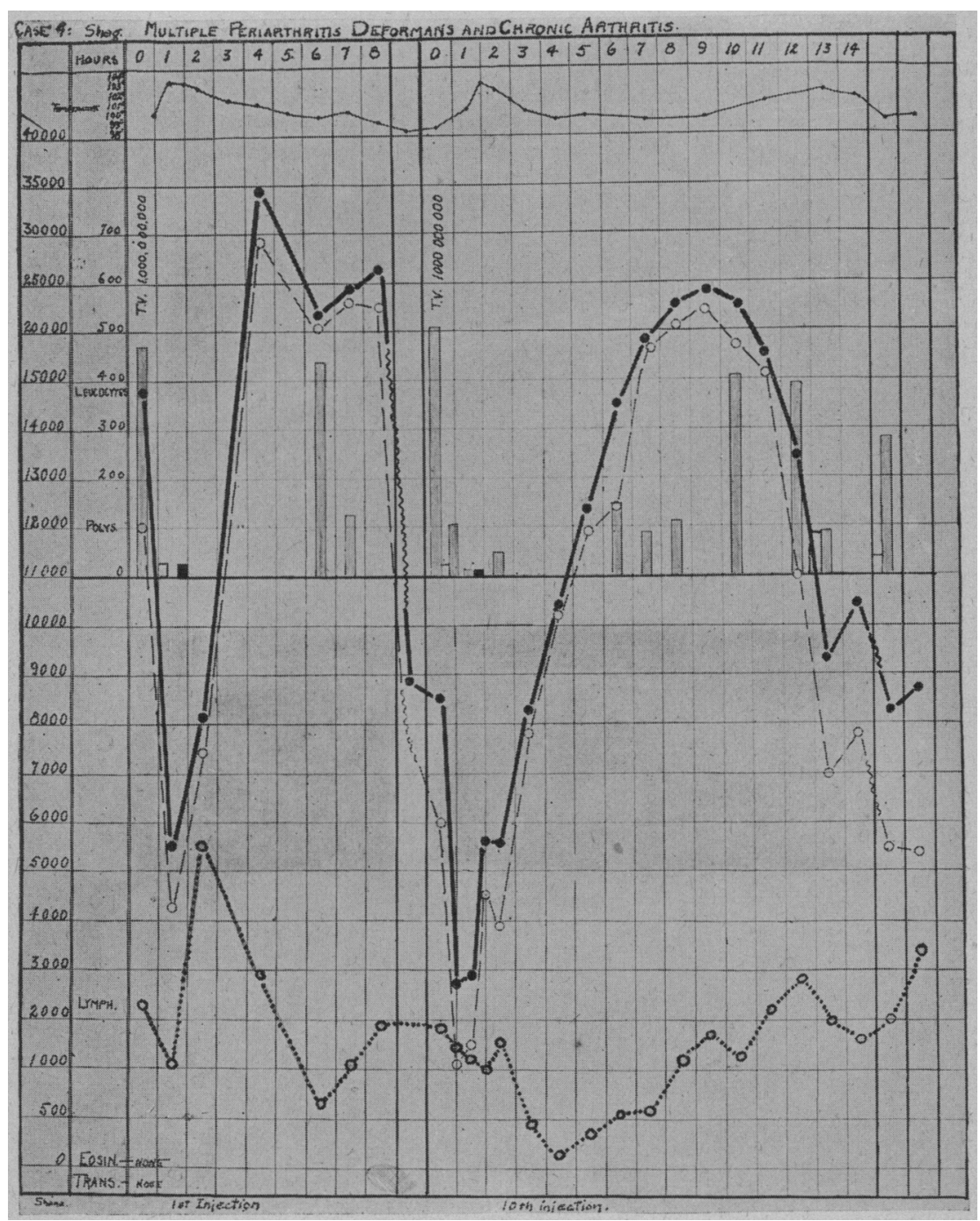

Fig. 5.-Case 4. Shag. Multiple periarthritis deformans and chronic arthritis.

the treatment. She learned to knit and to wheel herself about the ward in a wheel chair. The structural bony changes were unaltered, but the joint stiffness was very much less marked. No perceptible change was noted in the vaginal discharge, which was still fairly profuse and of a whitish, catarrhal character. No gonococci ${ }^{-}$were found on repeated examination. The reactions recorded are the first and tenth. 
CASE 5.-Acute rheumatism; joint swelling; no structural change.

History.-Miss W., a nurse, aged 22, was admitted to the medical ward of the University Hospital Jan. 29, 1917, complaining of swollen and painful knees. In 1914, she had a severe attack of quincy, lasting for four weeks. The abscesses were not lanced. Since that time she had had frequent sore throats. In December, 1916, she had a severe attack of tonsillitis with fever for three days. Following her recovery she was well until Jan. 22, 1917, when her back became lame. On the $23 \mathrm{~d}$ there was some pain in the left knee. The right

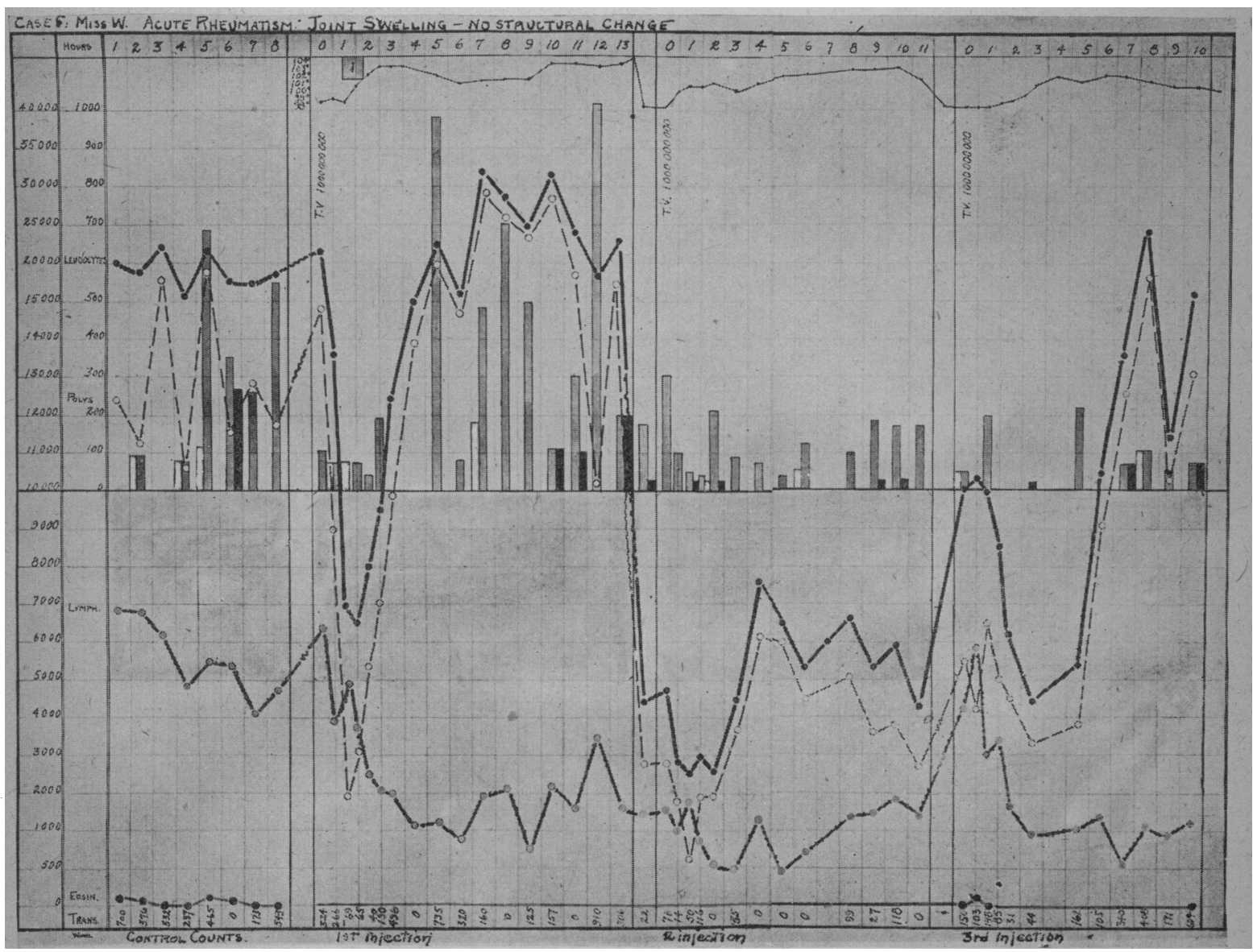

Fig. 6.-Case 5. Miss W. Acute rheumatism; joint swelling; no structural change.

knee was involved the following day. On examination both knees were swollen and tender but not reddened, and no fluid was demonstrable. There was slight swelling of the right ankle. The joints were warm and sweating. The tonsils were enlarged and septic. There were no heart murmurs. The patient was put to bed with the joints wrapped in cotton and given sodium salicylate, 160 grains per day. There was marked improvement under the salicylate treatment, and on Feb. 10, 1917, she was sent home to return for a tonsillectomy in several weeks. The last of March, 1917, the patient had her tonsils removed and six weeks later she had a slight attack of arthritis which cleared up in 
a week under sodium salicylate, 150 grains per day. From that time until December 21 she was well and gained 40 pounds. December 21 , following a severe head cold, she developed pains in her joints. The joints involved were the knees, hips and elbows. Just before the attack of cold she noted that she had dyspnea and some pain at the base of the heart. Examination on entrance showed a definite mitral insufficiency and a murmur at the base in the pulmonic area, probably functional, Roentgenogram of the teeth was negative; of the sinuses, showed normal frontals, increased density in the right posterior ethmoid and a hazy, indefinite density in the right antrum, without changes in the bony wall. She was treated with salicylates and oil of wintergreen applied to the joints. She did not make satisfactory improvement, and Dec. 29,1917 , she was transferred to us for nonspecific protein treatment. On the day of the injection she was complaining of soreness and stiffness in the elbows and knees.

History of Present Attack.-December 6, patient reported a cold, headache, sore throat and general aching of the body. Temperature at 4 a. m., $100.4 \mathrm{~F}$. Culture taken was negative. She returned to duty. December 22 she was unable to report for duty because of painful swelling of the knees. She was unable to walk. She made no satisfactory improvement on salicylate. No further foci could be found, and, for this reason, she was transferred to this department. The day of the first injection the patient was still complaining of soreness and stiffness in her joints, elbows and knees.

Jan. 22, 1918, the following note was made: "Left border of the heart is $10 \mathrm{~cm}$. from the midline; right border $2 \frac{1}{2} \mathrm{~cm}$. Apex is felt in the fifth intercostal space, nipple line. Upper border is, apparently, on the third rib. Careful palpation reveals no thrills. The heart impulse is not marked. A double murmur is heard at the apex, giving the sensation of distance. Both sounds are heard. The murmur, particularly the systolic, is heard in the axilla. The diastolic murmur becomes louder toward the sternum, and is very loud and exhaustlike at the pulmonic area. The pulmonic second sound is definitely accentuated, and is not to any degree displaced by the loud murmur in the pulmonic area. The diastolic murmur can be heard all over the precordia. The patient is very much better after her last injection."

Roentgen Report.-Roentgenogram of the teeth negative; roentgenogram of the sinuses shows normal frontals, increased density in the right posterior ethmoids and a hazy, indefinite density in the right antrum without changes in the bony wall. Diagnosis, posterior ethmoiditis. Stereogram of the knee, good rays. These plates show the bones normal in outline, density, texture and relationship. We see no evidence of involvement of the bones or cartilages; a soft tissue lesion.

Nonspecific Protein Therapy Record.-This patient was given three intravenous injections of typhoid vaccine, 1 billion each, December 29, January 1 and January 18. The individual reactions are recorded in Figure 6 . The patient's symptoms were some better after the first injection, and disappeared entirely after the second. Because of her heart condition she was allowed to be up only two or three hours a day until the 16th when she was up considerable. On the 18th she complained of being uncomfortable and unable to move her lower extremities. Six hours after the last food she was given her third injection This cleared her symptoms up completely within twentyfour hours There had been no return to date, May 21, 1918.

CASE 6.-Hypertrophic arthritis.

History.-Miss Wor., aged 22, stenographer, entered the University Hospital in the medical clinic complaining of swollen and painful joints and inability to walk.

Family History.-Mother had rheumatism and a chronic heart lesion.

Present Illness.-Began four years before admission with a gradual onset; first, there was sharp pain in the left hip and thigh, then in the right knee. 
Four days later the metacarpal-phalangeal joints were involved. Joints in the hands and fingers had been painful for three years; the ankles were affected one year prior to admission and since then she had had difficulty in walking. The past three weeks the jaw had been involved.

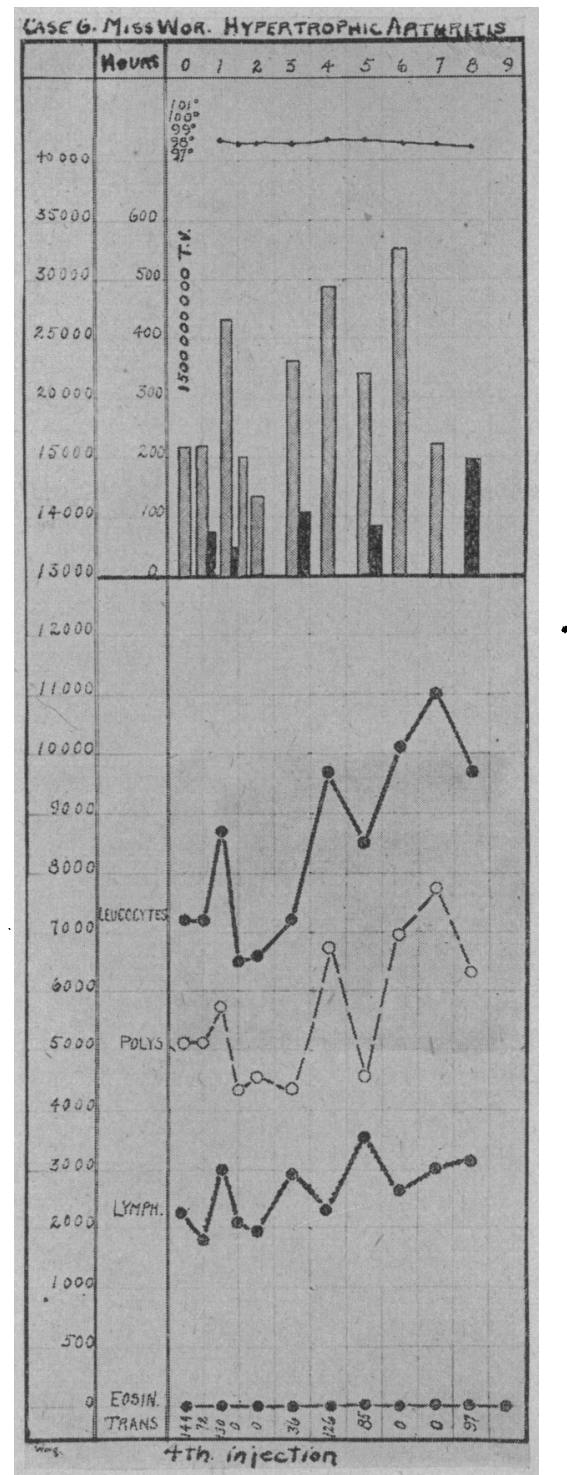

Fig. 7.-Case 6. Miss Wor. Hypertrophic arthritis.

Examination.-Patient was of moderate build with good musculature. The apex of the heart was in the fourth intercostal space and the sounds were clear and distinct, with no murmurs. The extremities showed hypertrophy of all the joints, especially the ankles and finger joints. There was beginning ulnar flexion of the latter. The picture was typical of hypertrophic arthritis. 
Nonspecific Protein Therapy Record.-The patient did not improve under salicylates and no focus of infection being found she was given $300,000,000$ typhoid vaccine Dec. 10,1917, at $1: 25$ p. m. This was followed by a chill beginning at 2 and lasting for twenty minutes; the temperature rose gradually, reaching a maximum of $100.8 \mathrm{~F}$. at $5 \mathrm{p}$. m. There were no focal symptoms accompanying the reactions. The patient thought the knees and ankles were more flexible.

Dec. 17, 1917. Patient was given two injections of $500,000,000$ and 1 billion typhoid vaccine with the same reactions as the first. Dec. 19, 1917, she was given agar agar intravenously. Two minutes after the injection the patient complained of feeling queer, with tickling and choking sensations in the throat and tingling in the feet. She was extremely cyanotic, with an anxious expression. The pulse was small, weak and rapid. Her condition resembled shock. In fifteen minutes she felt better, but the cyanosis was still present. In one hour her condition was normal.

Jan. 7, 1918, she was transferred to us for intravenous typhoid vaccine. She was given a dose of $1 \frac{1 / 2}{2}$ billion. Her temperature tose to $102.4 \mathrm{~F}$., and was preceded by chill (Fig. 7). Her joint condition showed no permanent improvement after these four injections of typhoid vaccine, so she was returned to the medical department where subsequently she received three doses of Colles' serum. These injections gave a severe symptomatic reaction, but the temperature never rose above $102.2 \mathrm{~F}$. After three injections she was markedly improved and able to walk.

CASE 7.-Atrophic arthritis.

History-Mrs. McD., aged 64, entered the Cowie Hospital Oct. 18, 1917, complaining of pain in the knees and difficulty in walking. Duration, four and a half years.

Five years prior to admission the patient had gastric ulcer with hemorrhage from the stomach. Six months later there was a second hemorrhage, and since that time there had been pain in her knees which gradually became worse. Both knees were affected. They were swollen, and it was impossible completely to extend them. The pain was more severe on walking. No other joints were affected. At 14 the patient had a severe attack of inflammatory rheumatism lasting three weeks. The left side and knee were involved. Recovered with a heart lesion which was perfectly compensated. Had never had any trouble with her tonsils. Except for a tooth removed recently which had a small pus pocket at the root, there had been no trouble with her teeth. In March, 1917, the patient had a severe attack of laryngitis which was followed immediately by "sciatica." Twenty-five years ago the patient was in a railroad accident. Her sternum was fractured (?) and her back was injured, and has been weak ever since. Fifteen years ago she was treated for "catarrh of the stomach." This was the first record of stomach trouble. Seven years ago the patient had ptomain poisoning from-oysters, and during the following year she lost 35 pounds. Fifteen months after this attack she had her first hemorrhage of the stomach (March, 1912). The second hemorrhage occurred in November, 1912. For the two years following she was troubled with pain in the epigastrium of a sharp, shooting character, occurring four hours after eating. In the fall of 1917 she had an acute attack of stomach trouble, and at the same time her knees became worse. She had never noticed any tarry stools. Menopause at 50 . Had a single severe hemorrhage which was repeated the second month. No other difficulty.

Family History.-A daughter is said to have had gastric ulcer. One son has had medical treatment for gastric ulcer. The patient's mother had severe stomach symptoms and one sister had "gastric ulcer."

Physical Examination.-Large frame. Fairly well developed musculature; muscles soft. Panniculus thick all over the body. Sight edema over both ankles. Inguinal glands just felt; otherwise glands were negative. Circumference of the knee, $44 \mathrm{~cm}$. both sides. Patella reflexes not obtained, probably due to position; elbows prompt. 
Lungs: Increased vesicular inspiration all over (moderate degree of emphysema); no other adventitious sounds. Patient had been short of breath for five or six years.

Heart: Apex difficult to locate, apparently the same as the left border$11 \mathrm{~cm}$. from the midsternal line just outside the mammary line. Right border

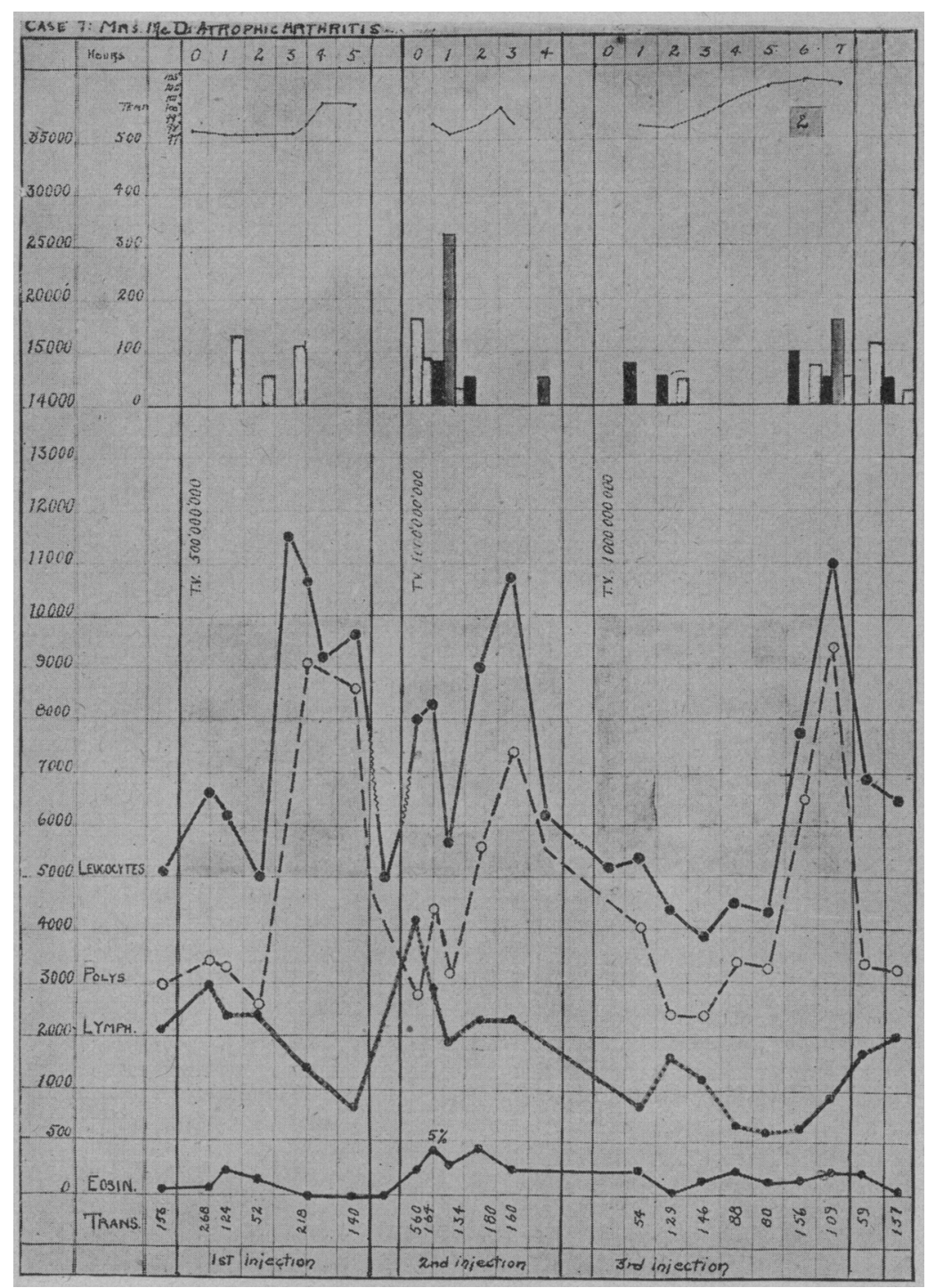

Fig. 8.-Case 7. Mrs. McD. Atrophic arthritis.

$2.5 \mathrm{~cm}$. Upper border on third rib. Aortic arch did not seem to be increased. Heart impulse moderate. No thrills. First strike of the apex about normal; it was followed quickly by a very distinct, short, blowing murmur which terminated in a flapping second sound. It was difficult to differentiate whether the murmur followed the first sound and was part of it, or whether it was 
part of the second. The murmur was not transmitted to the sternum, was not well transmitted into the axilla, but could be heard. Pulmonary second sound was, possibly, slightly accentuated and louder than aortic second sound. Aortic area seemed to be negative. The first sound in the carotid was very plainly heard, somewhat roughened, but no thrill could be felt on reexamination. Blood Pressure: Systolic, 125 ; diastolic, 70 ; pulse pressure, 55 . The pulse is regular, 78, fairly easily compressed; felt slightly after compression; not particularly tortuous; negative. The patient had been conscious of the ankle swelling. She had no characteristic pain in the left arm, but complained of some rheumatic pain in the right shoulder. No chest tightness.

Abdomen, negative.

Blood: Red cells, 5,180,000; white, 5,500; hemoglobin, 80 per cent. (Talqvist). Polynuclears, 56; small lymphocytes, 29 per cent.; large lymphocytes, 8.5 per cent.; transitionals, 2.5 per cent.; eosinophils, 1 per cent.; mast cells, 1.5 per cent.

Urine negative

Stomach functions negative.

Roentgenographic Record.- "Lateral stereogram of each knee and an anteroposterior including both knees. The pathology is virtually identical in both knees. Superficially the most striking feature is the marked osteophyte formation at the margins of the articular cartilages, but careful observation demonstrates a marked erosion of these cartilages with lateral luxation. The erosion is most marked over the internal condyle."

"Diagnosis, chronic atrophic arthritis."

Nonspecific Protein Therapy.-Nov. 7, 1917, the patient received the first intravenous injection of typhoid vaccine, dosage, 1 billion. At the end of three hours she had a marked chill and suffered from severe pains localized in the back, legs and knees and an increase in temperature (Fig. 8). November 8 , she was given her second intravenous injection. The chill in this reaction was delayed for four hours. It was very severe. The maximum temperature was only $100 \mathrm{~F}$. Pain was very severe. On the 12 th she received her third injection; the chill followed in three hours with a rise in temperature to $102.4 \mathrm{~F}$. following it. After the nonspecific protein therapy the soreness disappeared from the knees and they were straighter, although the difficulty in walking still persisted.

CASE 8.-Hypertrophic arthritis of spine.

History-Mrs. B., housewife, aged 46, entered Cowie Hospital because of neuralgiform pain, occurring in remittent attacks involving the right leg and thigh and the posterior cervical region. Family history negative.

Past History.-The attacks of pain were present for eight or nine years, the first attack lasting a year. At this time she had sharp shooting pains in the chest and soreness in the left arm. There had been remissions lasting a year or more when she had felt normal. For the previous two years the pain had been localized during the attacks in the right leg and hip and in the back of the head and neck. There was pain and soreness on pressure which was aggravated by walking or standing. Because of the pain she found it difficult to stoop over.

At the age of 18 she had an infected fallopian tube with abscess formation. The first child, born about twenty years previously, was delivered by high forceps, and the patient was badly lacerated. In 1913 one ovary, one tube, and the uterus were removed. This operation improved the patient's headaches and she was distinctly better following it. She has always been constipated and believes that the attacks of neuralgiform pain follow a period of constipation.

Physical Examination.-Examination showed a small, well built woman, who looked about 35 years old. Physical examination was negative except for absent pharyngeal reflex, inframammary tenderness, slight tremor of the 
extended hands, and tender points along the sciatic nerve, the second, third and fourth cervical vertebrae and the lumbar vertebrae. The heart on Aug. 30, 1916, showed the apex in normal place and the heart sounds negative. In November, 1916, examination showed apex and outlines normal, marked pulsation of the neck with slight thrill and the short soft puff which was not transmitted was heard at the apex. The pulse for this time was $104 \mathrm{~F}$. Aug. 6, 1917, the heart was negative.

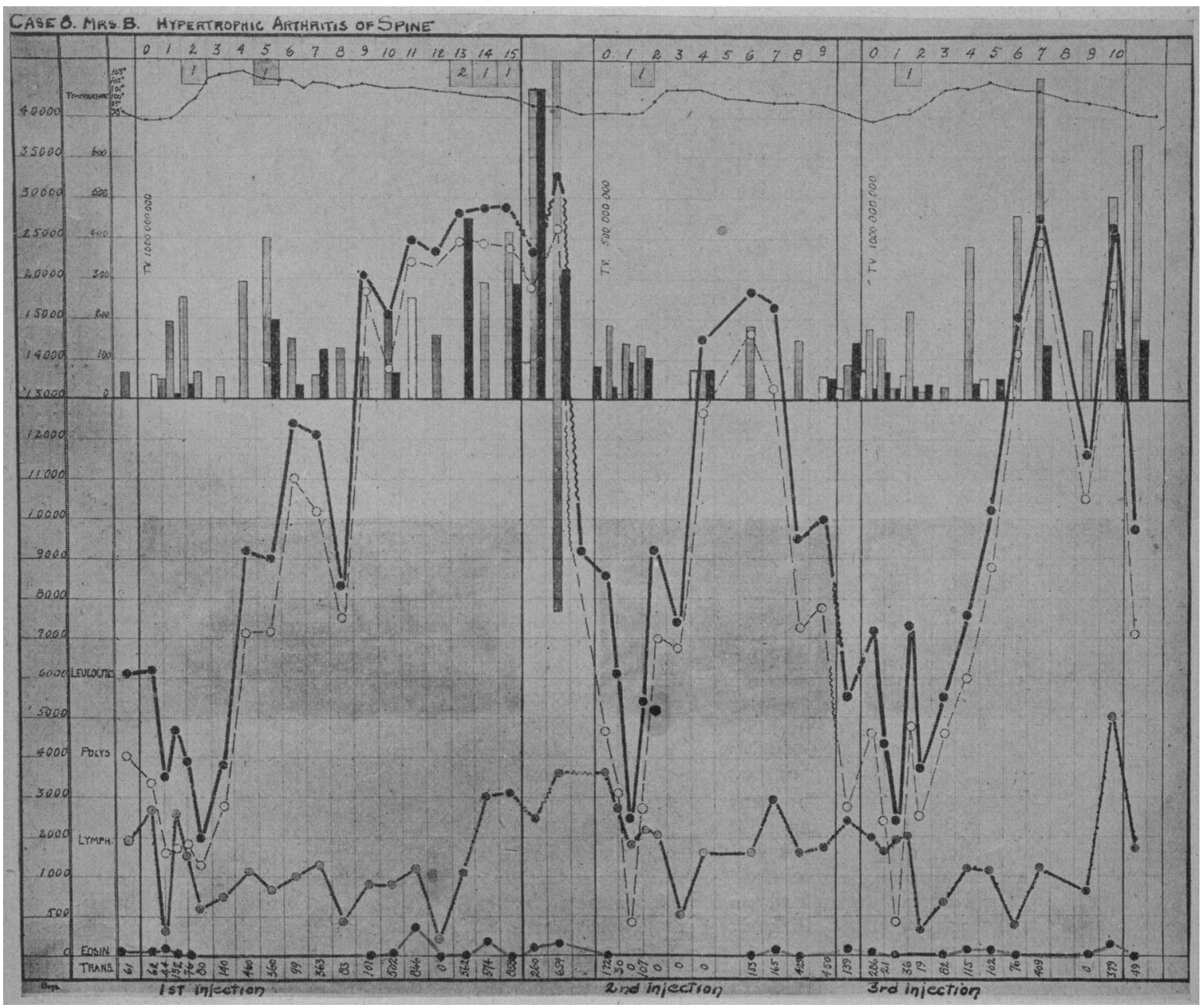

Fig. 9.-Case 8. Mrs. B. Hypertrophic arthritis of spine.

Neurologic examination showed areas of hyperesthesia on the right leg and thigh corresponding to the cutaneous distribution of the first, second, third and fourth lumbar roots and the first sacral. The upper boundary of the hyperesthesia was two finger breadths above the pubes and extended in a curved line to the lower dorsal vertebral spine. The lower limit extended diagonally across in front of the leg, involving a small semicircular area on the inner central aspect of the sole of the foot. There were pain points along the 
course of the sciatic nerve. A diagnosis of radiculitis of the Iumbosacral plexus was made and a roentgen-ray examination was recommended.

Roentgenographic Report.-A stereogram was made of the lower lumbar and upper sacral region. These were satisfactory roentgenograms, from the third lumbar to the sacrum, including both sacroiliac joints. The spine was straight and the fifth lumbar was of the free standing normal shape. The pathology appears to lie in the anterior or intercentral articulations of the lumbar spine. The findings consist of a roughening and accentuation of the upper and lower surfaces of these centra, with a distinct lipping at the angles. There is also a slight lipping at the lower margin of the iliosacral articulations. The majority of the pathology, however, is in the spine. The hip is negative. This is an anterior spinal arthritis.

Nonspecific Protein Therapy Record.-Feb. 7, 1918, the patient received intravenous injection of typhoid vaccine, dosage 1 billion. Within a half hour she was chilly and complaining of severe headache and backache (Fig. 9). Within three hours her temperature had risen to $104 \mathrm{~F}$.; she was very restless, nauseated, and delirious. Respirations were verry short and rapid and she was cyanotic. Because of the severity of the reaction she was given on the second injection, February 11, only $500,000,000$ as a dose. This was followed within half an hour by a severe chill and headache; the reaction was completed by 6 o'clock. The temperature did not rise as high as might have been expected from the severity of the chill. February 13, she was given her third and last intravenous injection of 1 billion typhoid vaccine. This was followed by a very severe chill lasting for twenty minutes, a marked increase in temperature and at the end of three hours delirium. She localized the pain in the occipital region, in the back and in the right leg and thigh. During her delirium she complained of having two heads, both of which ached. Temperatures taken showed the axillary temperature to be a degree and a half below the temperature taken in the right popliteal space. The temperature over the back of the neck was perceptibly higher than that of the face. On the day following the injection the patient found that she could stoop over without pain and since that time the spine has remained more flexible. She was told the intravenous injections might arrest the arthritic process but could not repair structural damage already done.

CASE 9.-Gonorrheal vulvovaginitis.

History.-Frances C., a girl, aged 2, entered the pediatric department, Jan. 4,1918 , because of profuse vaginal discharge.

Family History.-The mother denied vaginal discharge in herself and other little girl.

History.-Has no bearing on the case.

Present Illness.--This started four weeks prior to admission; yellow white vaginal discharge; genitals excoriated and red, causing much pain on micturition. Smear positive for gonorrhea.

Physical Examination--General examination negative.

Genitals: There was a very slight excoriation of the external parts; marked vaginal discharge of yellowish white pus. Anus normal and clean.

Vaginal smear positive. Wassermann negative. Neisser complement fixation positive Jan. 7, 1918. Neisser complemerit fixation negative Jan. 25, 1918.

Nonspecific Therapy Report.-This patient received five intravenous injections of typhoid vaccine; seven partly intravenous and partly intramuscular. With the exception of the final dose of $500,000,000$, the dosage was one billion. The injections were given January 9, 12, 19, 25, 28, and February 1, 4, 7, 9, $11,13,17$. Those in italics were partly intravenous and partly intramuscular. It was almost impossible to get a vein in this child. Most of the intravenous injections were given into the jugular. Marked leukocytic reactions followed each injection in which counts were made excepting the fifth recorded. The 
temperature reaction was not marked; $102 \mathrm{~F}$. recorded only once. The patient suffered no inconvenience whatever from the injection (Fig. 10).

There was no lessening of the vaginal discharge following the first injection. After the third injection the nurse was certain the discharge was distinctly less, but it still had to be charted profuse (3). After the sixth injection the discharge was distinctly less, now charted (2).

Two days later very little discharge could be obtained for a smear; only a few leukocytes and a few epithelial cells were present and a few intracellular cocci. After the ninth injection the discharge was still slight in amount and from then on there was very little visible discharge. The case at the time

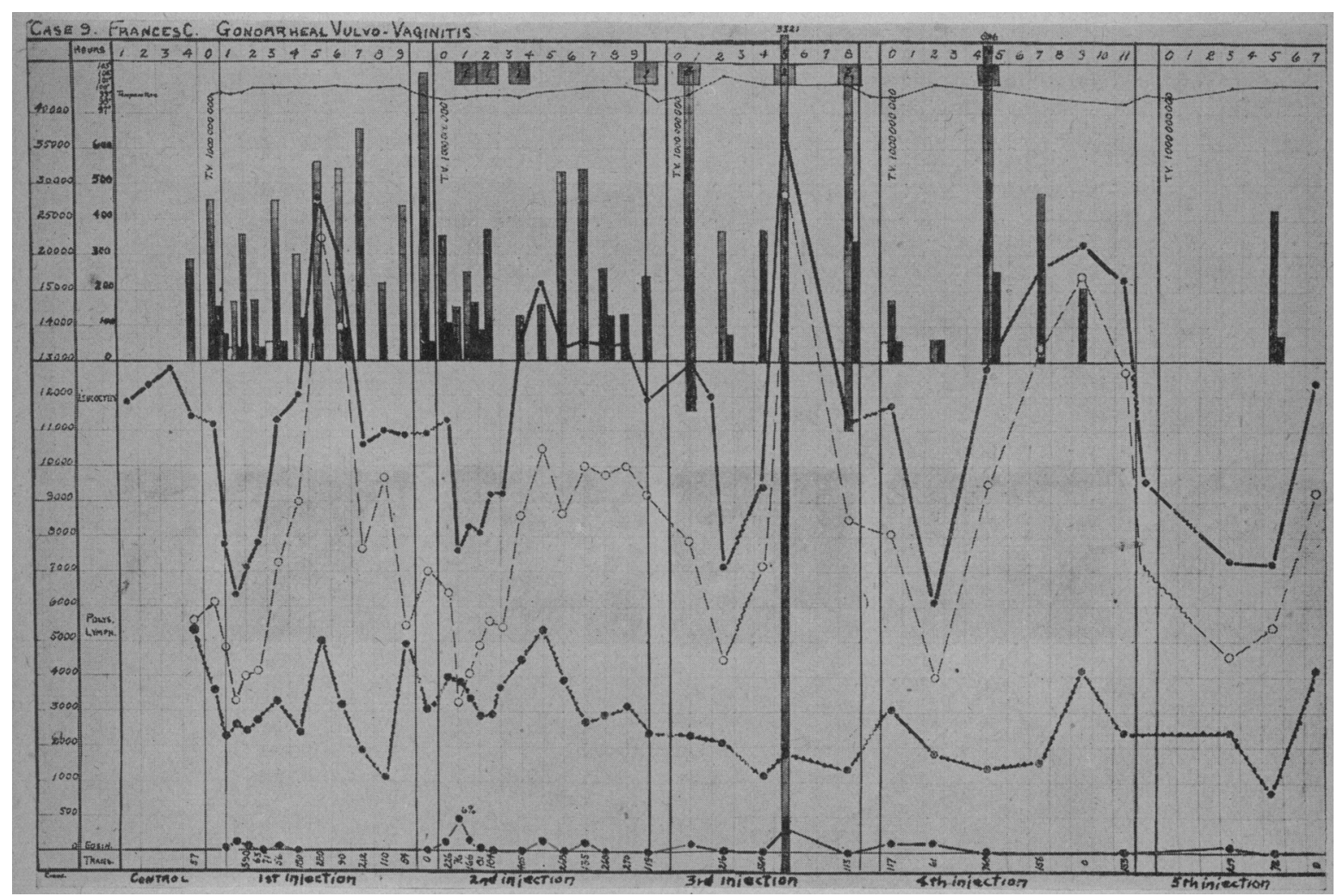

Fig. 10.-Case 9. Frances C. Gonorrheal vulvovaginitis.

of the report was practically clear without any further treatment. (NoteJuly 1, patient continued to have a slight discharge and occasionally intracellular organisms were found.)

CASE 10.-Suppurative mastoiditis with chronic pulmonary tuberculosis.

History.-Frei., a schoolboy, aged 9. The patient came to the University Hospital Oct. 17, 1917, because of double discharging ears. The temperature was normal. A double mastoid operation performed Oct. 18, 1917. The patient reacted well. There was a slight temperature reaction after the operation, but this subsided on the 21st and remained normal until the 28th, from which time until November 5, when he was referred to the pediatric department, it varied from 100 to $102 \mathrm{~F}$. Aside from the discharging ears our examination at this time was negative. 
Examination.-November 4, the patient was referred to us because of continued elevation of temperature ranging from 100 to $102 \mathrm{~F}$. in the afternoon, returning to 99 in the morning. At this time we were unable to find any definite signs in the heart and lungs. Lumbar puncture gave clear fluid under increased pressure; about 20 c.c. came away. Total cells 650 , all lymphocytes. Nonne, Noguchi, alcohol and Fehling tests negative. The blood pressure was found to be negative.

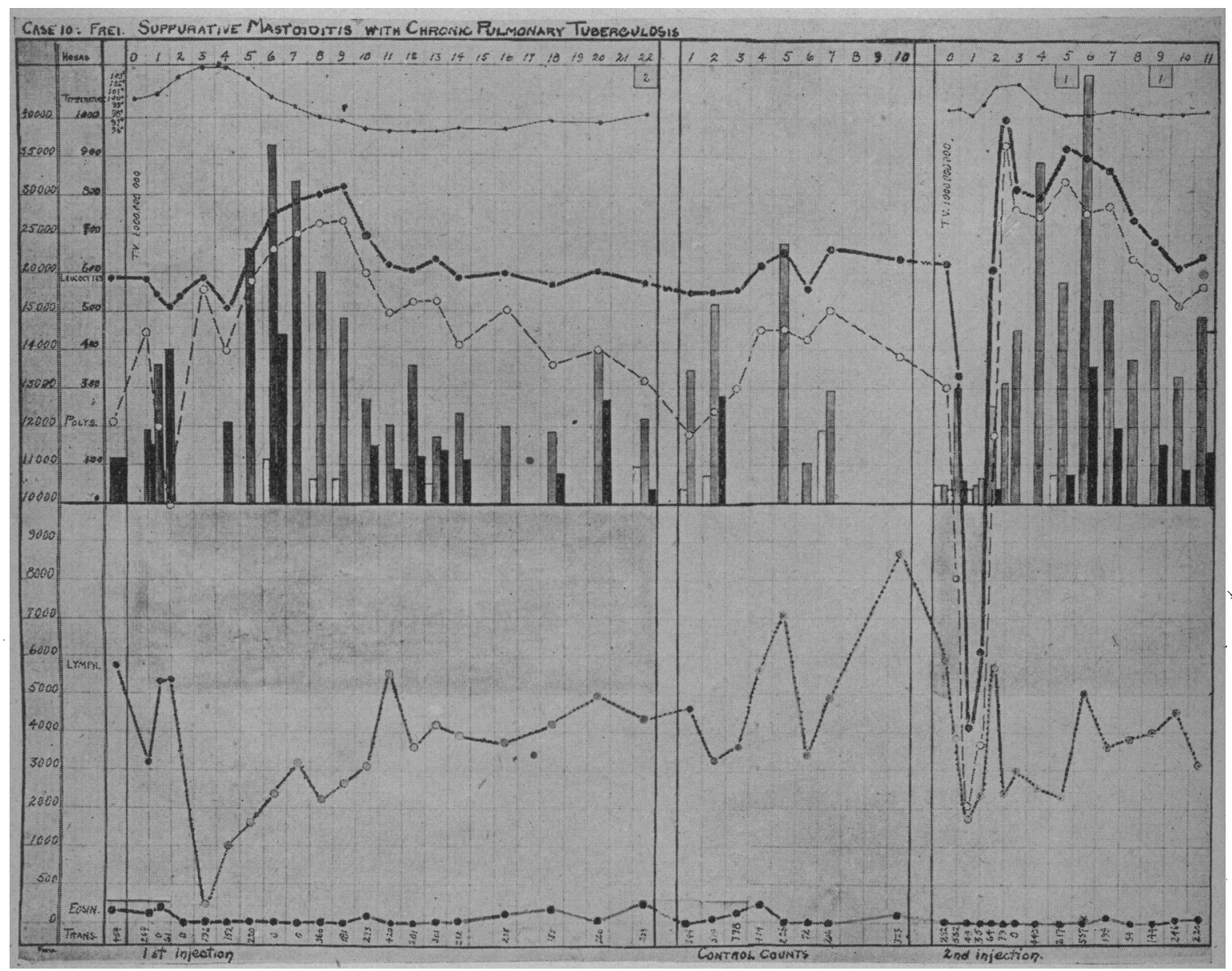

Fig. 11.-Case 10. Frei. Suppurative mastoiditis with chronic pulmonary tuberculosis.

December 13 , referred again; at this time the heart was 3.5 by $8 \mathrm{~cm}$. Roentgen ray showed cardiac enlargement over previous plate. Sounds negative; no murmur. Lungs: Low down in the right axilla there was slightly impaired resonance; exaggerated vesicular breathing, an occasional râle. Dulness in the right back below the angle of the scapula; bronchovesicular breathing over this area; increased whispered voice. Many râles. From now on definite chest signs were always present. A diagnosis of pulmonary tuberculosis was made on the physical finding of tubercle bacilli and by the roentgenogram. 
This case was selected because of the suppurating mastoid, to see if any effect could be produced on the discharge, and to determine what effect the typhoid vaccine (intravenous injection) would have on the blood in this condition associated with tuberculosis.

Nonspecific Protein Therapy Record.-A first injection of 500,000,000 typhoid vaccine was given Dec. 21, 1917. It was followed by a chilly sensation at the end of one hour and nausea at the end of three hours. The temperature rose to its maximum of $105.4 \mathrm{~F}$. three hours post-injection (Fig. 11).

The second injection was given Jan. 1,1918 , at $7: 30 \mathrm{a} . \mathrm{m}$.; the dosage was 1 billion; this was followed in two and one-half hours by a slight chill.

Two days after the injection the discharge from the ears had practically ceased, and a week later the department of otology found no discharge when the wound was dressed. The process was chronic and of three months' duration.

MOVEMENT OF NORMAL CELLS INDUCED BY FOREIGN PROTEIN

The Leukocytes.-Following an injection of typhoid protein there is almost invariably a decrease in the total leukocyte count. Commonly this decrease amounts to a distinct and often to marked leukopenia, but not always. In Cases 6 and 9, the leukocytes never went below normal. In Cases 1, 3, 4, 5, 7 and 10 the leukocytes did not go below normal until the second or third injection. This decrease in the leukocyte count in our cases varied from 1,600 in Case 6 to 16,000 in Case 10. The leukopenia usually immediately follows the injection. In twenty-nine reactions it occurred at the following hours. $\begin{array}{lllllllc}\text { Hours } \ldots \ldots \ldots \ldots \ldots \ldots & 2^{1 / 2} & 1 & 1^{1 / 2} & 2 & 21 / 2 & 3 & \text { Total } \\ \text { Number of Reactions.... } & 11 & 5 & 7 & 0 & 4 & 29\end{array}$

A reversal occurred in five cases $(4,5,7,8,9)$. Following the leukopenia there is always a rise in the leukocytes. This occurs whether the leukocytic movement is above or within the normal limits. The leukopenia in the four children studied was not as low as in the adult cases, 5,000 being the lowest count. The greatest upward excursion from the lowest point reached to the height of the reaction was 33,000 . The highest induced leukocytosis above the control was 29,000 . The height of the leukocytes is usually reached in from four to nine hours after the injection. In twenty-nine reactions the height was reached at the following hours:

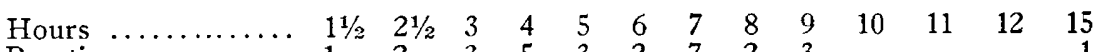

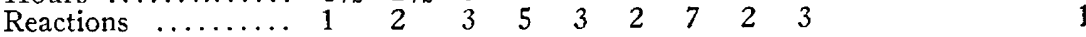

In one case, No. 8 , the last observation was made at the fifteenth hour, but the reaction continued throughout the next two days, when it reached its height, 35,000 . By reference to the charts it will be observed that intercurrent drops or pseudocrises may appear in the leukocyte curve. The movement downward may be as great as 4,300 (Case 8). One might thus be easily misled and think the leukocytic reaction was over when, as in this case, the most marked changes were to come many hours later - numerous myelocytes, atypical cells 
and nucleated reds. The end of the leukocytic reaction is usually characterized by a critical fall.

Influence of Size of Dose on the Reaction.-On three occasions a $500,000,000$ dose was given. In two of these the reaction was distinctly less marked; in one, a first injection, the reaction was the greatest. We have observed this many times in the simple clinical reaction, and at times when accidentaily only part of the injection went into the vein.

The Polymorphonuclears.-The polymorphonuclears generally follow the total leukocyte curves pretty closely (Figs. 1, 5, 6, 9, 11), excepting at the time of the leukopenia, when there is very frequently a reversal. This reversal always precedes a prompt rise in the leukocytes (Figs. 5, 6, 8, 9, 10). The polymorphonuclears induced by the injection of the foreign protein took the nuclear stain after the fashion of new cells, as shown by the chromatin network staining very distinctly. Our attention was frequently called to the large size of the nucleus. We have not as yet made any Arneth counts. This question is of interest because of the shift to the left in typhoid fever.

The Lymphocytes.-In all cases, except Case 9, the large lymphocytes almost invariably disappear from the blood at some time during each reaction. The small lymphocytes, on the other hand, never completely disappear. There seems to be no relationship between the appearance of atypical large lymphocytes and the disappearance of the normal large lymphocytes; for example, in Case 3, first reaction, the relation of atypical large lymphocytes to the normal lymphocyte is as follows:

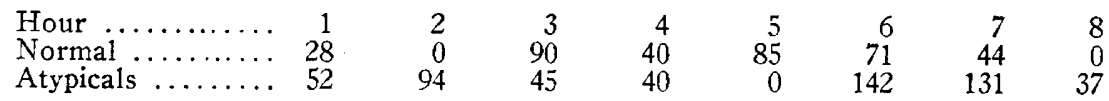

In four cases $(1,3,7,8)$ the number of large lymphocytes at times exceeded the number of small lymphocytes. In three of these cases $(1,3,7)$ this reversal of the normal relationship does not occur until after the first injection. In Case 8 it occurs late in the first reaction. Delany, ${ }^{6}$ and also Krause, ${ }^{7}$ found the large lymphocytes equalled or exceeded the small lymphocytes in a differential count of malarial blood. This was so constantly present that Delany considered it as diagnostic as finding the plasmodium.

The total lymphocyte count in normal blood ranges between 1,500 and 2,200 per c.mm. Following an injection of typhoid protein there is almost invariably a decrease in the total lymphocyte count, almost immediately after the injections. This may only be slight, but the

6. Delany: Brit. M. J., March 28, 1903.

7. Krause, W.: J. A. M. A., 43:1202, 1904. 
movement downward is nevertheless present. There is one exception, Case 3 , reaction 1 . Out of 29 reactions a lymphopenia occurred in 24 . The lowest recorded is 200 (Case 4 , second reaction). There were 10 reactions below 500 in 6 cases $(1,3,4,5,8,10)$. A lymphocytosis occurred in 21 reactions out of the 29; of these only 9 rose above the initial count. The highest lymphocytosis initiated by the injection was 8,800 and occurred during the interval between the first and second injections in Case 10. This patient had pulmonary tuberculosis and had an initial lymphocytosis of 5,800 . In 7 cases $(1,3,4,5,8,9,10)$ there was a lymphocytosis in the control, varying from 2,800 to 5,800 . In 15 reactions the final lymphocyte count was lower than the initial count preceding the injection.

A decrease in the number of lymphocytes followed the chill in 23 out of the 29 reactions. This occurred in all the reactions in children. In no case do we get the immediate rise following the chill. This calls to mind the work of Rause on struggle lymphocytosis in which we have been interested. In dogs during marked struggle he found an increase in the lymphocytes. The chills in some of our reactions were so violent that we were looking for a similar increase in the lymphocytes, but it did not occur.

The Transitionals. - The total number of transitionals in normal blood ranges between 230 and 380,3 per cent. and 5 per cent. In twenty-five reactions the transitionals ran below the normal; four of these showed an initial low count. In thirteen reactions the transitional count was above normal, two of them having an initial high count. The highest count is $866-3.5$ per cent.

The Eosinophils.-In two cases only did the eosinophils show an increase, and this increase was only slight - Case 7, second reaction, 5 per cent., or a total of 400 cells ; Case 9, second reaction, 6 per cent., or a total of 450 cells. The eosinophils, indeed, were conspicuous by their absence. This is strong proof that the reaction is not of an anaphylactic nature. In Cases 7 and 9 the increase came, in each case one-half hour after the second injection, suggesting an anaphylactic response to the previous injection. In Cases 3 and 5 they were present in the control and almost invariably absent during the reaction.

OCCURRENCE OF ABNORMAL CELLS

The Myelocytes.-Myelocytes were quite regularly found after the injection, twenty-four out of twenty-nine reactions. They were rarely present in the controls. In one case (8) a total of 800 cells were found. The basophil myelocyte was most frequently encountered. Myelocytes most frequently made their first appearance very soon after the injec- 
tion, in from one-half to one hour. Of the twenty-four reactions in which they occurred they appeared at the following hours.

$\begin{array}{llllllllllll}\text { Hours after Injection.. } & 11 / 2 & 1 & 11 / 2 & 2 & 3 & 4 & 5 & 6 & 7 & 10 & \text { Total }\end{array}$

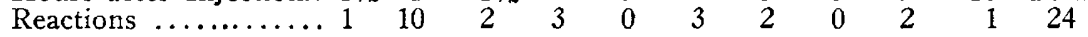

The Nucleated Red Cells.-Nucleated red cells were found in seven out of the ten cases; both megaloblasts and normoblasts were found. Their appearance was not necessarily associated with the appearance of myelocytes. This is interesting in view of Stockard's ${ }^{8}$ conclusion that "vascular endothelium erythrocytes and leukocytes though arising from mesenchyme are really polphyletic, each with a different mesenchymal fundament or anlage, and if one is destroyed the others cannot replace it." That is, if the fundament producing myelocytes is destroyed, nucleated reds may still be manufactured but the myelocytic function can never be recovered. That the nucleated reds do not necessarily appear at the same time as the myelocytes might lead one to argue that the same stimulus reacts differently on two different "fundaments."

The Platelets.-We have been impressed with the large number of platelets present in the reaction smears. We were unable to make systematic counts. The morphology of these bodies was frequently quite remarkable ; 9 large sized well preserved ones were quite numerous. In Case 7 the plates were at times from one-half to two-thirds the diameter of the red corpuscles with distinct collections of nuclear matter, and at times a reticulated cytoplasm. Similar platelets were seen in several other cases.

Very early in the reaction we observed a stage when it was difficult to obtain a complete count from a single stab of the finger, uwing probably to increased coagulation time (Cases 1 and 8 particularly).

Duke ${ }^{10}$ has observed after the administration of small doses of typhoid vaccine an increase in the number of the platelets; after large doses, a fall in the curve or a rise followed by a fall. In a typhoid innoculation he believes the effect is irritant (increase) and a toxic dose is not reached, while in typhoid fever the irritant dose is exceeded and a reduced count is the rule.

The Spectroscope.-Early in our work we became impressed with the cyanotic appearance in some cases and particularly a darker appearance in the blood when drawn into the pipet. This was most marked in Cases 7 and 8 . In Case 6 intense cyanosis followed an intravenous injection of agar agar. This suggested the advisability of spectroscopic examination to detect the presence or absence of reduced hemoglobin.

8. Stockard: Am. J. Anat., 18: 1915.

9. Similar platelets have been described by Kemp, Harris and Calhouns. Brit. M. J., Dec. 22, 1906, and Am. J. Physiol., February, 1904.

10. Duke: J. A. M. A., 65:1600, 1916. 
In Case 1, spectroscopic examinations were made with each count. Two bands of oxyhemoglobin were present at all times. In Case 8, the result was the same. In this case the blood looked dark, but this was not due to reduced hemoglobin. In Case 1 the blood never looked dark.

\section{THE ATYPICAL CELLS}

Atypical cells almost constantly appeared in the blood stream very soon after the injection of the foreign protein. They commonly continued throughout the reaction. They consisted largely of atypical large lymphocyte forms, and many small lymphocyte forms. In addition to these atypical cells, abnormal cell forms were frequently encountered, myelocytes, and nucleated reds both normoblasts and megaloblasts. Most of these forms are illustrated in the colored plates (Figs. 12 and 13). In Figure 12 Turck irritation forms, changes in the small lymphocyte group, are shown on the first and second lines. Granular, reticulated and multinucleated forms of the small lymphocyte group appear on lines three, four and five. Irregular nucleated and granular large lymphocytes are shown on lines six and seven and in Figure 13.

The Turck irritation forms are usually only found in pathologic blood, inflammatory processes, during or following a leukocytosis. They were only found preceding the first injection; that is, in the first control, before any foreign protein had been injected, in two cases ( 4 and 9). The former patient had an active gonorrhea, the latter a marked vulvovaginitis in which no gonococci could be found. Both of these patients were children. Four of these eight cases had previously had subcutaneous injections of so-called serum or vaccine. One had typhoid vaccination a year preceding the treatment. These findings would seem to show that an intravenous injection of typhoid protein initiates the appearance of Turck irritation forms.

Acidophil Granular Lymphocyte Forms. - These cells are frequently found in normal blood, but not in large numbers. We have noted two types of these cells. Those with very fine granules and those with large granules sometimes reaching the size of microcytes and not unlike them in appearance. The larger granular forms are the ones charted. Some of these cells show nuclei poor in chromatin and others have a vacuolated protoplasm. Many are binucleated and occasionally a mitotic form is seen. With one exception these forms were never encountered in the control. This patient showed 8 per cent. of the red granular forms in the control, and, in addition to this, there were many of the fine granular forms. The patient had recently been treated with vaccines preceding our investigation. 

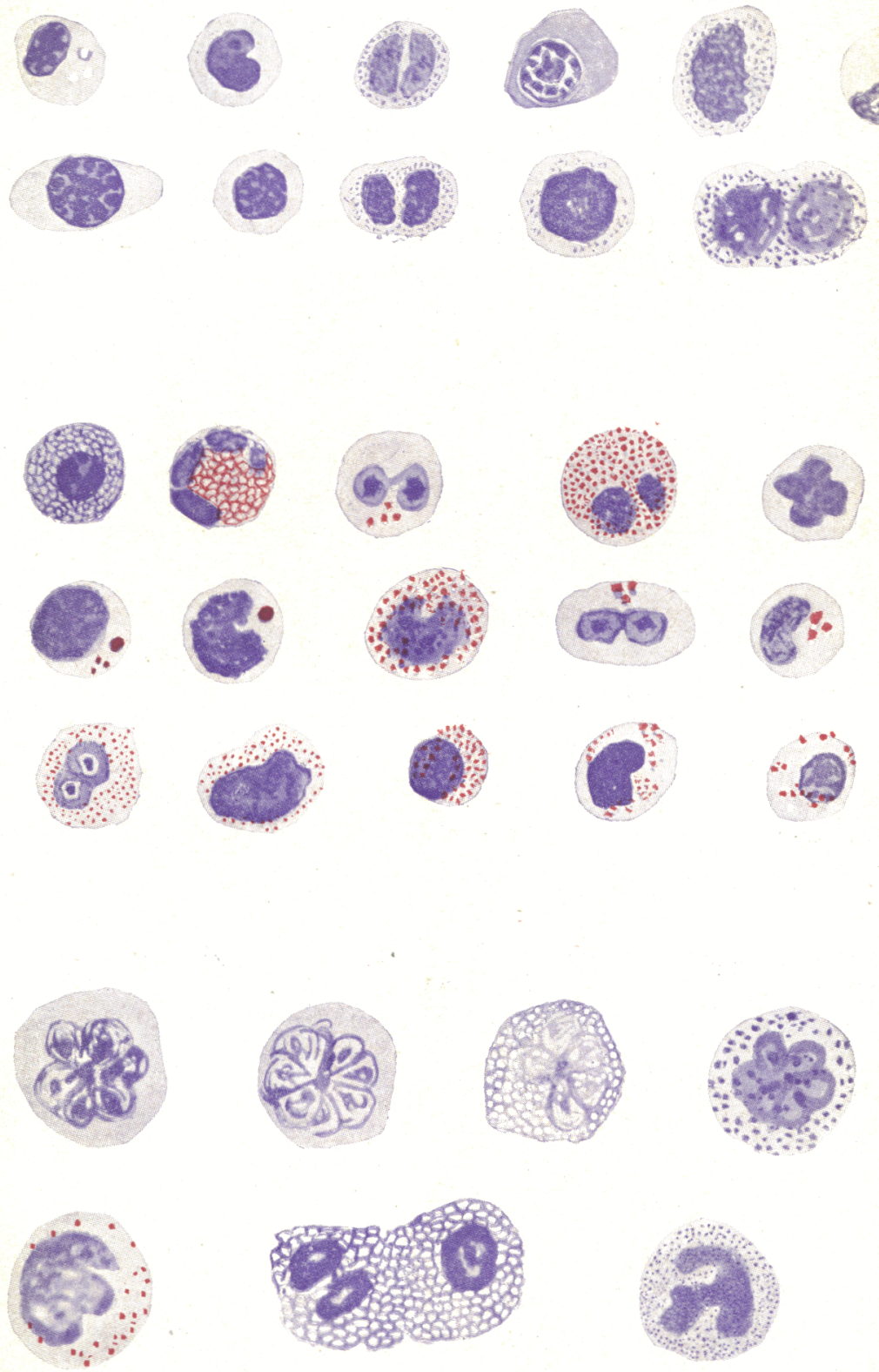

Plate I

Atypical White. Blood Corpuscle

Illustrating Article by David Murray Colite, M.D., and Henrietta Calioun, M.D. Downloaded From: http://archinte.jamanetwork.čm/ by a Ñew York Û́niversity User on 06/25/2015 

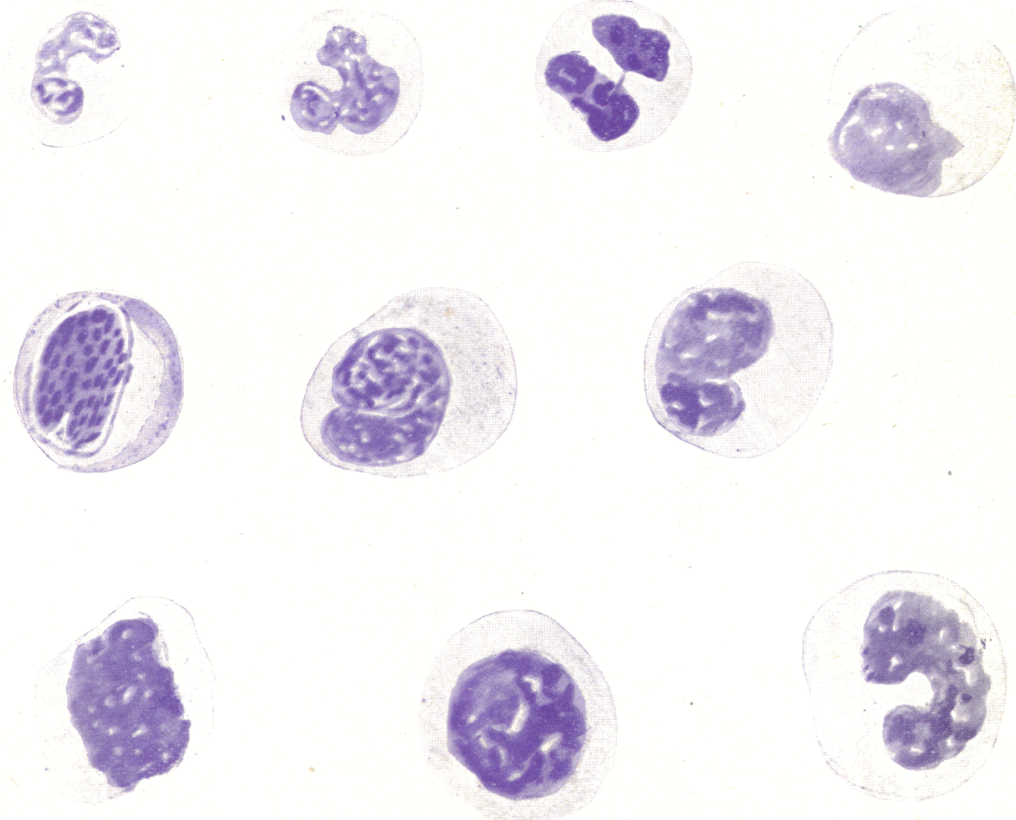

Plate II

Atypicai. Large Iymphocytes-Nongranular Form

Illustratixg Article by David Merray Cowie, M.D., and Henrietta Calhoun, M.D.

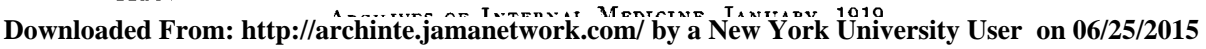


The significance of these cells has never been explained. Schleip remarks that they "are noted in every specimen" and have "no pathologic significance as yet." Their increase in numbers following the injection of typhoid protein would seem to indicate that they really are of pathologic significance.

The nature of the granules is not known. Being acidophil in reaction, their staining is akin to the particles found in eosinophilous cells and to erythrocytes, which are acidophil cells. These granules were also but seldom found in atypical large lymphocyte forms (last line, Fig. 12). Pepper and Miller ${ }^{11}$ observed in one animal at the height of the leukocytosis following intravenous typhoid vaccine injec,tion, "phagocytoses of erythrocytes" in smears from the peripheral blood. These phagocytic cells were large mononuclear cells. The same observation has been made in the blood of typhoid patients. So far as we know, the small lymphocyte has no phagocytic power either under normal or abnormal conditions. It seems improbable that these granules can be phagocyted erythrocytes. They stain more brilliantly than do the erythrocytes around them. It seems to us that the red granule is due to some degenerative process or is present in response to some toxic substance.

The reticulated forms were found in the large and small lymphocyte groups. Not many were encountered. The reticulation was either basophil, acidophil or neutrophil. Examples of these cells are shown on lines three, six and seven, Figure 12.

The irregular small lymphocytes consisted of cells with rosette, cross-shaped, mitotic and bizarre formed nuclei. They were present in four out of seven controls and were distinctly more numerous after the intravenous injection. Small atypical forms were almost invariably the predominating cells where high atypical counts were shown.

When atypical large lymphocytes were found the percentage of typical large lymphocytes was always low, but there was no decrease from the preceding counts. The atypical large lymphocytes were almost always forms with a large pale nucleus taking a pale nuclear stain with the chromatin network well preserved. We have taken the ground that the transitional cell belongs in the small lymphocyte group and we do not care to enter any controversy over the possible relationship of the transitionals to these atypical cells. There is still no unaminity of opinion on the transitional question. Without exception, in the ten cases studied there was always an increase over the control in the number of the atypical large cells. We have regarded these as newly formed cells.

11. Pepper and Miller: J. Infect. Dis., 19: 1916. 
DISCUSSION

The changes in the blood following the injection of a foreign protein (typhoid vaccine) are most remarkable. There is a sudden disappearance of the polymorphonuclear cells, which are soon replaced by an increase amounting in most cases to a hyperleukocytosis. Whether the disappearance is due to a destruction of cells or simply to their deposition in the tissues is not quite clear. The fact that we did not find an increase in the ordinary degenerating cells during the stage of leukopenia inclines us to the opinion that the leukopenia is due to migration. Then again, we are examining only peripheral blood and we have no knowledge of what has happened in the internal circulation. Pepper and Miller think that at least some of the leukocytes are destroyed. They could not find the usual accumulation of leukocytes in smears or tissue sections during the leukopenia stage.

When one watches from hour to hour the procession of cells into the blood stream during the stage of leukocytosis one is impressed with the newness of everything and with the idea that the whole affair is one of genesis. The polynuclears are young and the presence of myelocytes and of nucleated reds points to renewed activity of the respective mesenchymal tissues. Arneth counts made by Pepper and Miller during the leukocytosis showed a great increase in young forms.

The foreign protein seems to have stimulated all the mesenchymal tissues simultaneously. The order in which they are usually called on in infectious processes is, first, the neutrophil leukocytes without immature forms, second, metamyelocytes, third, myelocytes, fourth, promyelocytes, and fifth, megaloblasts (Photakes ${ }^{12}$ ).

The return of the leukocytes to normal, we believe, indicates that the increased production has ceased and that the excess of cells in the circulation is probably still passing into the tissues.

From these observations it will be seen that no matter what the pathologic condition is, injection of typhoid protein brings forth a similar reaction in all cases. The response differs only in degree. An important observation is that made from Case 3 . We had no patient who reacted more violently in a pyrogenic way than this one; during the chill his bed would shake; his sweating was drenching and his pain was acute. He received ten injections, but never gave a leukocyte count above normal. This was a case of long standing. The leukocyte response grew less as the injections increased in number. On the other hand, a similar case, in a child (Case 1) of equally long standing reacted vigorously both pyrogenically and leukocytically. The result in this case was decidedly more marked and the patient still shows improvement two months after the treatment.

12. Photakes: Deutsch. med. Wchnschr., Oct. 28, 1915. 
The cases which showed the most improvement are 5, 8, 9, 10 and 1, all of which responded with marked leukocytosis, atypical cells and abnormal cells. All showed a marked myelocyte production and nucleated reds.

Cases 2 and 3 showed only slight myelocytic reaction. In the reactions $(1,2,4)$ where myelocytes occurred in Case 3 , the patient was very much better following the reactions. In the latter reactions no myelocytes were found, and he made very little if any improvement.

While nucleated red cells are present in most of the reactions where improvement was marked, they were also present in other cases.

An interesting observation is made in Case 4. This patient reacted with marked pyrogenic and leukocytic changes. The simplicity of the blood counts is remarkable. She showed no transitionals, no eosinophils, and in only one count were normal large lymphocytes present. Megalocytes occurred once in each of the two reactions studied; very few. No nucleated red cells were found. Atypical cells, though high at times, did not go far above the number in the control. These were almost entirely of the small lymphocyte type, atypical large cells being present in only three counts. These findings are of importance because of their association with a developmental absence of the epiphyses.

A CONSIDERATION OF THE ANALOGY BETWEEN THE TYPHOID PROTEIN PAROXYSM AND THE MALARIAL PAROXYSM

When we place side by side a series of temperature charts of typhoid protein reactions with the interval temperature curves between we have a very good picture of a case of simple tertian malaria. When we consider the mechanism at work producing the febrile reaction in each case we are still more impressed with their similarity. It is classic knowledge that the malarial paroxysm is associated with the birth of a new crop of young parasites, or due to it. We think there is every reason to warrant $u$ in believing that the malarial paroxysm is a protein reaction due to the death of the parent cell, setting free in the blood stream a dose of dead malarial protein, and this brings about a group of symptoms analogous to or almost identical with that induced by the intravenous injection of typhoid protein.

In the reactions we have watched we note early slightly unpleasant feelings preceding slight chilliness, which frequently develops into a definite chill with rigor; then there is marked elevation of temperature, a general feeling by the patient of heat and a localized increase in the affected parts. This in turn is frequently followed by profuse sweating. The protein paroxysm lasts from eight to fifteen hours, when the patient again feels as well as before the reaction.

We are unable to find any record of consecutive or successive differential counts during a malarial paroxysm. At one time the absence of leukocytosis, with a rapidly rising temperature was con- 
sidered "corroborative of malaria." A relative leukocytosis has been observed with a diminishing of the leukocytes toward the end of the reaction.

Krause $^{7}$ reports a large number of differential counts on malaria patients. These counts were made at various times during a paroxysm on different patients, but no consecutive counts were made. He found a relative increase in the lymphocytes and a decrease in the polymorphonuclears, excepting from the beginning of the paroxysm up to about the fastigium or later, when there may be a decided absolute and relative increase in the polynuclears. He also noted at times a marked polymorphonuclear leukocytosis without the high fever; especially was this the case in an old infection. These findings fit in quite well with our findings during a protein paroxysm. It would be of great value to have a series of hourly counts during a malarial paroxysm.

The etiologic analogy between the two conditions is quite marked in the typhoid protein paroxysm. There is a billion dose of dead typhoid bacilli set free in the blood stream. It has been shown that in order to infect a mosquito the patient's blood must contain one crescent to every 500 leukocytes. It has also been shown that there may be from sixty-seven to ninety-two crescents per hundred leukocytes. A simple calculation will show that if this is the case, an ounce of blood might easily contain one billion malarial parasites; when these die the analogy is complete, a billion dose of dead malarial parasites has been set free in the blood stream and the typical reaction follows.

\section{CONCLUSIONS}

1. No matter what the condition is an intravenous injection of typhoid protein (vaccine) almost invariably initiates a leukopenia followed by a leukocytosis which is associated with, but not necessarily proportional to, the pyrogenic reaction.

2. The induced leukocytosis is chiefly polymorphonuclear even in those cases in which there is an initial lymphocyte increase.

3. A marked feature of the protein reaction is the appearance of atypical cell forms, particularly in the lymphocyte group; accompanying these there are nucleated reds and myelocytes.

4. We are inclined to the opinion that during the leukopenia stage the polynuclears leave the blood stream and enter the tissues, and that the subsequent increase in cells is due to an overproduction of cells from the respective mesenchymal fundaments, as is witnessed by the presence of myelocytes and nucleated reds. This view is further substantiated by the clinical findings of increased joint heat and swelling. 
5. The temperature reaction and the clinical findings are not in the nature of an anaphylactic response, as is shown by the absence of an eosinophilia.

6. The cyanosis observed is not due to methemoglobin.

7. Improvement is most marked following those reactions in which there is a good myelocytic response. This is probably a measure of the capacity of the body to react.

8. The marked similarity between the typhoid protein paroxysm and the malarial paroxysm leads us to the belief that their production is due to a common etiologic factor - dead protein. The death of the malarial parasite sets free in the blood stream a sufficient amount of malarial protein to produce the typical protein reaction. The malarial paroxysm, therefore, is not due to the presence of the new organisms, as has been suggested, but to the death of the old ones.

We wish to acknowledge the kind assistance of Drs. Walthall, Beavin, and Kempton, members of the Pediatric Staff, in making leukocyte counts and clinical records.

The talles accompanying the article of Drs. Cowie and Calhoun will be found on the next and following pages. 
TABle 1.-Case 1. Florence S., Aged 11/1/2 Years.-

\begin{tabular}{|c|c|c|c|c|c|c|c|c|}
\hline $\begin{array}{l}\text { Date and } \\
\text { Hour }\end{array}$ & $\begin{array}{l}\text { Total } \\
\text { Leuko- } \\
\text { cytes }\end{array}$ & Polys. & $\begin{array}{l}\text { Eosin. } \\
\text { Polys. }\end{array}$ & $\begin{array}{l}\text { Baso. } \\
\text { Polys. }\end{array}$ & $\begin{array}{l}\text { Small } \\
\text { Lymph. }\end{array}$ & $\begin{array}{c}\text { Large } \\
\text { Lymph. }\end{array}$ & $\begin{array}{l}\text { Transi- } \\
\text { tionals }\end{array}$ & $\begin{array}{l}\text { Mast } \\
\text { Oells }\end{array}$ \\
\hline $\begin{array}{l}11 / 16 / 17 \\
2: 00 \text { p. m. ............ }\end{array}$ & ..... & ........ & ...... & $\cdots$ & ...... & ...... & ..... & $\cdots$ \\
\hline Per cent. ......... & 100 & 54 & 0 & 0 & 31 & 13 & 2 & $\mathbf{0}$ \\
\hline Number .......... & 7,200 & 3,888 & 0 & 0 & 1,332 & 936 & 144 & 0 \\
\hline $\begin{array}{l}\text { 11/19/17 } \\
\text { First injection. Dose } \\
\text { 500,000,000 T. V. }\end{array}$ & & & & & & & & \\
\hline 12:15 p. m. ............ & $\cdots \cdots$ & ....... & ...... & $\cdots$ & ...... & ...... & … & $\cdots$ \\
\hline Per cent. ........... & 100 & $\ldots \ldots \ldots$ & ...... & $\cdots$ & $\ldots \ldots$ & $\ldots \ldots$ & $\cdots \cdot$. & $\cdots$ \\
\hline Number ........... & ..... & $\ldots \ldots$. & ...... & $\cdots$ & ...... & ...... & $\cdots \cdot \cdot$ & $\cdots$ \\
\hline 1:15 p. m. . ............ & $\cdots \cdots$ & $\ldots \ldots$. & ...... & $\cdots$ & $\cdots \cdots$ & $\cdots \cdots$ & $\cdots \cdots$ & $\cdots$ \\
\hline Per cent. .......... & 100 & $771 / 2$ & $\mathbf{0}$ & $\mathbf{0}$ & 20 & 2 & $3 / 2$ & 0 \\
\hline Number ............ & 5,400 & 4,175 & 0 & 0 & 1,080 & 108 & 27 & 0 \\
\hline 2:15 p. m. ........... & .... & ....... & $\ldots \ldots$ & $\cdots$ & $\cdots \cdots$ & ...... & ..... & ... \\
\hline Per cent. ........... & 100 & 75 & 1 & 0 & 20 & 2 & 0 & 0 \\
\hline Number ........... & 5,000 & 3,750 & 50 & 0 & 1,100 & 100 & 0 & 0 \\
\hline 4:15 p. m. ........... & ..... & ....... & ...... & ... & ...... & ...... & ..... & $\cdots$ \\
\hline Per cent. ........... & 100 & $881 / 2$ & $31 / 2$ & 0 & 4 & 8 & $1 / 2$ & 0 \\
\hline Number ............ & 11,400 & 8,089 & 398 & 0 & 456 & 342 & 57 & 0 \\
\hline $\begin{array}{l}11 / 22 / 17 \\
\text { Second injection. } \\
\text { Dose } 1,000,000,000 \\
\text { T. V. }\end{array}$ & & & & & & & & \\
\hline 1:30 p. m. .............. & $\ldots .$. & $\ldots \ldots$. & ...... & .... & ...... & ...... & ..... & $\cdots$. \\
\hline Per cent. .......... & 100 & 56 & 3 & 0 & $211 / 2$ & 16 & $\mathbf{3}$ & 0 \\
\hline Number ........... & 4,900 & 2,745 & 147 & 0 & 1,051 & 785 & 147 & 0 \\
\hline 2:30 p. m. .......... & ..... & $\ldots \ldots$ & ...... & $\cdots$ & ...... & ...... & ..... & .... \\
\hline Per cent. ........... & 100 & $\ldots \ldots$. & ...... & $\cdots$ & ...... & ....... & ..... & $\ldots$ \\
\hline Number ............ & ..... & ....... & ....... & $\ldots$ & ...... & ...... & ..... & $\ldots$. \\
\hline s:30 p. m. .......... & $\ldots$. & $\ldots \ldots$. & ...... & $\cdots$ & ...... & ...... & $\ldots \ldots$ & .... \\
\hline Per cent. ........ & 100 & 61 & 1 & 0 & 29 & 6 & 1 & $\mathbf{0}$ \\
\hline Number ........... & 2,300 & 1,403 & 23 & 0 & 667 & 138 & 23 & 0 \\
\hline 4:30 p. m. ........... & ..... & ........ & ....... & $\ldots$. & ...... & ...... & $\ldots$. & .... \\
\hline Per cent........... & 100 & $881 / 2$ & 0 & 0 & 7 & $21 / 2$ & $\therefore$ & 0 \\
\hline Number ............ & 5,200 & 4,602 & 0 & 0 & 364 & 130 & 52 & $\mathbf{0}$ \\
\hline 5:45 p. m. ............. & ..... & ........ & ...... & $\ldots$. & ...... & ...... & .... & .... \\
\hline Per cent. ........... & 100 & 89 & $1 \frac{1}{2}$ & 0 & 3 & $31 / 2$ & $1 / 2$ & 0 \\
\hline Number ........... & 5,200 & 4,628 & 78 & 0 & 156 & 192 & 26 & 0 \\
\hline 6:45 p.m. .......... & $\cdots .$. & ....... & ...... & $\ldots$ & $\ldots \ldots$ & ...... & $\ldots .$. & .... \\
\hline Per cent. .......... & 100 & $891 / 2$ & 1 & 0 & 4 & 4 & 1 & 0 \\
\hline Number ............ & 5,600 & 4,812 & 56 & 0 & 224 & 224 & 56 & 0 \\
\hline 8:00 p. m. .......... & ..... & ....... & ...... & $\cdots \cdot$ & ...... & ...... & $\cdots .$. & .... \\
\hline Per cent. ........... & 100 & 86 & 0 & 0 & 5 & 4 & 4 & 0 \\
\hline Number ........... & 14,500 & 13,470 & 0 & 0 & 725 & 580 & 580 & $\mathbf{0}$ \\
\hline $9: 00$ p.m. ........... & ..... & ....... & ....... & $\cdots$ & a.... & ...... & $\cdots \cdots$ & .... \\
\hline Per cent. ........... & 100 & 81 & 0 & $1 / 2$ & 5 & 2 & 0 & 0 \\
\hline Number ............. & 15,900 & 14,469 & 0 & 80 & 795 & 318 & 0 & $\mathbf{0}$ \\
\hline
\end{tabular}




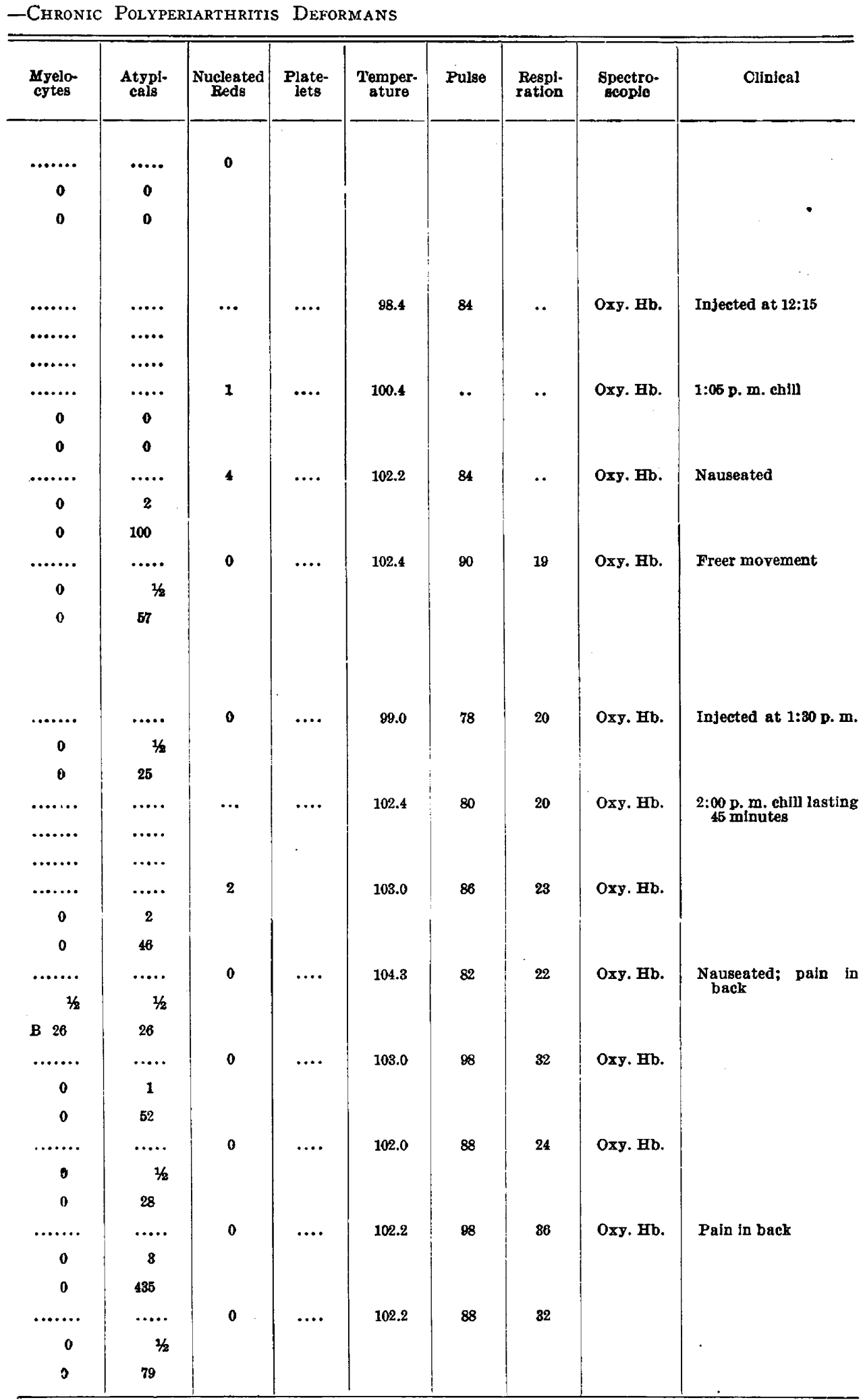


TABle 1.-Case 1. Florence S., Aged 111/2 Years.-

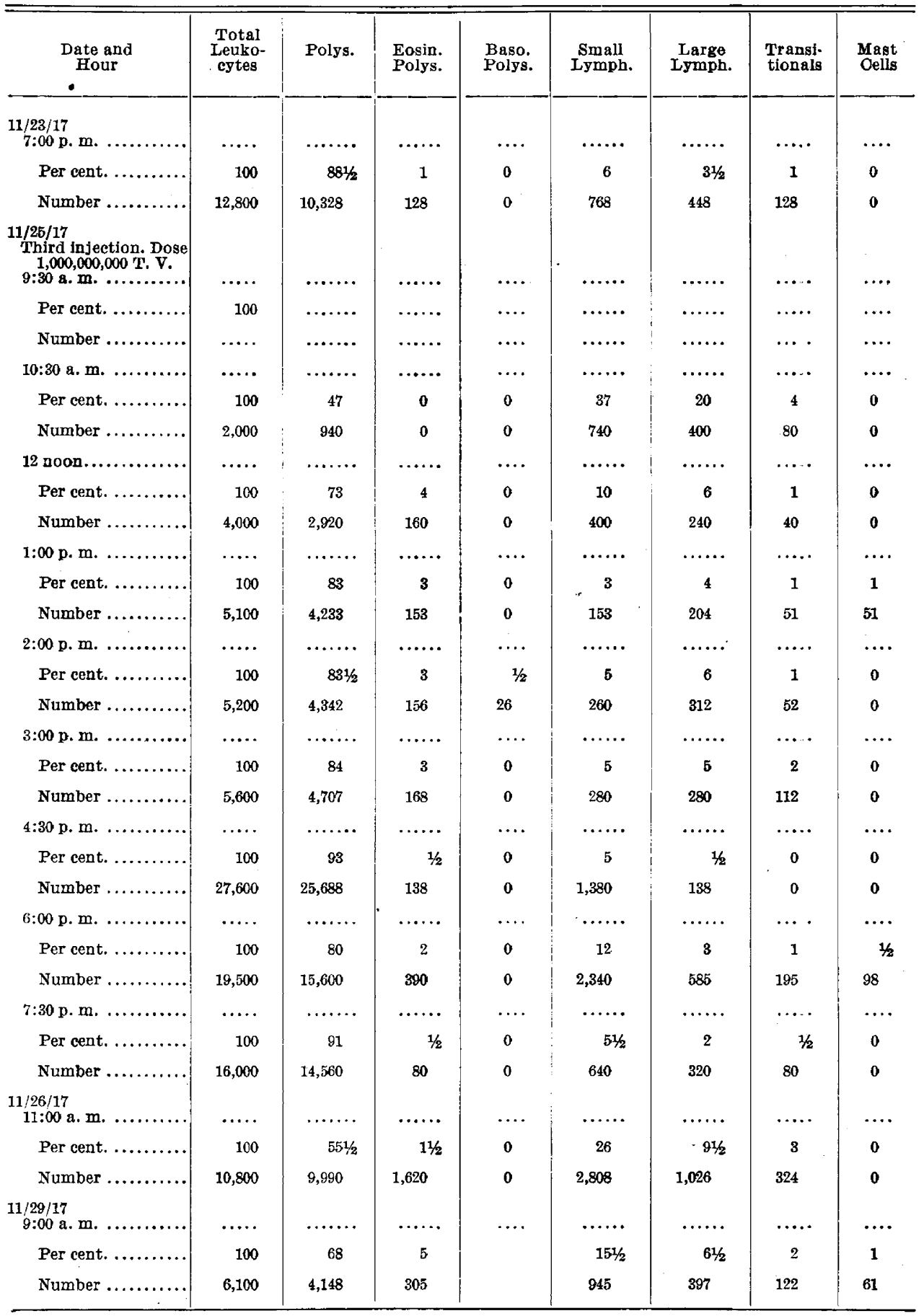


-Chronic Polyperiarthritis Deformans-(Contimued)

\begin{tabular}{|c|c|c|c|c|c|c|c|c|}
\hline $\begin{array}{l}\text { Myelo- } \\
\text { cytes }\end{array}$ & $\begin{array}{l}\text { Atypi- } \\
\text { cals }\end{array}$ & $\begin{array}{c}\text { Nucleated } \\
\text { Reds }\end{array}$ & $\begin{array}{l}\text { Plate- } \\
\text { lets }\end{array}$ & $\begin{array}{l}\text { Temper- } \\
\text { ature }\end{array}$ & Pulse & $\begin{array}{l}\text { Respi- } \\
\text { ration }\end{array}$ & $\begin{array}{l}\text { Speetro- } \\
\text { scopic }\end{array}$ & Clinical \\
\hline ........ & $\ldots .$. & 0 & $\ldots$ & 88.4 & 76 & 20 & & \\
\hline 0 & 0 & & & & & & & \\
\hline 0 & 0 & . & & & & & & \\
\hline $\begin{array}{l}\ldots \ldots . . \\
\ldots \ldots \ldots\end{array}$ & $\cdots \cdot$ & $\cdots$ & $\cdots \cdot$ & $\underset{99.2}{9: 40 \text { a.m. }}$ & .. & .. & $\cdots \cdots \cdots$ & $\begin{array}{l}\text { Injected at } 9: 30 \mathrm{a}, \mathrm{m} . ; \\
8: 40 \text { chill }\end{array}$ \\
\hline$\cdots \cdots \cdots$ & $\begin{array}{l}\cdots \cdots \\
\cdots \cdots\end{array}$ & & & & & & & \\
\hline ....... & $\cdots \cdots$ & 0 & $\ldots$. & 100.0 & 80 & 26 & Oxy. Hb. & \\
\hline 2 & 0 & & & .. & & & & \\
\hline 40 & 0 & & & 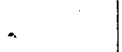 & & & & \\
\hline ....... & $\ldots \ldots$ & 0 & $\ldots$ & 102.0 & 86 & 32 & Oxy. Hb. & Pain in back \\
\hline 0 & 6 & & & & & & & \\
\hline 0 & 240 & & & & & & & \\
\hline ....... & $\ldots \ldots$ & 0 & .... & 101.6 & 100 & 38 . & Oxy. Hb. & \\
\hline 3 & 2 & & & & & & & \\
\hline B 153 & 102 & & & & & & & \\
\hline$\cdots \cdots$ & $\cdots \cdot$ & 0 & $\ldots$. & 101.0 & 82 & 32 & Oxy. Hb. & \\
\hline $11 / 2$ & $1 / 2$ & & & & & & & \\
\hline B 78 & 26 & & & & & & & \\
\hline$\ldots \ldots .$. & $\ldots \ldots$ & 0 & $\cdots$ & 100.8 & 80 & 29 & Oxy. Hb. & \\
\hline 1 & 0 & & & & & & & \\
\hline B 56 & 0 & & & & & $\ddots$ & & \\
\hline ....... & $\ldots \ldots$ & 0 & $\ldots$ & 100.0 & 78 & 26 & Oxy. Hb. & \\
\hline 0 & 1 & & & & & & & \\
\hline 0 & 276 & & & & & & & \\
\hline ....... & $\ldots \ldots$ & 0 & $\cdots$ & 99.6 & 80 & 26 & Oxy. Hb. & \\
\hline $1 / 2$ & 1 & & & & & & & \\
\hline B 97 & 195 & & & & & & & \\
\hline ........ & $\cdots \cdot$. & 0 & $\cdots \cdot$ & & & & & \\
\hline 0 & $1 / 2$ & & & & & & & \\
\hline 0 & 80 & & & & & & & \\
\hline$\cdots \cdots$ & $\cdots$ & 0 & $\cdots$ & $\cdots$ & .. & .. & Oxy. सвb. & \\
\hline 2 & $21 / 2$ & & & & & & & \\
\hline B 216 & $\angle 70$ & & & & & & & \\
\hline ........ & $\cdots \cdot$. & 0 & $\cdots$ & & & & & \\
\hline 0 & 2 & & & & & : & & \\
\hline 0 & 122 & & & & & & & \\
\hline
\end{tabular}




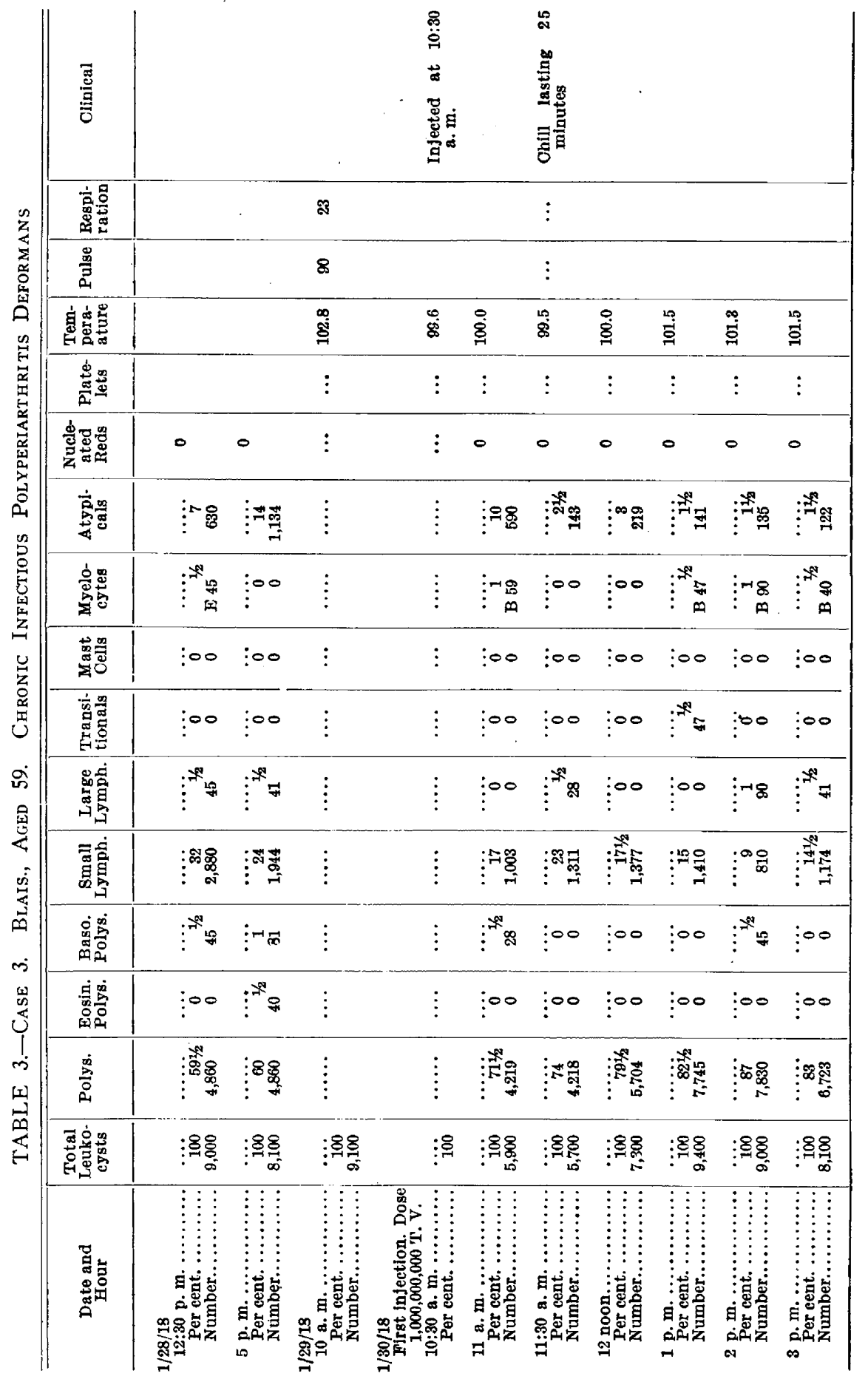




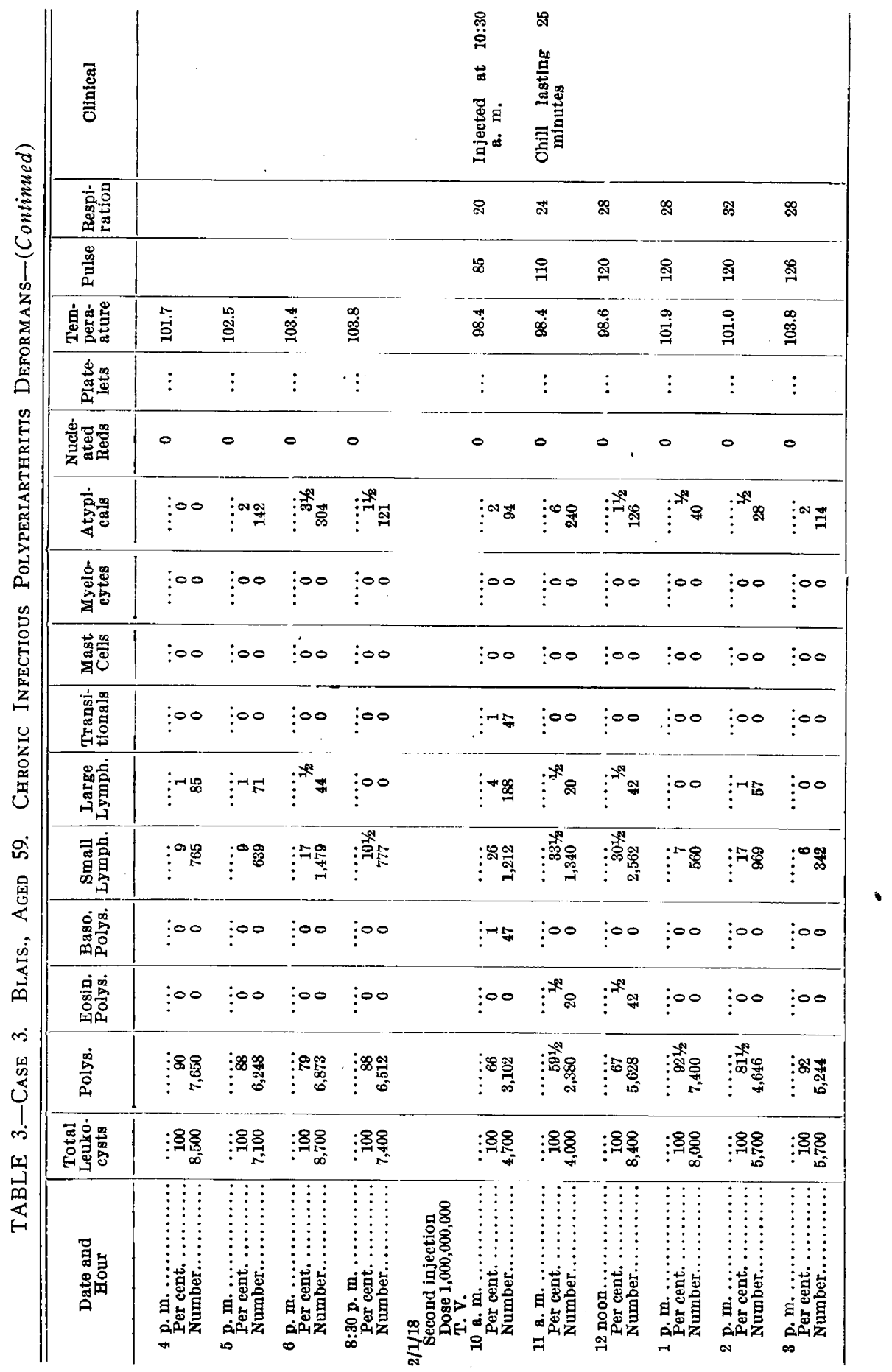




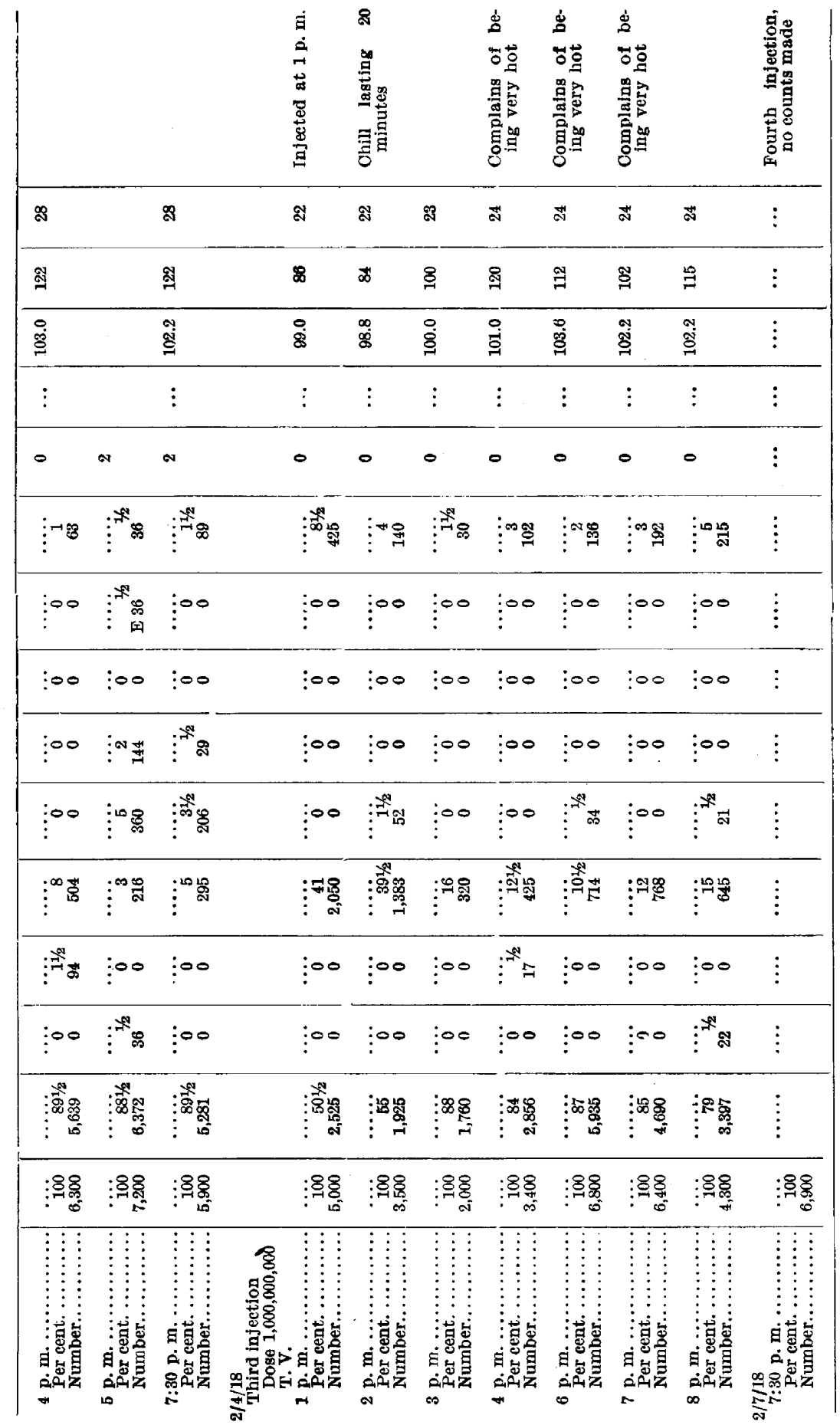




\begin{tabular}{|c|c|c|c|c|c|c|c|c|}
\hline 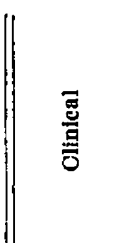 & 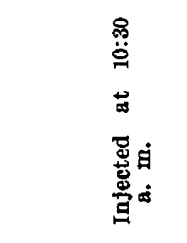 & 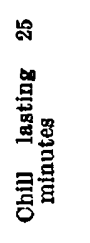 & & & & & 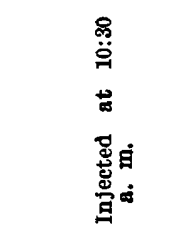 & \\
\hline 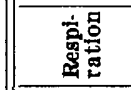 & $\approx$ & \& & $\approx$ & $\approx$ & \& & \& & ฆ & $\approx$ \\
\hline 惫 & 8 & \& & \& & ฏ & $\Phi$ & $\Xi$ & 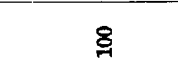 & $\infty$ \\
\hline 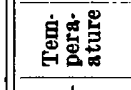 & 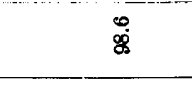 & $\stackrel{8}{8}$ & $\stackrel{\dot{g}}{\dot{g}}$ & 兽 & 过 & 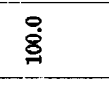 & $\stackrel{\mathrm{g}}{\mathrm{g}}$ & $\stackrel{q}{\tilde{g}}$ \\
\hline 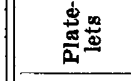 & $\vdots$ & $\vdots$ & $\vdots$ & $\vdots$ & $\vdots$ & $\vdots$ & $\vdots$ & $:$ \\
\hline 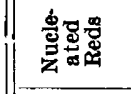 & $\circ$ & $\circ$ & $\circ$ & $\circ$ & $\circ$ & 0 & $\circ$ & 0 \\
\hline 育骂 & : & 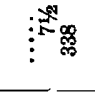 & $\vdots^{\infty}$ & $\vdots^{\infty}$ & 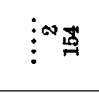 & :- & $\vdots \sim 8$ & $\vdots^{* x^{*}}$ \\
\hline 高要 & $\overbrace{}^{* \prime \prime} 88$ & $\vdots^{\infty}$ & :o & $\vdots^{\infty}$ & $\vdots \infty$ & $\vdots^{\infty}$ & $\vdots 00$ & $\vdots^{\infty}$ \\
\hline 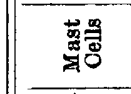 & $: 00$ & :00 & $: 00$ & $: 00$ & 100 & 100 & :00 & :00 \\
\hline 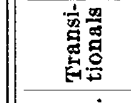 & 100 & : : & : & !०o & : & 100 & !oo & $\vdots^{*=}$ \\
\hline 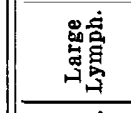 & $\underbrace{* n^{\prime \prime}}$ & $\vdots \cdots$ & $\vdots^{\infty}$ & $0^{\infty 0}$ & $\vdots^{* *} \infty$ & :o & $0^{00}$ & $!^{* * *} \&$ \\
\hline 要育 & 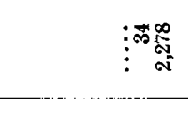 & 活密哭 & 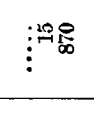 & : & 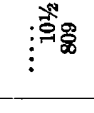 & $e^{*}$ & & : \\
\hline 总商 & !०o & 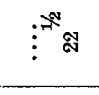 & :00 & !०o & !) & 00 & !०o & $:^{\prime \prime \prime}$ \\
\hline 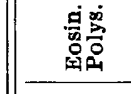 & $\vdots \infty$ & !) & :00 & :ంo & !o & : & $\vdots 00$ & : \\
\hline 兽 & 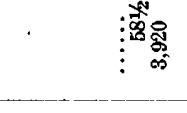 & : & :澟曼 & 滵营 & : & : & : : & :R\% \\
\hline 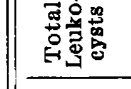 & 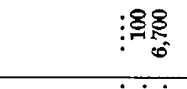 & 沲费 & 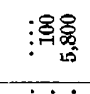 & : & 很疍 & : & : & : $: 88$ \\
\hline 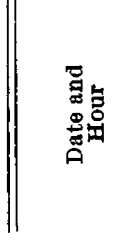 & 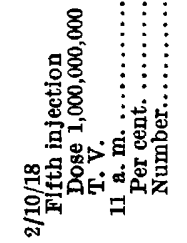 & 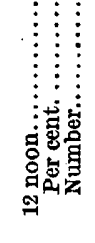 & 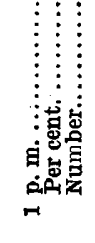 & 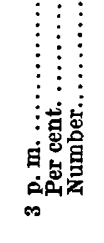 & 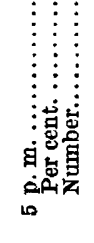 & 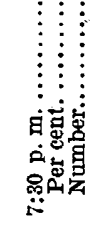 & 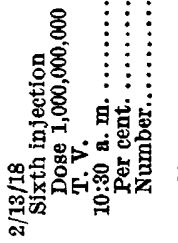 & 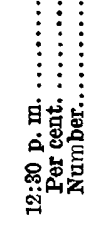 \\
\hline
\end{tabular}




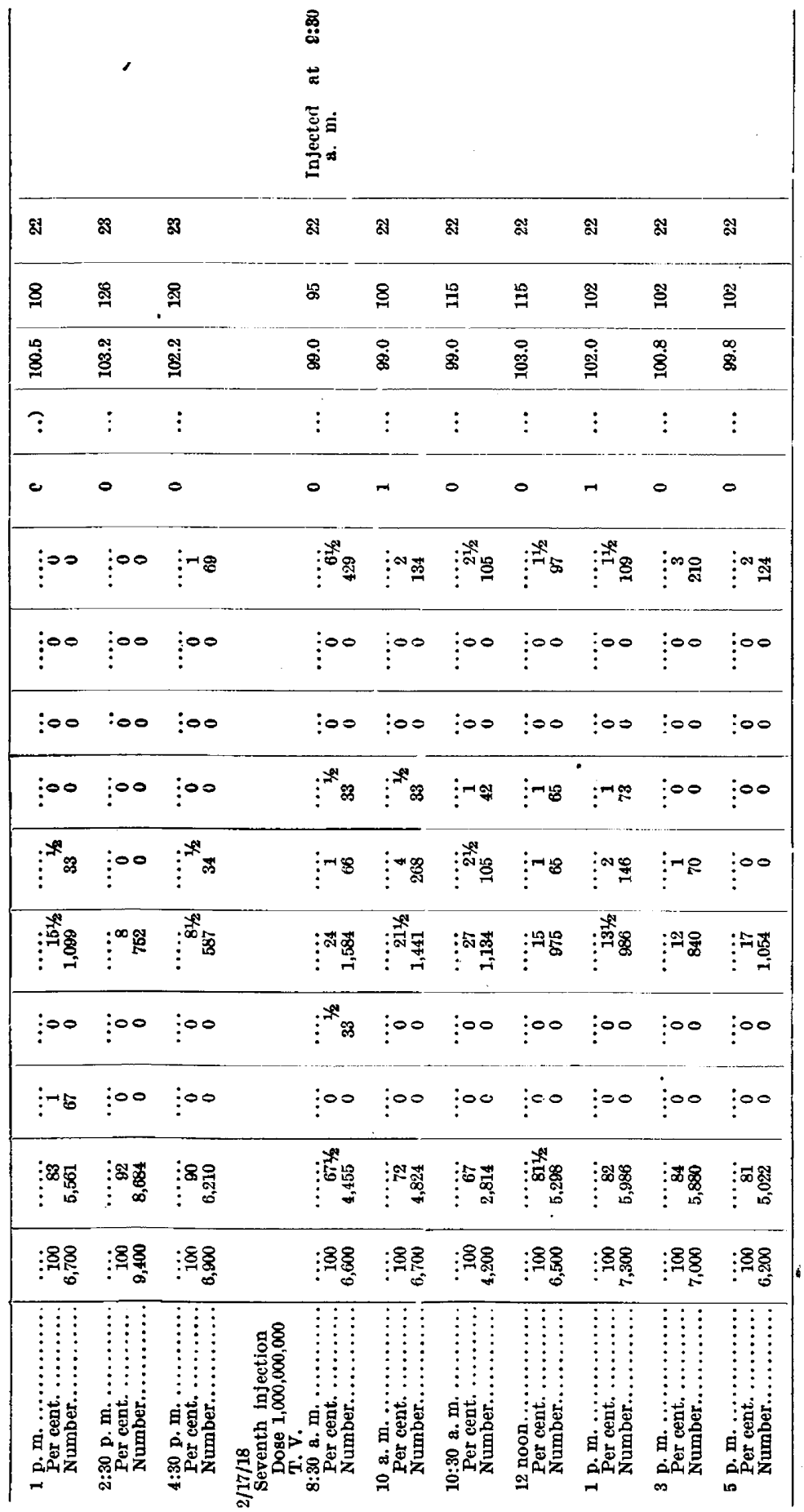




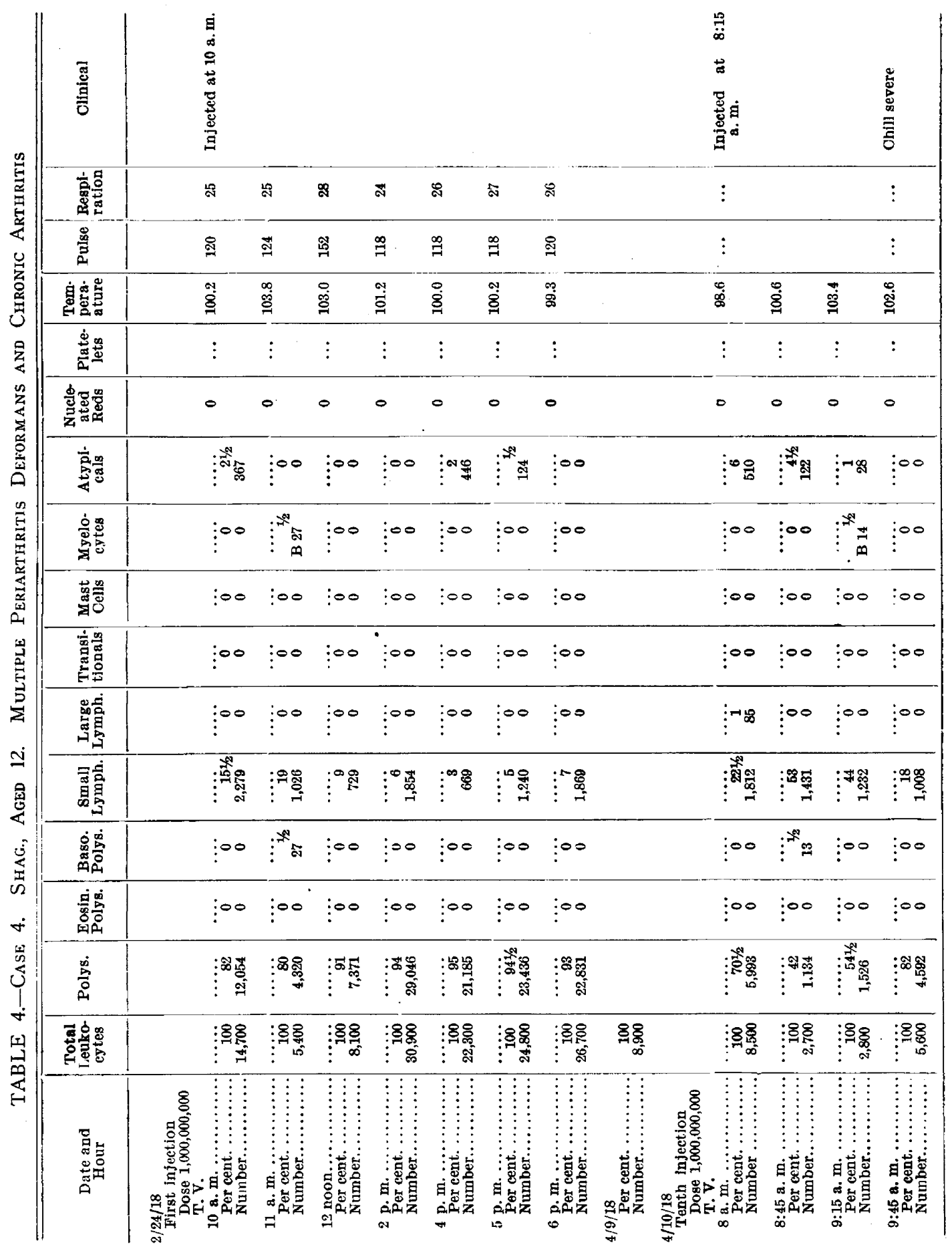




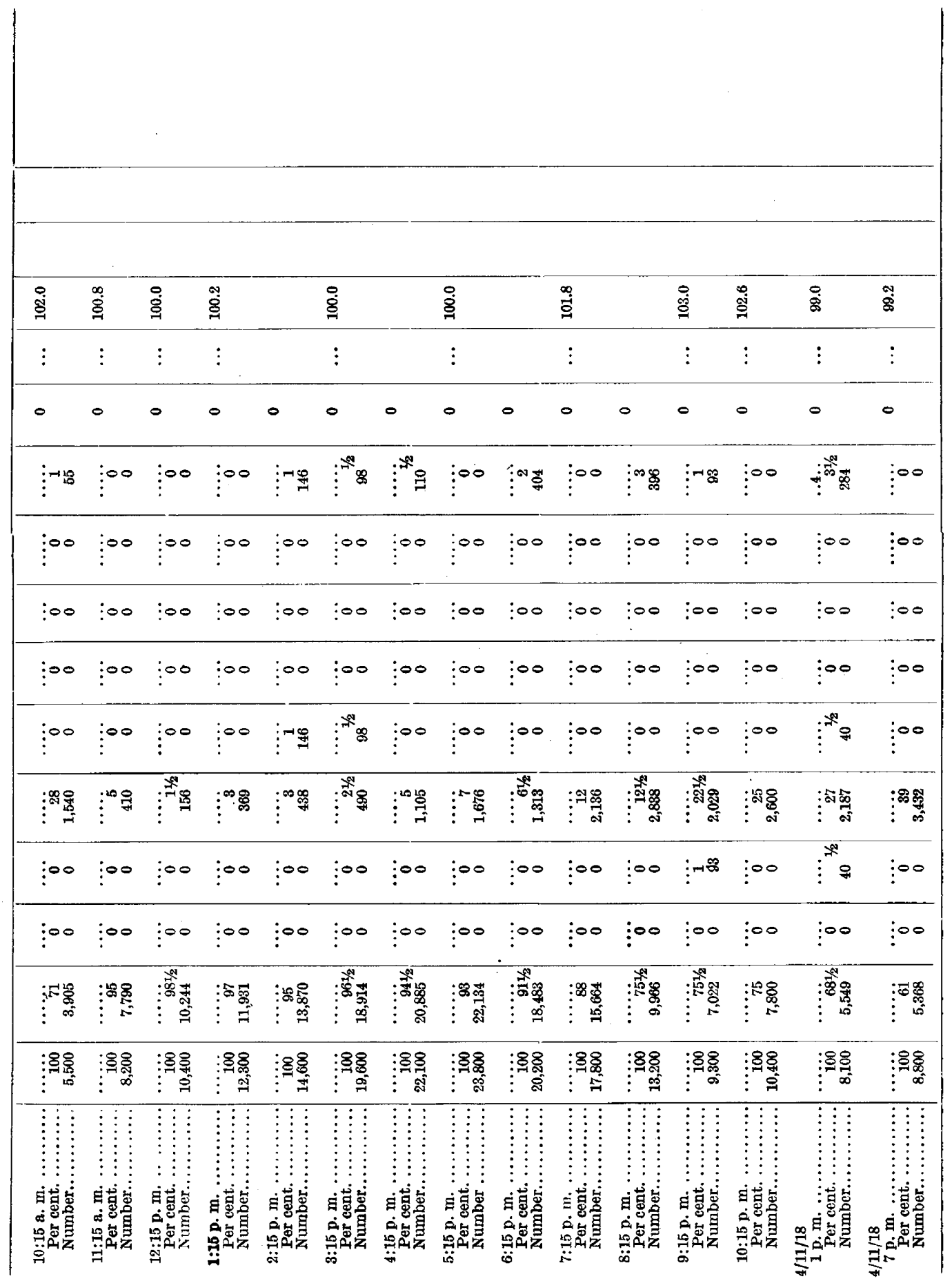




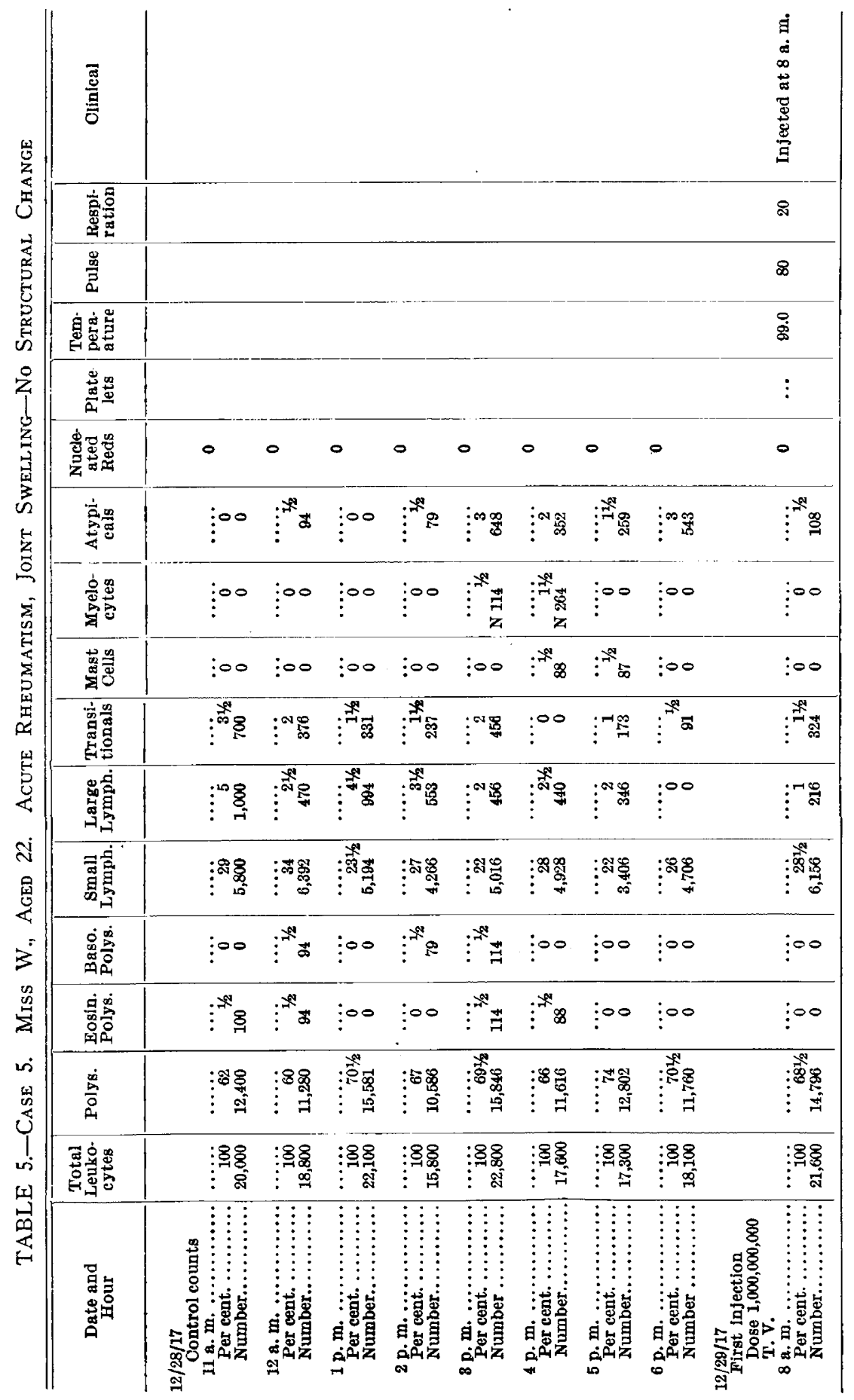




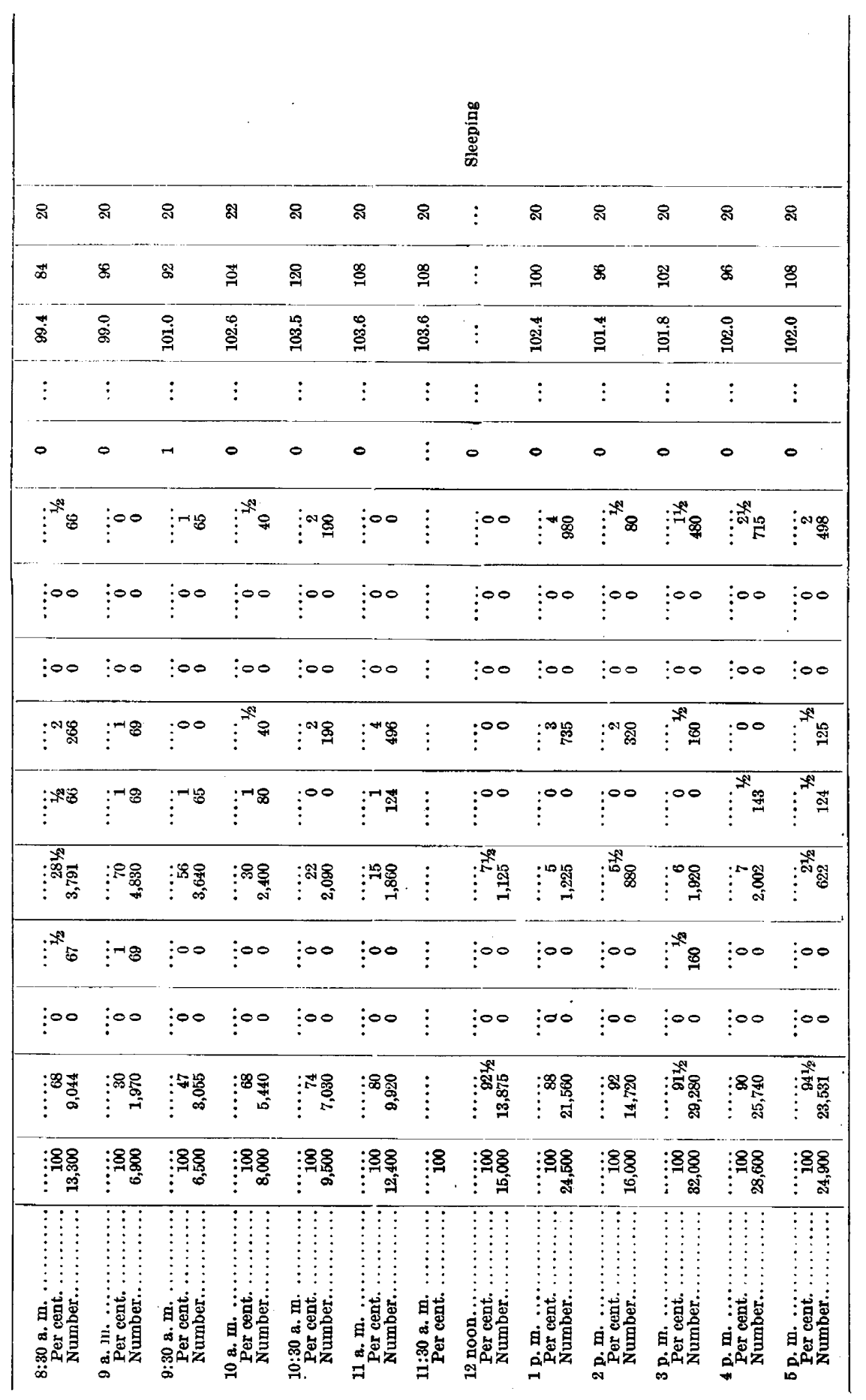




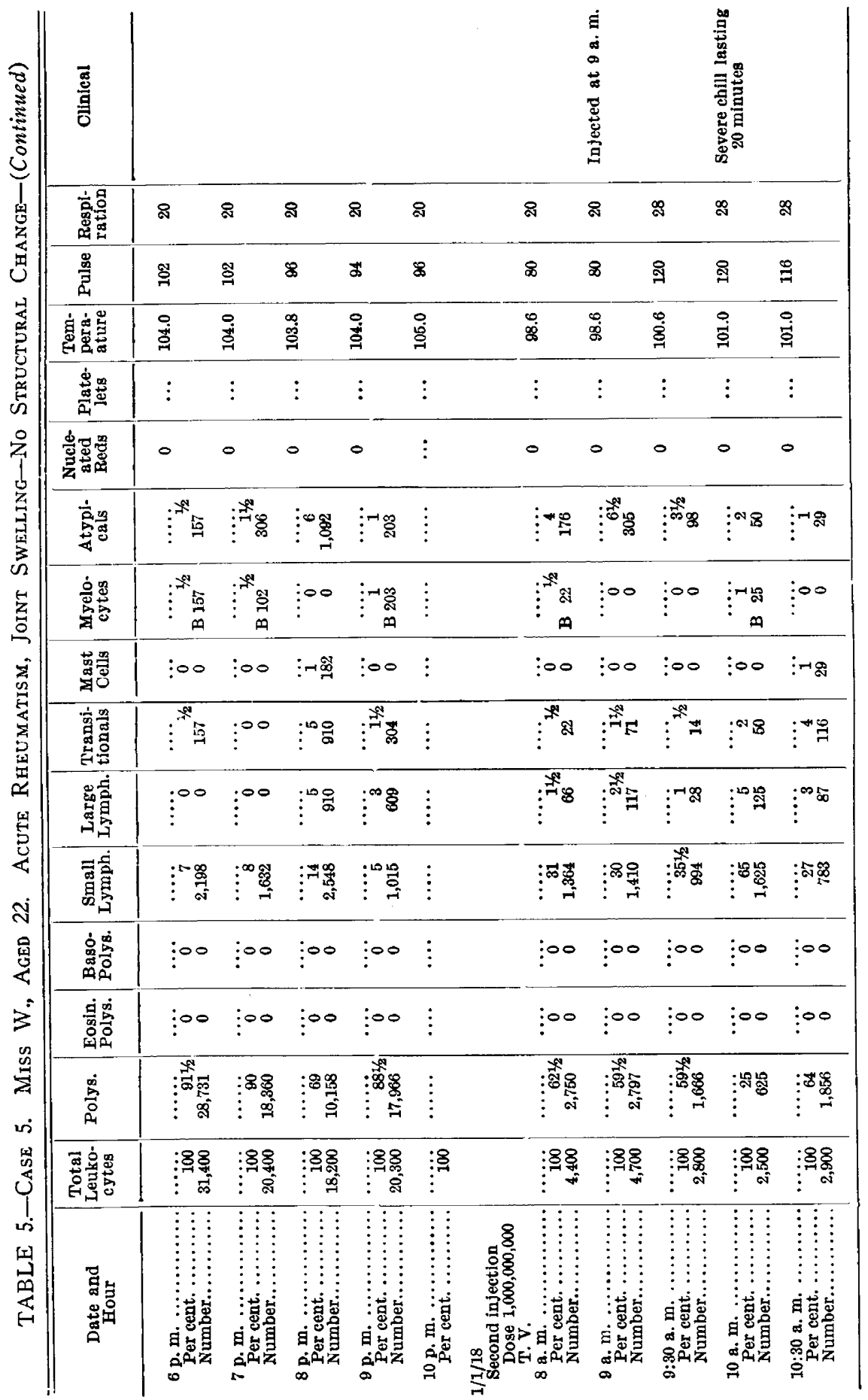




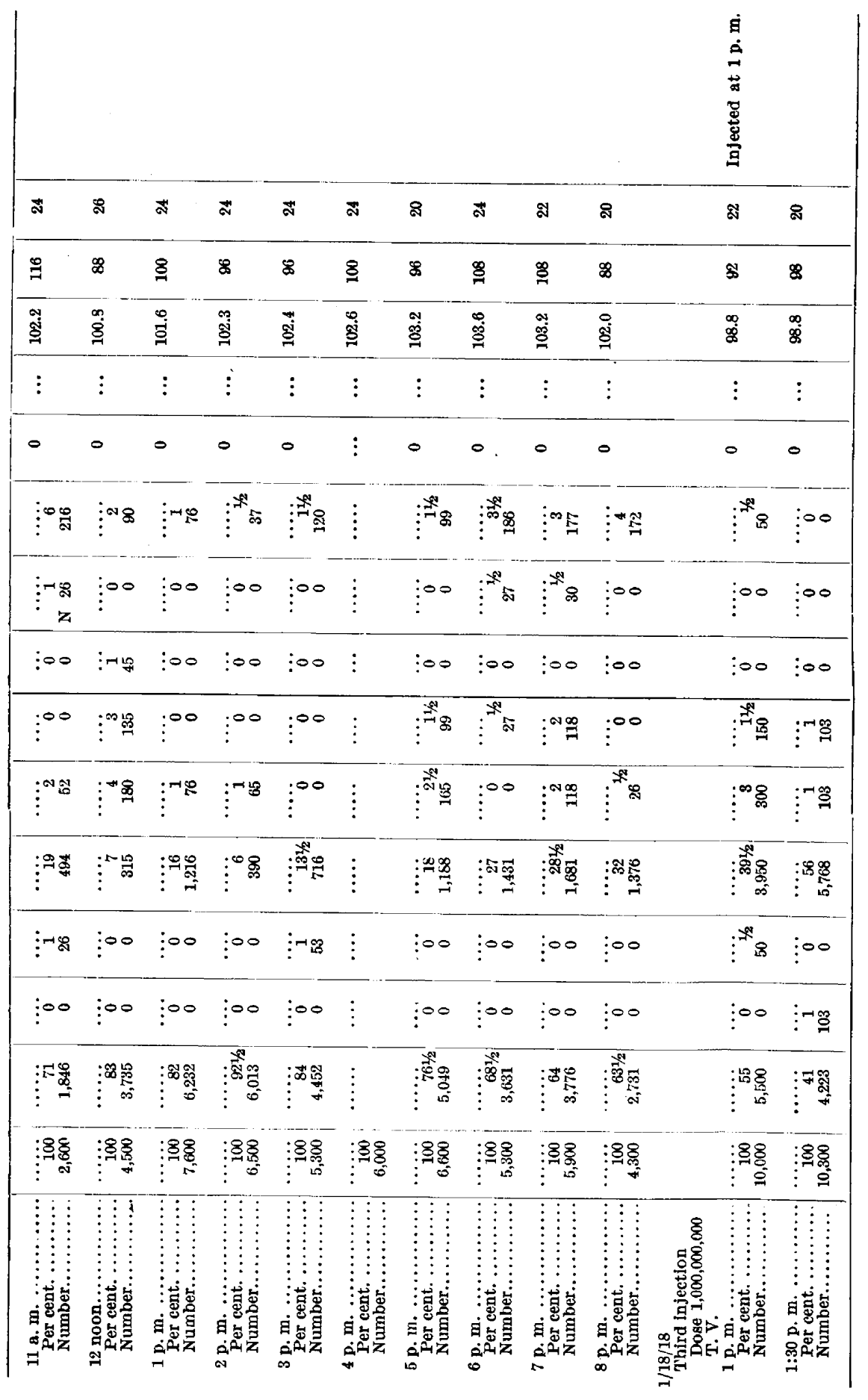




\begin{tabular}{|c|c|c|c|c|c|c|c|c|c|c|}
\hline $\begin{array}{l}\text { 啫 } \\
\text { 言 }\end{array}$ & & 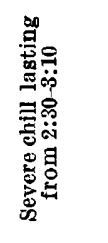 & & 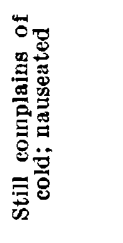 & & & & & & \\
\hline 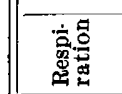 & \& & ్ㅗ & 为 & $\approx$ & s & s & " & ชิ & จิ & ช \\
\hline 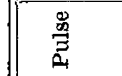 & 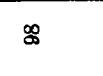 & 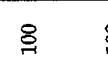 & 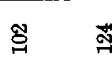 & $\Xi$ & ฐ & @ & 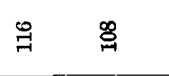 & $\approx$ & $\approx$ & $\$$ \\
\hline 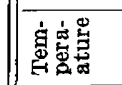 & $\infty$ & \& & 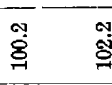 & s: & 兽 & 密 & $\stackrel{\infty}{\Xi}$ & 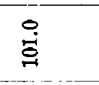 & 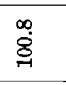 & $\stackrel{8}{\circ}$ \\
\hline 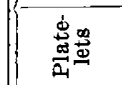 & $\vdots$ & $\vdots$ & $\vdots$ & $\vdots$ & $\vdots$ & $\vdots$ & $\vdots$ & $\vdots$ & $\vdots$ & $\vdots$ \\
\hline 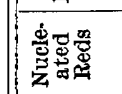 & . & 。 & . & $=0$ & $0 \quad 0$ & $0=$ & 0. & $\circ$ & $\vdots$ & $\vdots$ \\
\hline 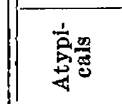 & : & : & $\vdots^{\infty}$ & 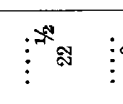 & $\vdots^{00}$ & $:^{* \prime \prime} 8$ & 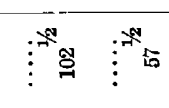 & $i^{*}$ & $\vdots$ & $\vdots$ \\
\hline 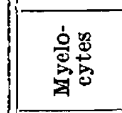 & :o & :0 & :o & :00 & $\vdots^{\infty} \quad:^{\circ 0}$ & $i_{z}^{* \prime \prime}$ & : & 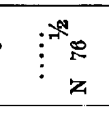 & $\vdots$ & $\vdots$ \\
\hline 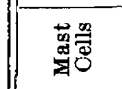 & :00 & :00 & $: 00$ & $\vdots 00:$ & $: 00: 00$ & :00 & $: 00: 00$ & $: 00$ & $\vdots$ & $\vdots$ \\
\hline 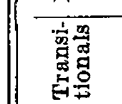 & 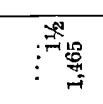 & $\vdots^{-1 / \infty}$ & $i^{\infty}$ & $\vdots$ & 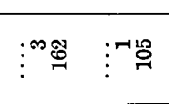 & 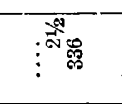 & $\vdots^{N \infty}$ & : " & $\vdots$ & $\vdots$ \\
\hline 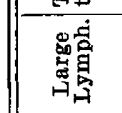 & 等: & 象 & $i^{\infty}$ & & $i^{\infty \infty ⿻ ⿰ 丨 丨 丷 一 心 ~}$ & " & $n^{n *}$ & : & $\vdots$ & \\
\hline 禫离 & : & : & 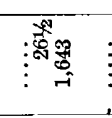 & : & 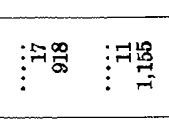 & 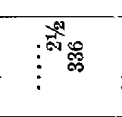 & 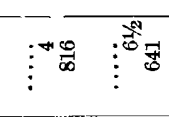 & ${ }^{N_{0}^{n}}$ & 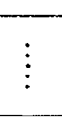 & $\vdots$ \\
\hline 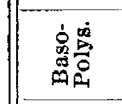 & :0 & $\vdots 00$ & :oo & !o & $: 00 \quad: 00$ & :०o & 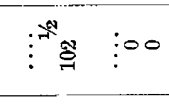 & :0o & $\vdots$ & $\vdots$ \\
\hline 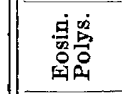 & :०o & $\vdots 00$ & :o : & $\vdots 00 \vdots$ & :00 :00 & $\vdots \infty 0$ & :00 :00 & :०o & $\vdots$ & $\vdots$ \\
\hline 总 & 湾 & : & 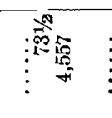 & 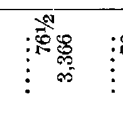 & 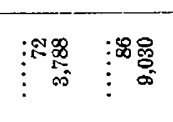 & : & 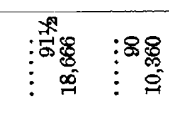 & 漓跓 & $\vdots$ & $\vdots$ \\
\hline 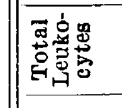 & : & : & : & : & 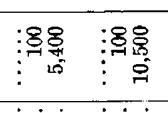 & : & 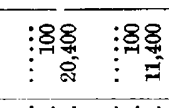 & : 888 & 远 & : \\
\hline 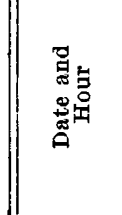 & 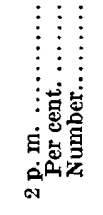 & 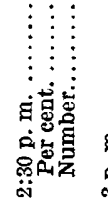 & 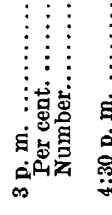 & 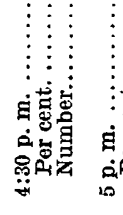 & 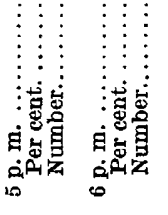 & 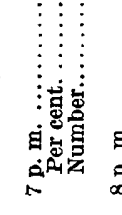 & 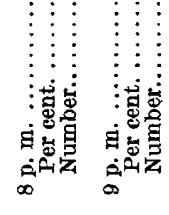 & 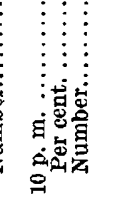 & 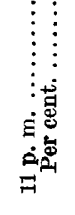 & 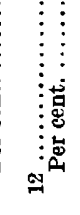 \\
\hline
\end{tabular}




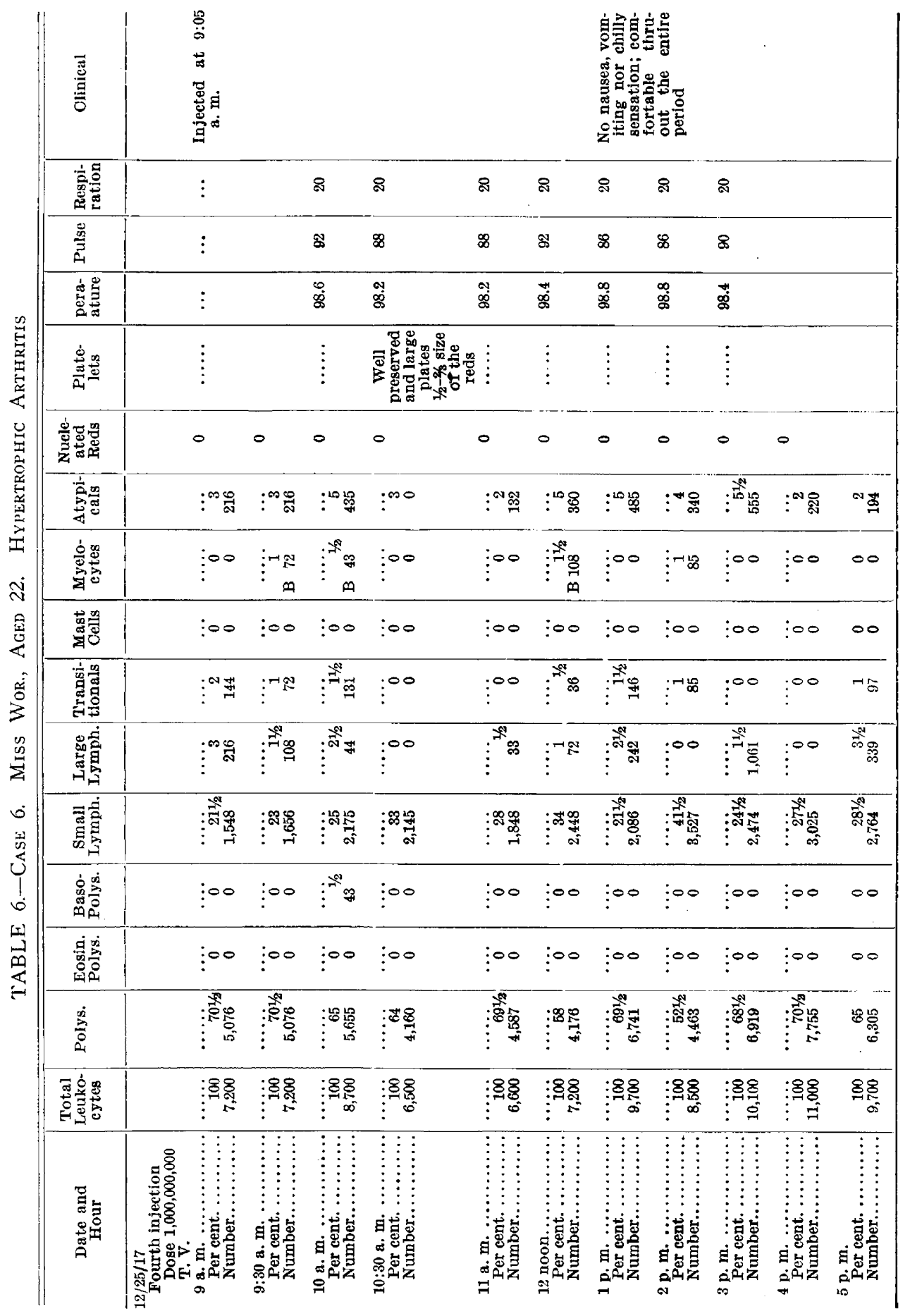




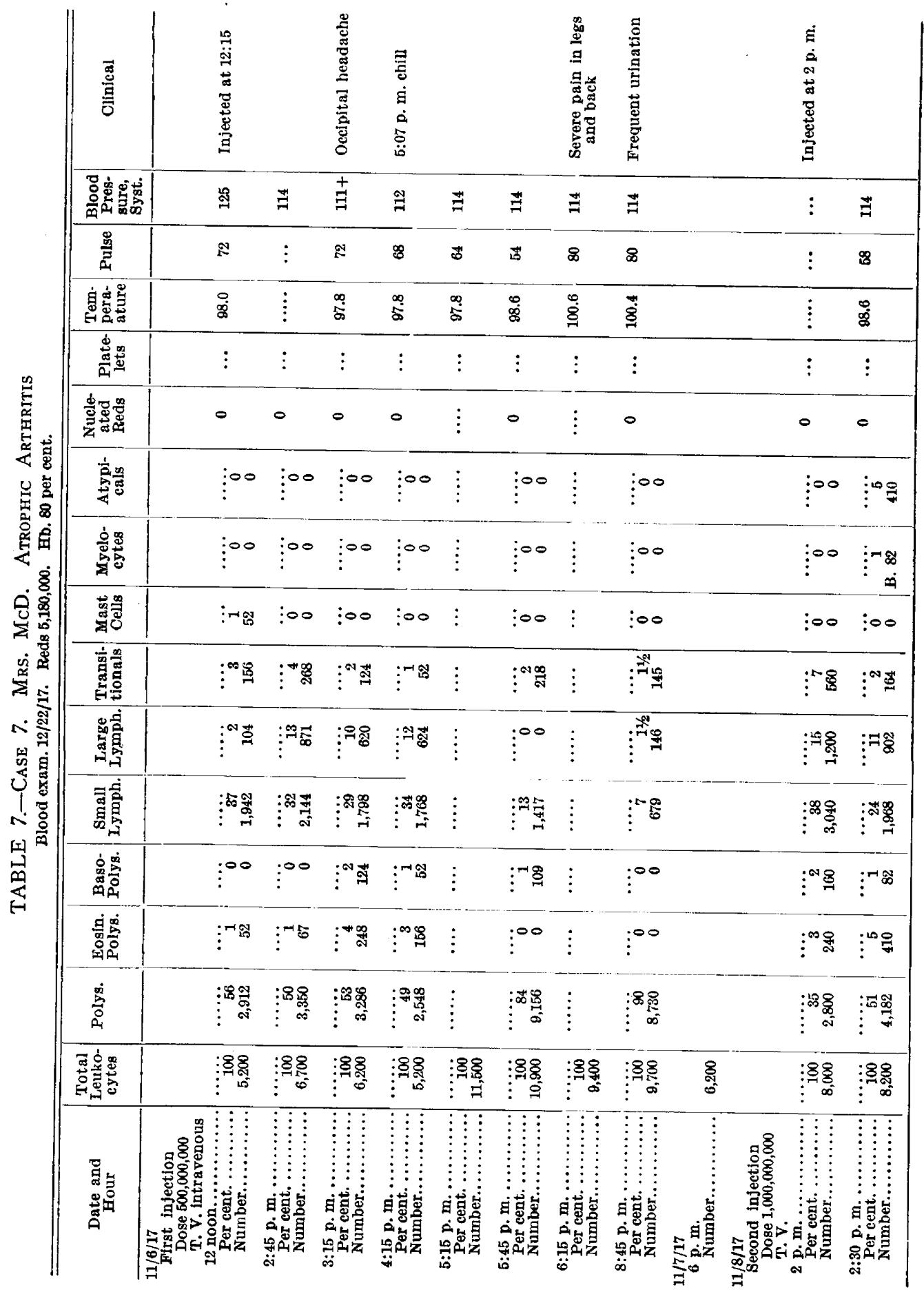




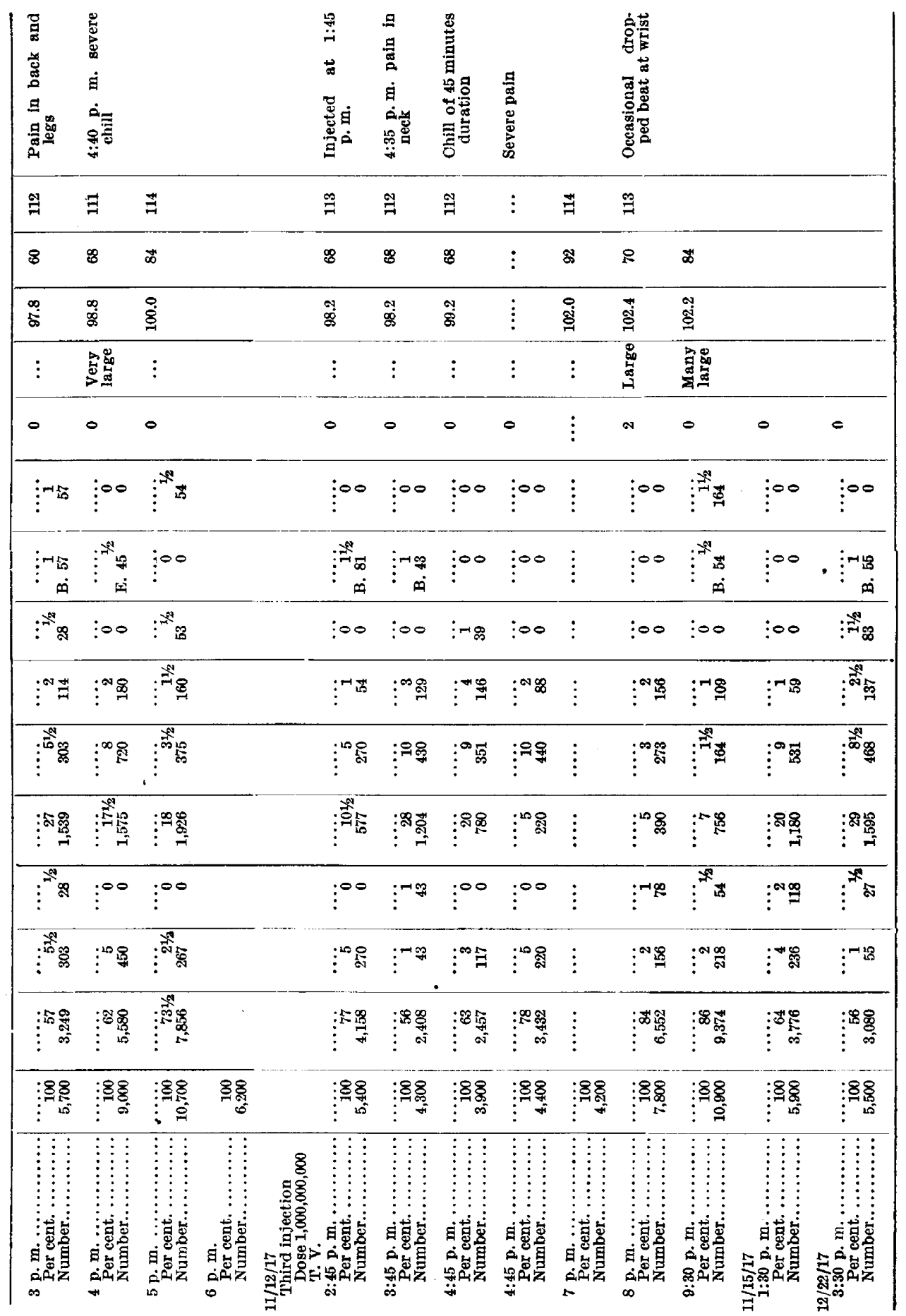




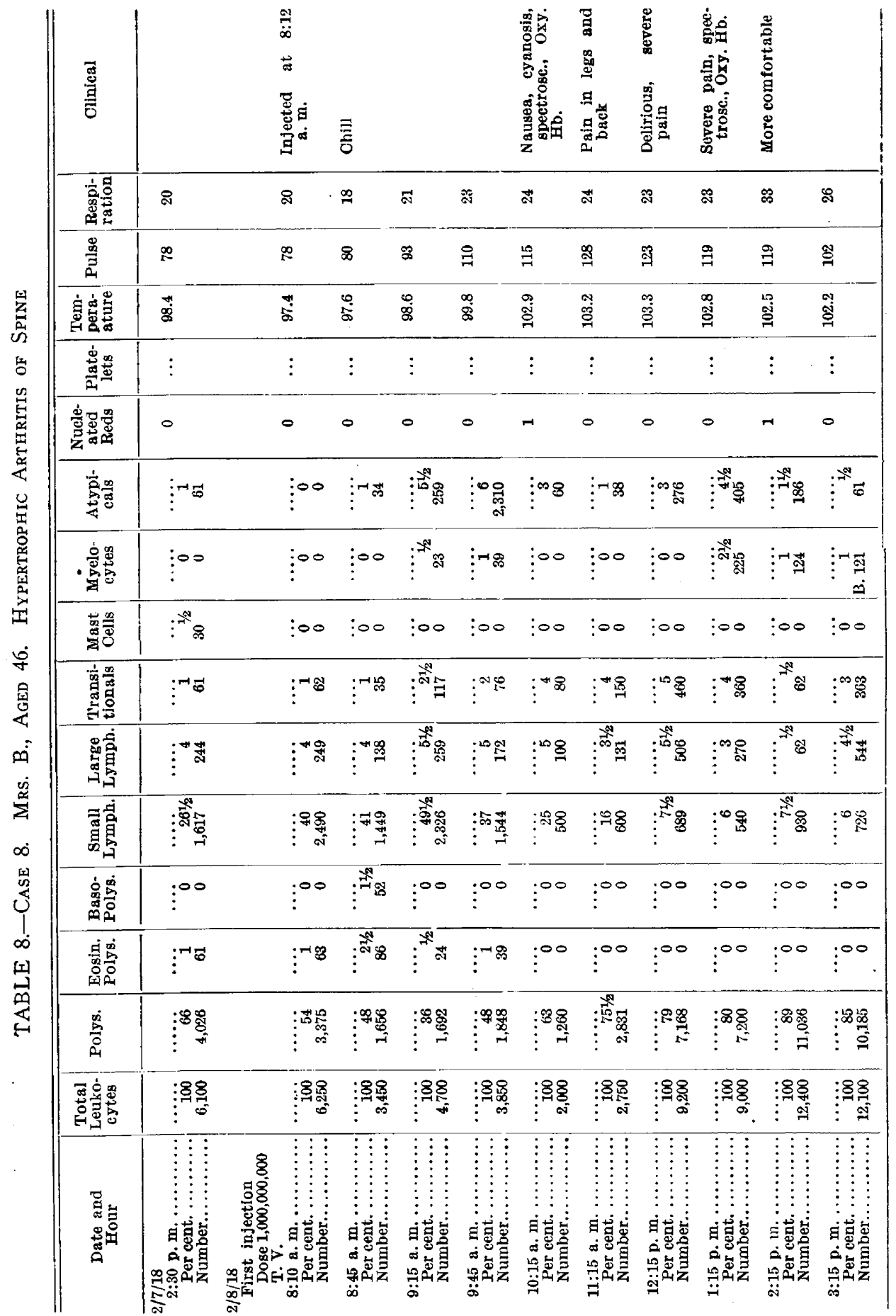




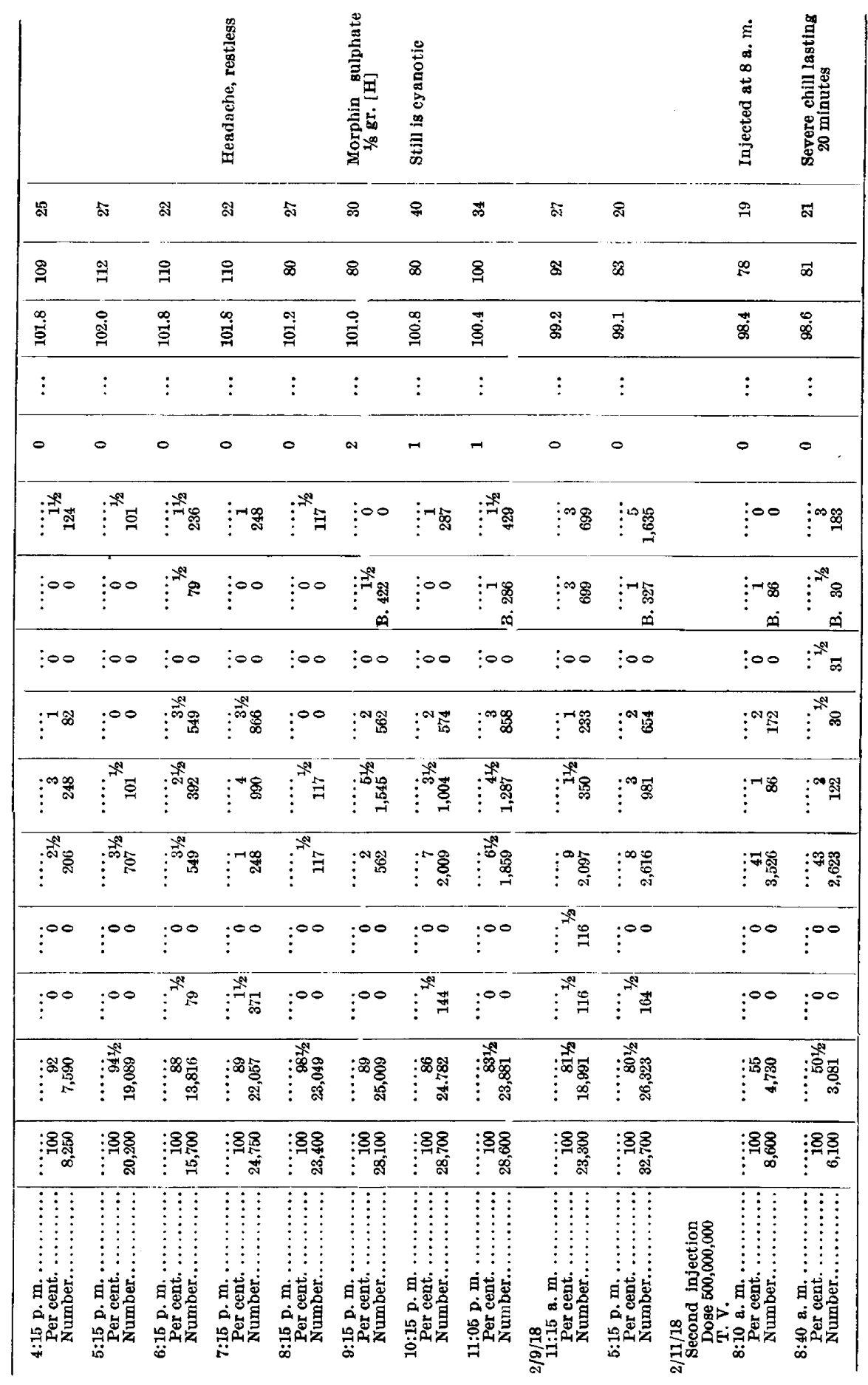




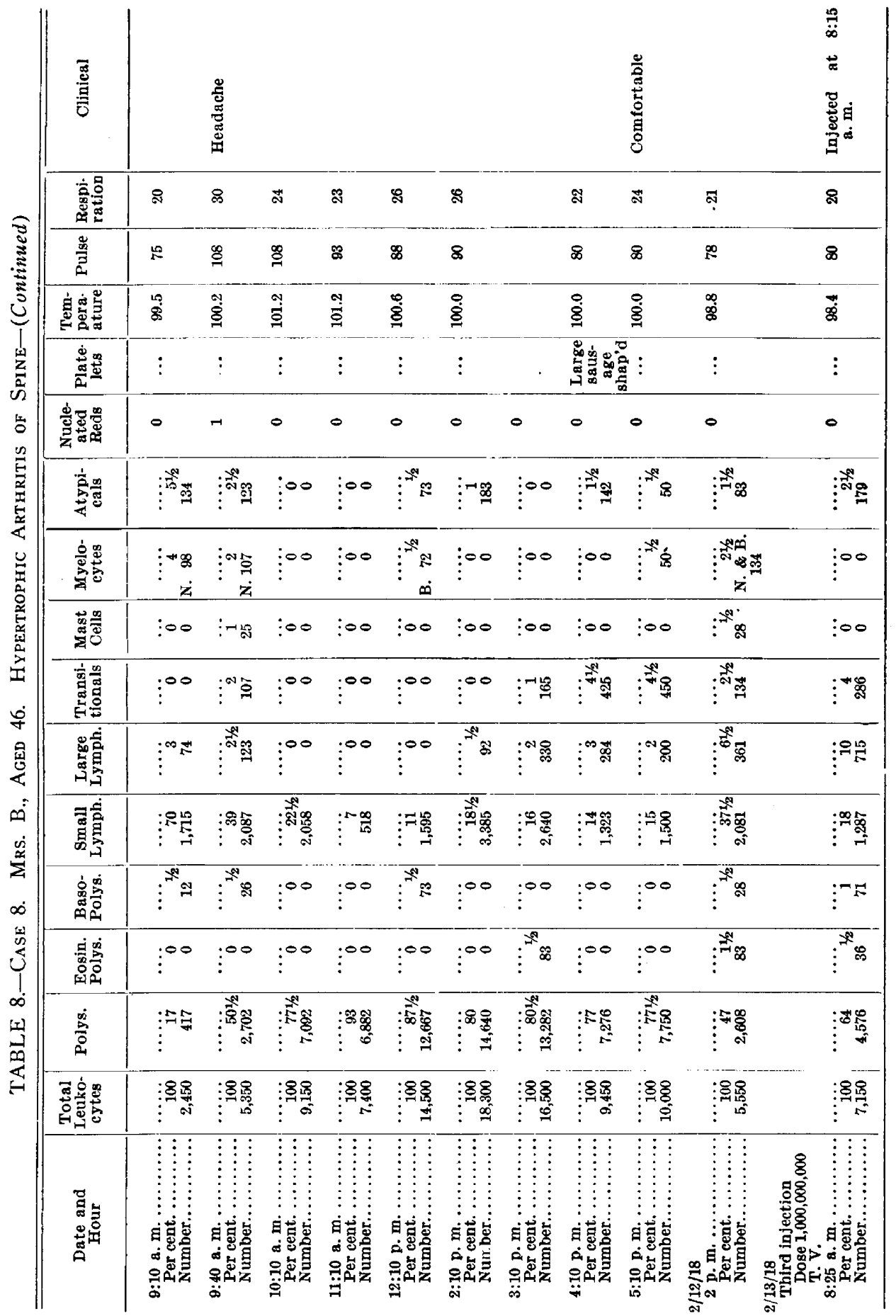




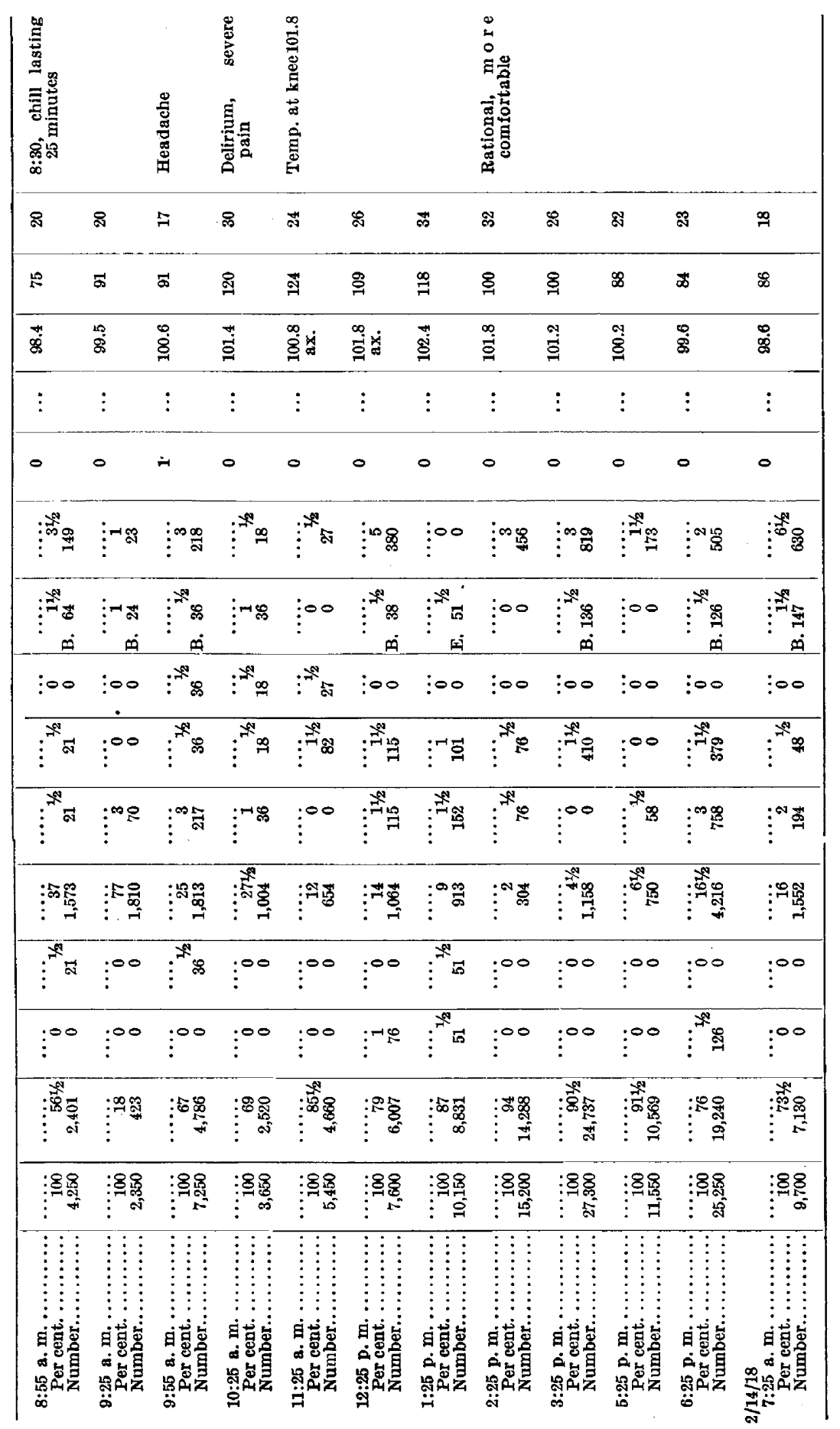




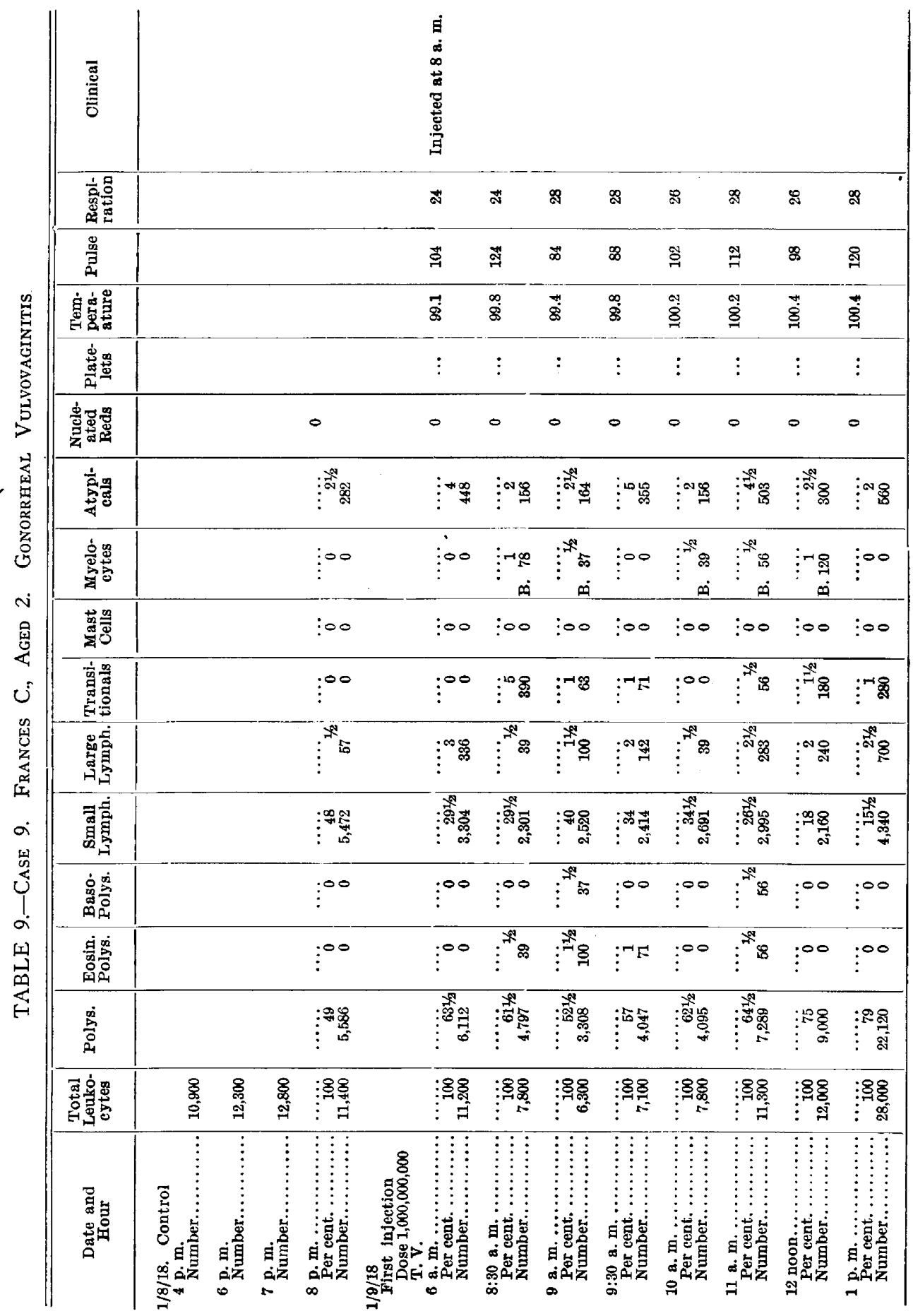




\begin{tabular}{|c|c|c|c|c|c|c|c|c|c|c|c|c|c|}
\hline & & & & & & 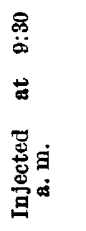 & & & & & & & \\
\hline$\ddot{\varnothing}$ & 古 & $\ddot{\varnothing}$ & 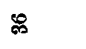 & & & $\Xi$ & I & สิ & $\vec{\omega}$ & శి & 8 & \& & ঞ్ణ \\
\hline$\stackrel{2}{\sharp ్ ~}$ & త̈ & 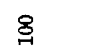 & 욤 & & & ळ’ & 8 & $\oiint$ & $\vec{\infty}$ & $\vec{\infty}$ & $\Phi$ & 芦 & $\stackrel{8}{0}$ \\
\hline ث્ه & 足 & 怘 & 我 & & & 品 & 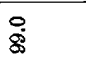 & $\stackrel{\circ}{8}$ & $\stackrel{\oplus}{8}$ & $\ddot{8}$ & $\ddot{~}$ & $\$$ & $\stackrel{0}{8}$ \\
\hline$\vdots$ & $\vdots$ & $\vdots$ & $\vdots$ & & & $\vdots$ & $\vdots$ & $\vdots$ & $\vdots$ & $\vdots$ & $\vdots$ & $\vdots$ & $\vdots$ \\
\hline$=$ & 0 & 0 & 0 & 0 & & 0 & 0 & -1 & 0 & - & 0 & -1 & 0 \\
\hline$\vdots$ 禹 & 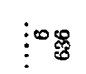 & $\vdots \vdots^{\infty}$ & $\vdots$ & $\vdots^{\infty}$ & & 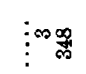 & 噣 & $\vdots \stackrel{m}{g^{\prime}}$ & $\vdots^{\infty}$ & $\vdots^{-10}$ & $\vdots 00$ & $\vdots^{-12}$ & $\vdots^{-1}$ \\
\hline $\begin{array}{l}\vdots^{*} \\
\vdots\end{array}$ & $\vdots 00$ & $\vdots^{\vdots 00}$ & $\vdots \vdots^{\circ}$ & 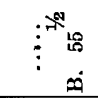 & & 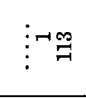 & $\vdots 00$ & $\begin{array}{c}\vdots \\
\vdots \\
\vdots\end{array}$ & $\begin{array}{l}\vdots-\infty \\
\vdots \\
\end{array}$ & & $\vdots 00$ & $\vdots 00$ & $\vdots^{\infty}$ \\
\hline$\vdots 00$ & :00 & $\vdots 00$ & :00 & $\vdots \infty 0$ & & :oo & $\vdots 00$ & :00 & :00 & $\vdots 00$ & $\vdots 00$ & :00 & :00 \\
\hline$\vdots^{+N} 8$ & 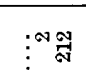 & & $\vdots^{* 7}$ & & & $\vdots^{N}$ & $\vdots^{-10}$ & $\vdots^{\infty}$ & $\vdots^{-\infty}$ & $\vdots^{N}$ & $\vdots^{\infty}$ & $\vdots^{\infty} \stackrel{8}{\sharp}$ & $\vdots^{\infty 0}$ \\
\hline$\vdots^{* *}$ & $\vdots^{\infty 0}$ & $\vdots^{\infty 0}$ & 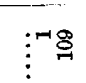 & $\vdots^{-1}$ & & $\vdots^{N}$ \& & $\vdots \stackrel{N}{\stackrel{N}{\leftrightarrow}}$ & 摘 & $\vdots^{10}$ & $\vdots^{\infty}$ & $\vdots^{\infty}$ & $\vdots_{\vdots}^{\infty}$ & $\vdots^{\sim}$ 串 \\
\hline 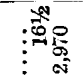 & $\vdots^{\infty} \stackrel{\infty}{\stackrel{8}{8}}$ & 得备 & $\vdots$ & 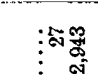 & & : & 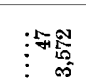 & : & $\vdots^{*}$ & 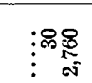 & :요용 & $\vdots^{\vdots}$ & 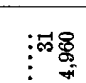 \\
\hline$\vdots^{\infty 0}$ & $\vdots^{\infty 0}$ & $\vdots^{\infty 0}$ & $\vdots^{00}$ & $\vdots^{\infty 0}$ & & $\vdots^{00}$ & $\vdots^{00}$ & $\vdots^{\infty 0}$ & $\vdots^{00}$ & $\vdots^{\infty}$ & $\vdots^{00}$ & $\vdots^{00}$ & $\vdots^{\infty 0}$ \\
\hline$\vdots^{\infty 0}$ & $\vdots^{\infty 0}$ & $\vdots^{\infty 0}$ & $\vdots^{00}$ & $\vdots^{\infty 0}$ & & $\vdots \stackrel{-\infty}{7}$ & $\vdots^{\infty}$ & $\vdots^{*} \mathbb{8}$ & $\vdots^{-\infty}$ & $\vdots^{00}$ & $\vdots^{\infty 0}$ & $\vdots^{\infty 0}$ & $\vdots^{-1} \stackrel{8}{8}$ \\
\hline 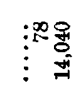 & 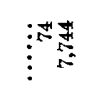 & 占通 & 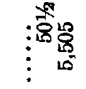 & 数总 & & $\vdots^{:}$ & :\$\& & :88 & 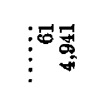 & $\begin{array}{c}: \mathbb{8} \\
\vdots \\
\vdots \\
0\end{array}$ & $\begin{array}{l}\text { :88 } \\
\vdots \\
\vdots \\
\quad 10\end{array}$ & 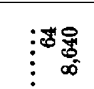 & $\begin{array}{c}\text { :8 } \\
\vdots \\
\vdots\end{array}$ \\
\hline \begin{tabular}{l} 
: \\
$\vdots$ \\
$\vdots$ \\
\hdashline
\end{tabular} & : & 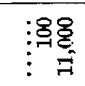 & 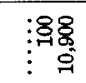 & $\begin{array}{l}\text { :8, } \\
\vdots \\
\vdots\end{array}$ & & : & : & : & : & : : ; & : & :88 & : \\
\hline 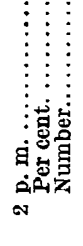 & 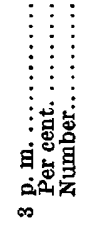 & 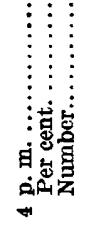 & 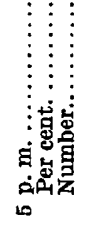 & 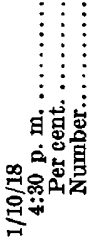 & 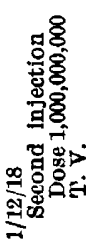 & 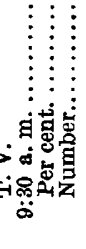 & 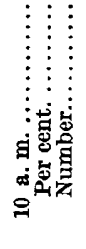 & 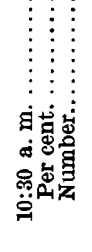 & 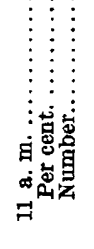 & 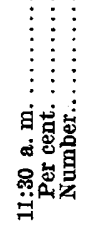 & 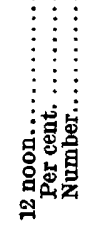 & 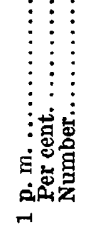 & 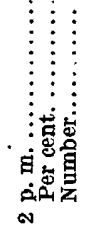 \\
\hline
\end{tabular}




\begin{tabular}{|c|c|c|c|c|c|c|c|c|c|c|}
\hline 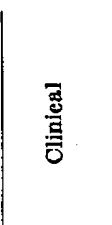 & & & & & & 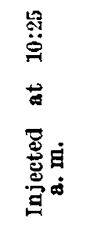 & & & & \\
\hline 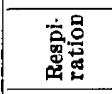 & $\mathscr{\varnothing}$ & 8 & ஜ & \& & \& & s" & $\infty$ & $\infty$ & $\$$ & q \\
\hline 善 & 总 & $\Phi$ & $\cong$ & $\nexists$ & $\stackrel{\infty}{=}$ & $\$$ & $\stackrel{g}{2}$ & 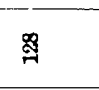 & $\approx$ & $\$$ \\
\hline 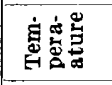 & : & $\stackrel{\circ}{8}$ & 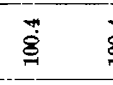 & 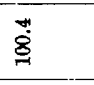 & $\stackrel{8}{8}$ & @ & $\stackrel{\dot{g}}{\dot{g}}$ & g్ & $\stackrel{i}{g}$ & $\stackrel{i}{\dot{g}}$ \\
\hline 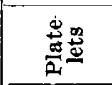 & $\vdots$ & $\vdots$ & $\vdots$ & $\vdots$ & $\vdots$ & $\vdots$ & $\vdots$ & $\vdots$ & $\vdots$ & $\vdots$ \\
\hline 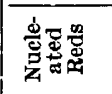 & $\circ$ & $\circ$ & $\circ$ & $\circ$ & 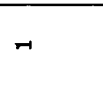 & $\infty$ & $\circ$ & . & $\infty$ & $\infty$ \\
\hline 高爱 & :舑 & : & : & $\vdots^{-}$ & 沙 & )$^{\infty}$ & : & : & 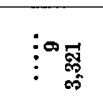 & 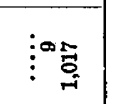 \\
\hline 窎爵 & :o & $\vdots^{00}$ & 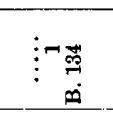 & $\vdots^{\infty}$ & $\vdots \infty$ & :oo & 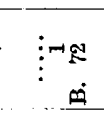 & $\vdots^{\infty}$ & : & 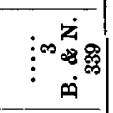 \\
\hline 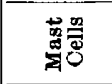 & $: 00$ & $: 00$ & $: 00$ & $: 00$ & $: 00$ & :00 & $: 00$ & $: 00$ & $: 00$ & $: 00$ \\
\hline 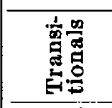 & : & $\vdots^{-\cdots}$ & $\vdots^{* N \mathscr{g}}$ & : & $\vdots^{\sim 1}$ & $\vdots^{\circ 0}$ & $!^{\infty \infty}$ & $\vdots^{\infty}$ 曹 & $i_{\text {og }}$ & $\vdots^{-\infty}$ \\
\hline 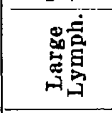 & : & $i^{-}$ & $\vdots^{\infty}$ & 赵 & $i^{-\infty}$ & $!^{\infty}$ & $\vdots^{\infty}$ & $!^{\infty}$ 吕 & $i^{-\infty}$ & : \\
\hline 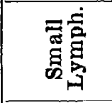 & : & : & 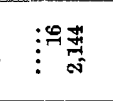 & : & : & : & 㧒费 & :유융 & $:^{+\infty}$ & 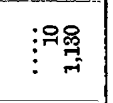 \\
\hline 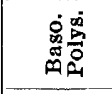 & $\vdots^{\infty 0}$ & $\vdots^{\infty 0}$ & $\vdots^{\infty}$ & $\vdots^{\infty 0}$ & $\vdots^{\infty 0}$ & $\vdots^{\circ 0}$ & $\vdots^{\infty}$ & $\vdots^{\infty 0}$ & $\vdots^{\infty 0}$ & $\vdots^{\infty 0}$ \\
\hline 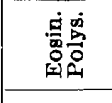 & $i^{\infty 0}$ & $i^{-n^{\circ}}$ & $:^{\infty}$ & $\vdots^{\infty}$ & $\vdots^{\infty}$ & $\vdots^{-\pi} \AA$ & $!^{\infty 0}$ & $\vdots^{\infty}$ & $i^{-1} \%$ & $\vdots^{\infty 0}$ \\
\hline 㟢 & 路 & 湯 & 施器 & 㴗 & : & 要桑 & : & 祀曼 & 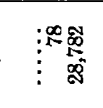 & 战器 \\
\hline 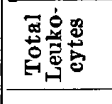 & : 880 & 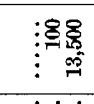 & 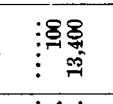 & 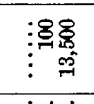 & 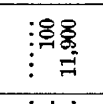 & 海要 & : & 渒奠 & : & 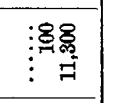 \\
\hline 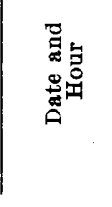 & 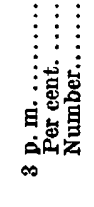 & 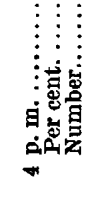 & 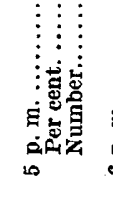 & 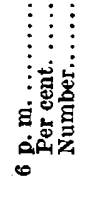 & 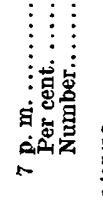 & 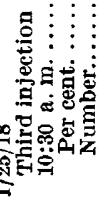 & 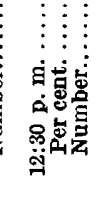 & 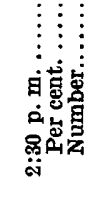 & 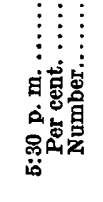 & 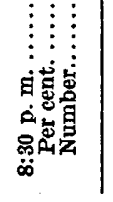 \\
\hline
\end{tabular}




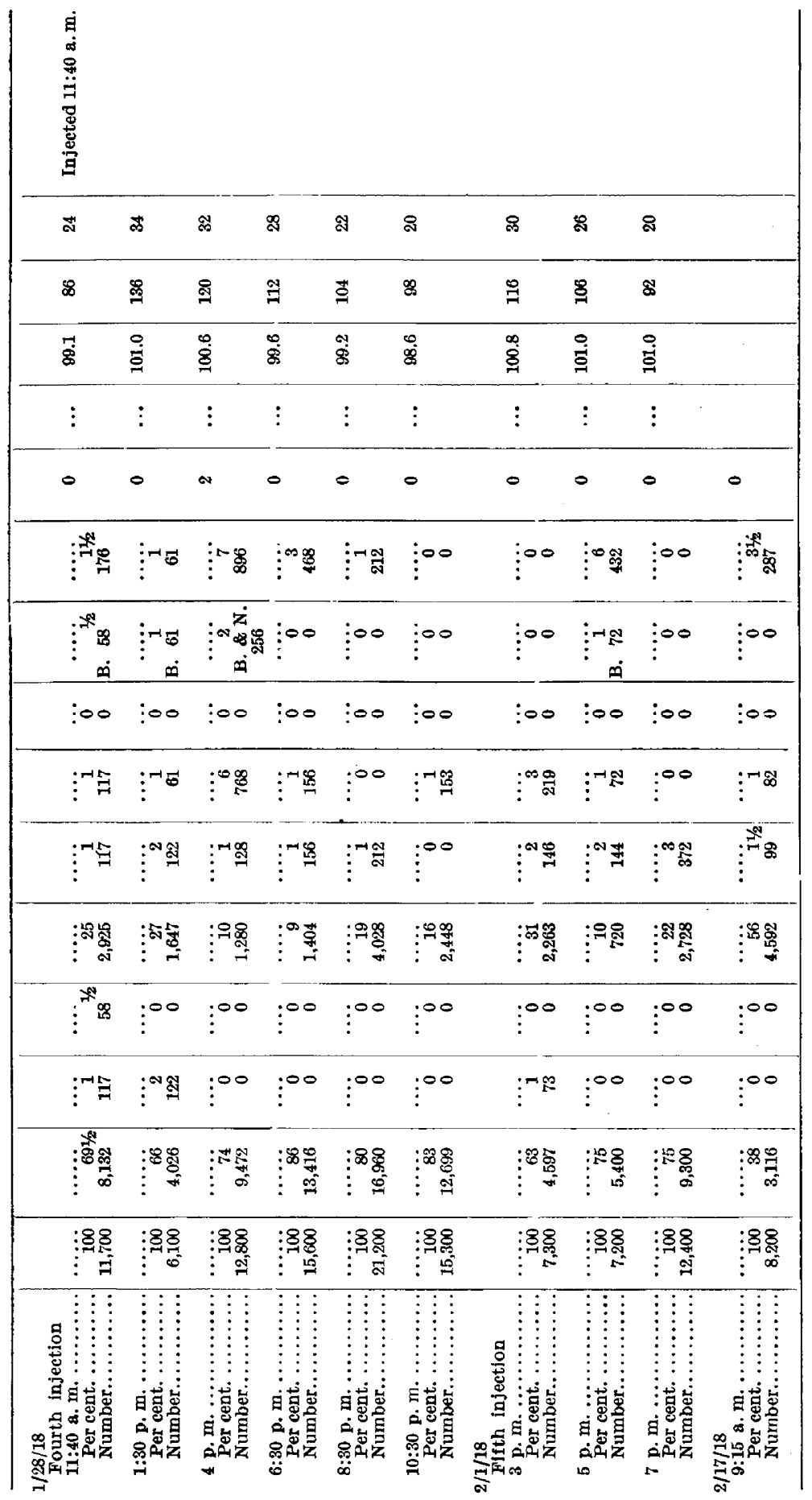




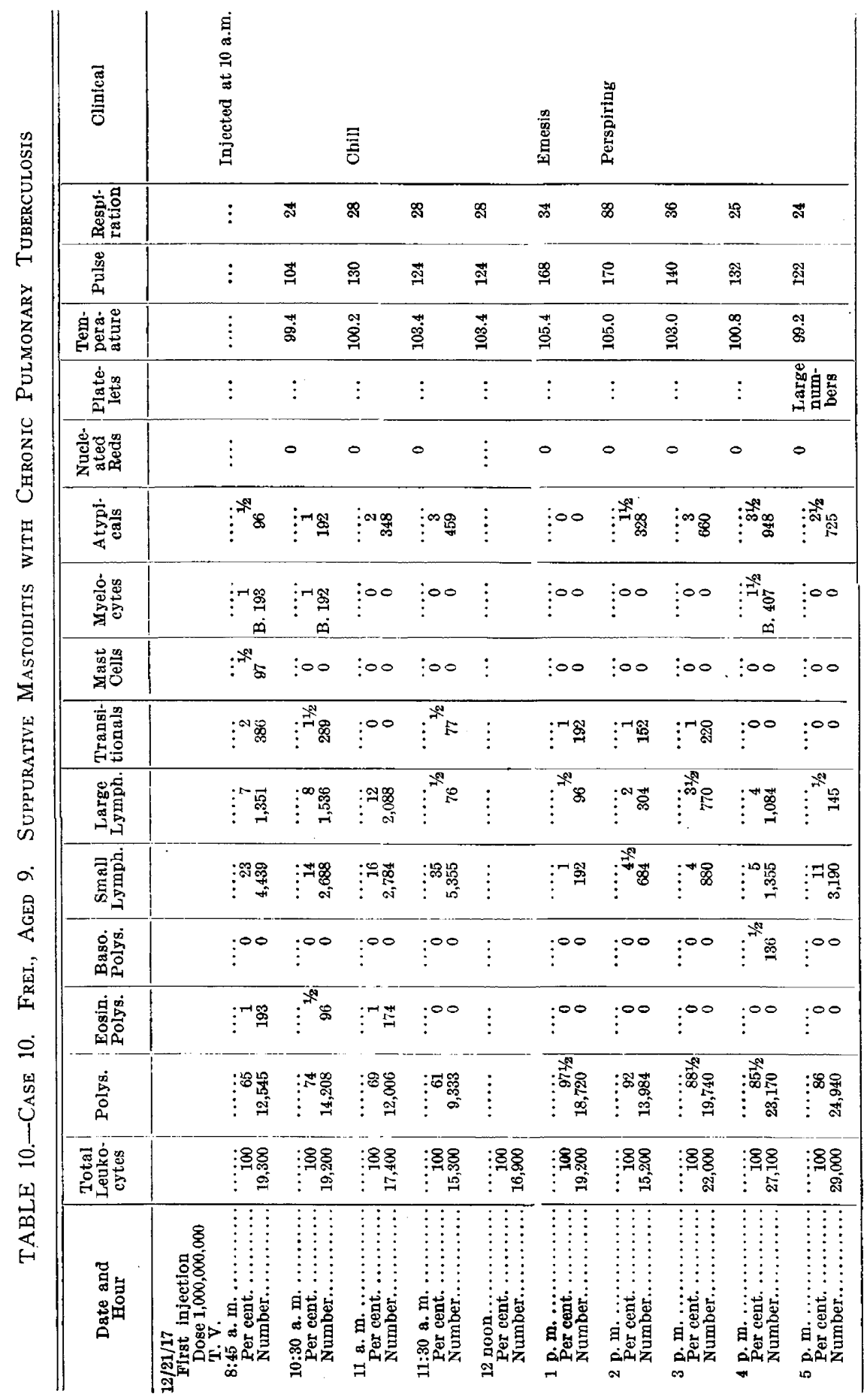




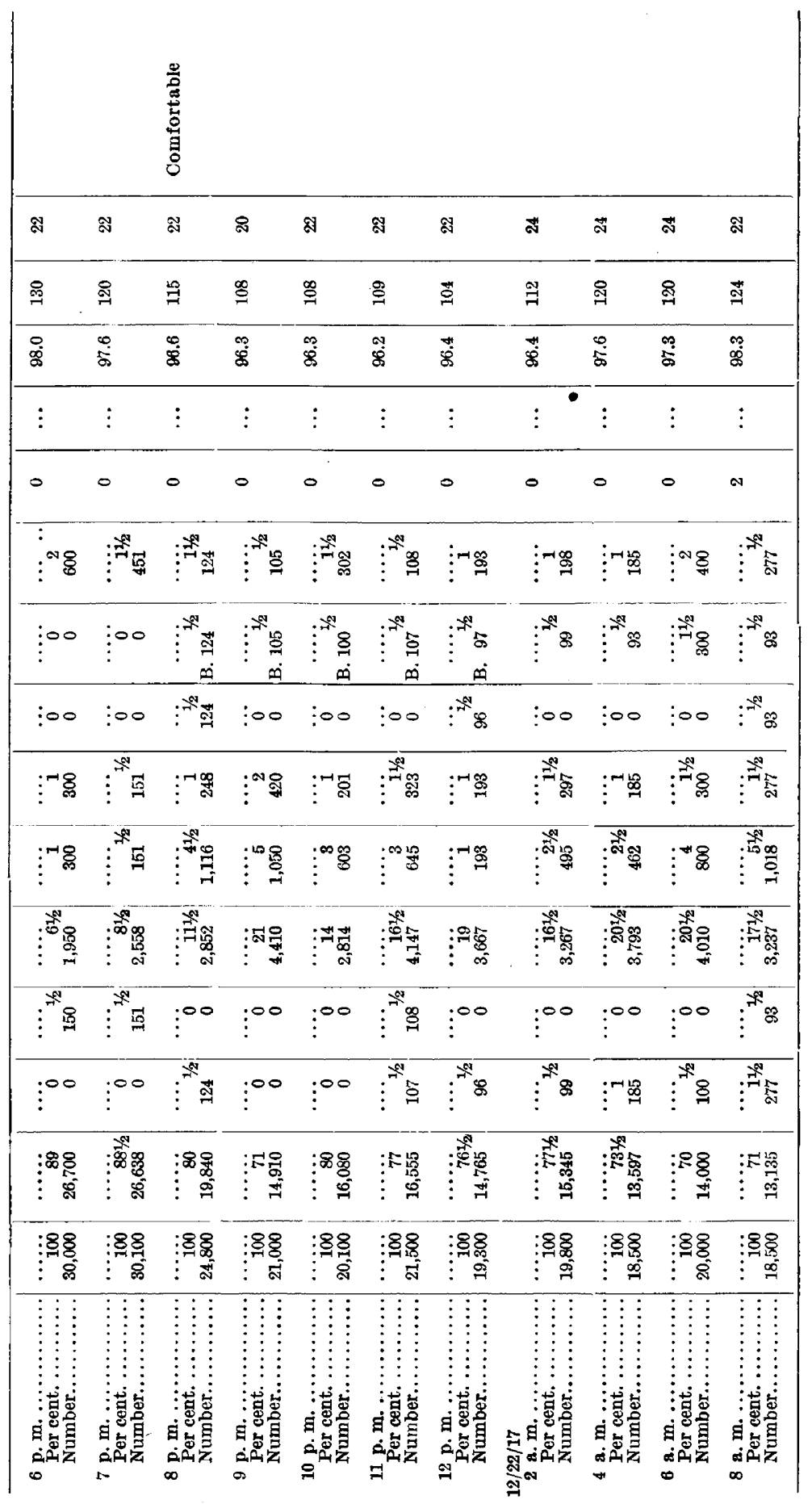




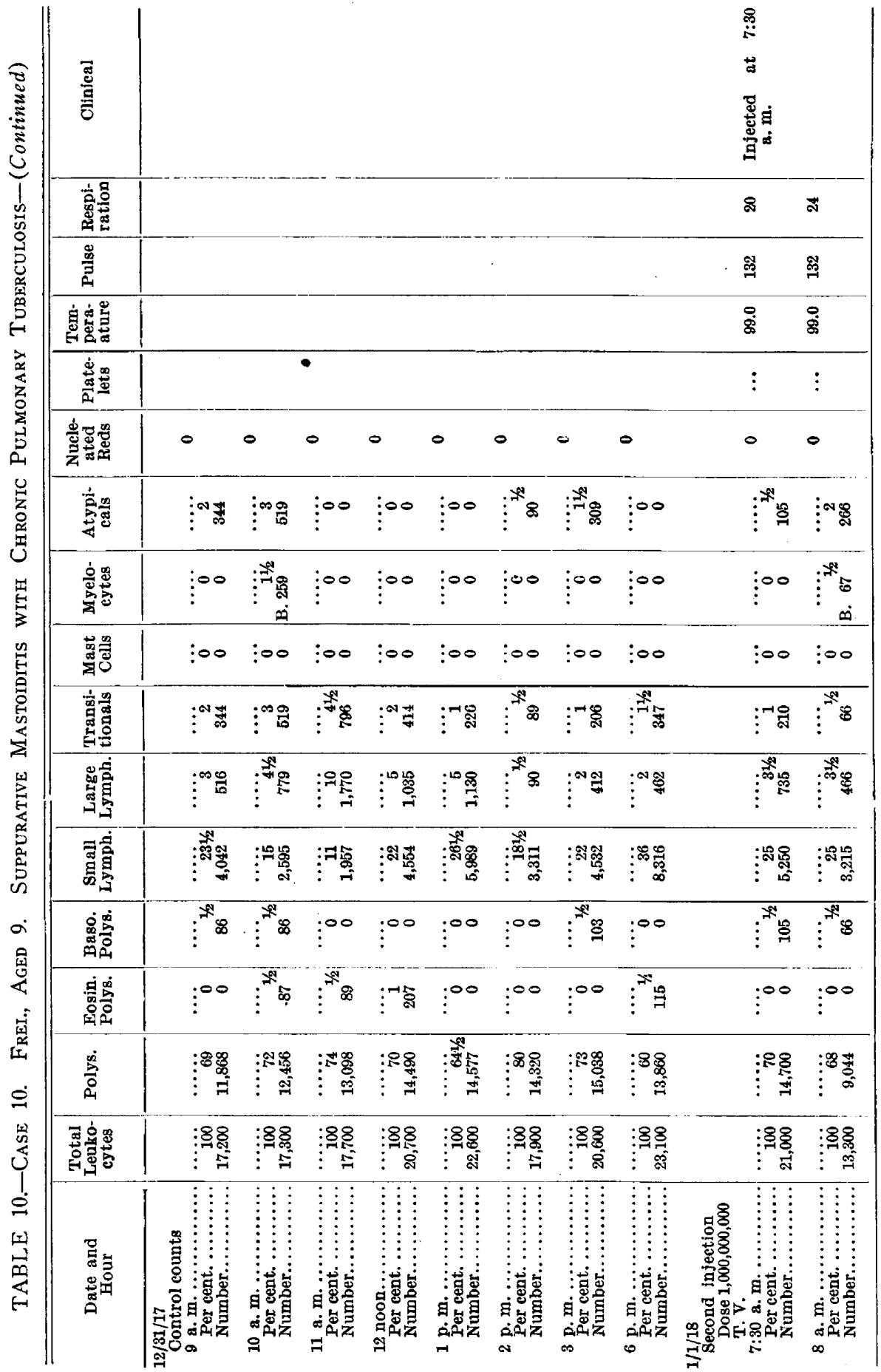




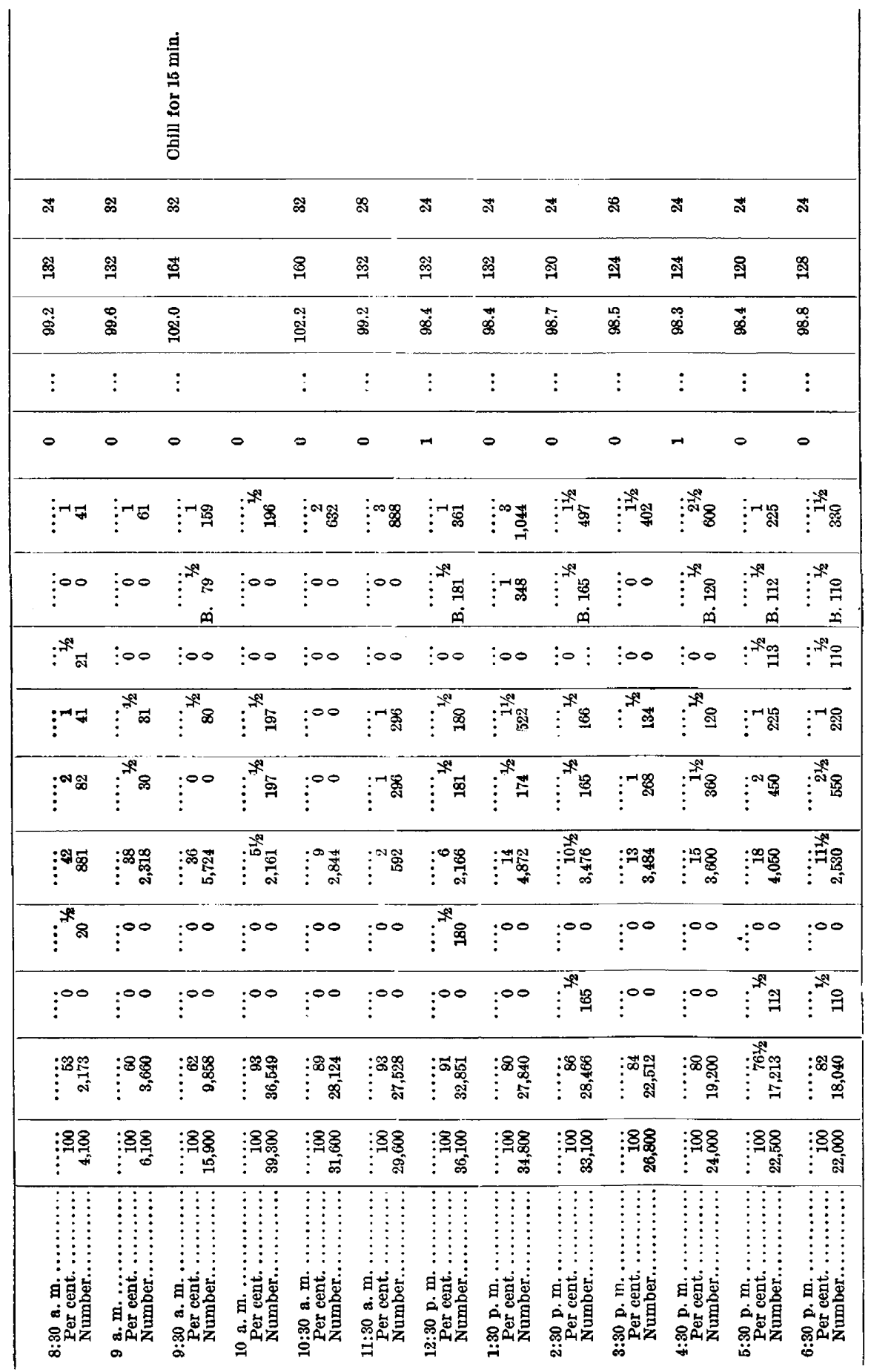

